OPEN ACCESS

Edited by:

Smita Kulkarni,

Texas Biomedical Research Institute, United States

Reviewed by: Hamed Shoorei,

Birjand University of Medical Sciences,

Kun Yang,

East Tennessee State University,

United States

*Correspondence:

Mohammad Taheri

mohammad_823@yahoo.com

Normohammad Arefian

narefian@yahoo.com

Specialty section: This article was submitted to

Microbial Immunology,

a section of the journal

Frontiers in Immunology

Received: 20 October 2021 Accepted: 19 November 2021 Published: 09 December 2021

Citation:

Ghafouri-Fard S, Khoshbakht T, Hussen BM, Taheri M and Arefian N

(2021) Regulatory Role of

Non-Coding RNAs on Immune

Responses During Sepsis.

Front. Immunol. 12:798713.

doi: 10.3389/fimmu.2021.798713

\section{Regulatory Role of Non-Coding RNAs on Immune Responses During Sepsis}

\author{
Soudeh Ghafouri-Fard ${ }^{1}$, Tayyebeh Khoshbakht ${ }^{2}$, Bashdar Mahmud Hussen ${ }^{3,4}$, \\ Mohammad Taheri ${ }^{5 *}$ and Normohammad Arefian ${ }^{6 *}$ \\ 1 Department of Medical Genetics, School of Medicine, Shahid Beheshti University of Medical Sciences, Tehran, Iran, \\ ${ }^{2}$ Phytochemistry Research Center, Shahid Beheshti University of Medical Sciences, Tehran, Iran, ${ }^{3}$ Department of \\ Pharmacognosy, College of Pharmacy, Hawler Medical University, Erbil, Iraq, ${ }^{4}$ Center of Research and Strategic Studies, \\ Lebanese French University, Erbil, Iraq, ${ }^{5}$ Institute of Human Genetics, Jena University Hospital, Jena, Germany, ${ }^{6}$ Skull Base \\ Research Center, Loghman Hakim Hospital, Shahid Beheshti University of Medical Sciences, Tehran, Iran
}

Sepsis is resulted from a systemic inflammatory response to bacterial, viral, or fungal agents. The induced inflammatory response by these microorganisms can lead to multiple organ system failure with devastating consequences. Recent studies have shown altered expressions of several non-coding RNAs such as long non-coding RNAs (IncRNAs), microRNAs (miRNAs) and circular RNAs (circRNAs) during sepsis. These transcripts have also been found to participate in the pathogenesis of multiple organ system failure through different mechanisms. NEAT1, MALAT1, THRIL, XIST, MIAT and TUG1 are among IncRNAs that participate in the pathoetiology of sepsis-related complications. miR-21, miR-155, miR-15a-5p, miR-494-3p, miR-218, miR-122, miR-208a-5p, miR-328 and miR-218 are examples of miRNAs participating in these complications. Finally, tens of circRNAs such as circC3P1, hsa_circRNA_104484, hsa_circRNA_104670 and circVMA21 and circ-PRKCl have been found to affect pathogenesis of sepsis. In the current review, we describe the role of these three classes of noncoding RNAs in the pathoetiology of sepsis-related complications.

Keywords: IncRNA, miRNA, sepsis, expression, biomarker

\section{INTRODUCTION}

Sepsis is a systemic inflammatory response to different infections, namely bacterial, viral, or fungal agents. This condition is the principal source of mortality in intensive care units (1). These infectious microorganisms can stimulate inflammatory reactions through induction of cytokines release. These reactions lead to multiple organ system failure. Other factors that contribute in this 
devastating condition during sepsis are systemic hypotension and abnormal perfusion of the microcirculatory system (2). No specific treatment modality has been suggested for prevention of multiple organ system failure during sepsis (2). Thus, identification of sepsis-related changes at cellular and biochemical levels is important. Currently, there is no effective pharmacological therapy for sepsis. Thus, early diagnosis, resuscitation and instant administration of suitable antibiotics are essential steps in decreasing the burden of this condition \{Thompson, 2019 \#562\}.

Lipopolysaccharide (LPS) as the main constituent of the cell wall of Gram-negative bacteria has been found to stimulate apoptotic pathways in tubular epithelial cells of kidney (3). Moreover, it can prompt acute inflammatory responses through activation of NF- $\mathrm{KB}$ during the course of acute kidney injury (4). This molecular pathway is an important axis in mediation of immune-related organ damage.

Recent studies have shown altered expressions of several non-coding RNAs such as long non-coding RNAs (lncRNAs), microRNAs (miRNAs) and circular RNAs (circRNAs) during sepsis. These transcripts have also been found to participate in the pathogenesis of multiple organ system failure through different mechanisms. In the current review, we describe the role of these three classes of noncoding RNAs in the pathoetiology of sepsis-related complications.

\section{LNCRNAS AND SEPSIS}

LncRNAs are transcripts with sizes larger than 200 nucleotides. These transcripts regulate gene expression through modulation of chromatin configuration, regulation of splicing events, serving as decoys for other transcripts and making structures for recruitment of regulatory proteins (5). These transcripts participate in the regulation of immune reactions and pathoetiology of several immune-related disorders (6).

Experiments in animal model of acute lung injury have shown down-regulation of TUG1 and induction of apoptosis and inflammation. Up-regulation of TUG1 in these animals could ameliorate sepsis-associated lung injury, apoptosis and inflammatory reactions. TUG1 could also protect lung microvascular endothelial cells from deteriorative effects of LPS. In fact, TUG1 inhibits cell apoptosis and inflammatory reactions in LPS-stimulated microvascular endothelial cells through sponging miR-34b-5p and releasing GAB1 from its inhibitory effects. Cumulatively, TUG1 ameliorates sepsisassociated inflammation and apoptosis through miR-34b-5p/ GAB1 axis (7). Another study has demonstrated downregulation of TUG1 while up-regulation of miR-223 in the plasma samples of sepsis patients. They have also reported a negative correlation between expressions of TUG1 and miR-223 in sepsis patients. Besides, expression levels of TUG1 have been negatively correlated with respiratory infection, serum creatinine, white blood cell, C-reactive protein, APACHE II score, and SOFA score. Based on these results, TUG1 has been suggested as a biomarker for prediction of course and prognosis of sepsis (8). TUG1 has also been shown to interact with miR27a. Over-expression of TUG1 has resulted in down-regulation of TNF- $\alpha$, while up-regulation of miR-27a has enhanced expression of TNF- $\alpha$ in cardiomyocytes. TNF- $\alpha$ and miR-27a up-regulation could enhance LPS-induced apoptosis of cardiomyocytes. On the other hand, TUG1 up-regulation has exerted opposite effects (9).

MALAT1 is another lncRNA that affects immune responses of rats with LPS-induced sepsis through influencing the miR146a/NF- $\kappa$ B P65 axis (10). Moreover, MALAT1 could increase apoptosis skeletal muscle cells and sepsis-associated immune responses through down-regulating BRCA1 levels via recruitment of EZH2 (11). The miR-150-5p/NF- $\kappa B$ axis is another axis that mediates the effects of MALAT1 in sepsisassociated cardiac inflammation (12). In addition, the protective effects of Ulinastatin against LPS-associated dysfunction of heart microvascular endothelial cells have been shown to be exerted through down-regulation of MALAT1 (13). Most notably, MALAT1/miR-125a axis has been shown to discriminate sepsis patients based on their severity of diseases, organ damage, levels of inflammatory responses and mortality (14). Figure 1 depicts function of MALAT1 in sepsis-related events.

NEAT1 is another lncRNA whose participation in the pathophysiology of sepsis has been vastly investigated. This lncRNA could promote inflammatory responses and aggravate sepsis-associated hepatic damage through the Let-7a/TLR4 axis (15). Moreover, NEAT1 can accelerate progression of sepsis via miR-370-3p/TSP-1 axis (16). This lncRNA could also promote LPS-induced inflammatory responses in macrophages through regulation of miR-17-5p/TLR4 axis (17). NEAT1 silencing could suppress immune responses during sepsis through miR-125/ MCEMP1 axis (18). Figure 2 shows the function of NEAT1 in sepsis-related events. Several other lncRNAs have also been found to influence course of sepsis through modulation of immune responses (Table $\mathbf{1}$ ).

\section{miRNAs AND SEPSIS}

miRNAs have sizes about 22 nucleotides and regulate expression of genes through binding with different regions of target mRNAs, particularly their 3' UTR. They can either degrade target mRNA or suppress its translation. Several miRNAs have been found to influence course of sepsis. Altered expression of these small-sized transcripts has been reported in sepsis by numerous research groups. For instance, plasma levels of miR-494-3p have been shown to be decreased in sepsis patients compared with healthy controls in correlation with up-regulation of TLR6. Expression level of miR-494-3p has been decreased in LPS-induced RAW264.7 cells, parallel with up-regulation of TLR6 and TNF- $\alpha$. Forced over-expression of miR-494-3p in RAW264.7 cells could reduce TNF- $\alpha$ level and suppress translocation of NF- $\kappa \mathrm{B}$ p 65 to the nucleus. 


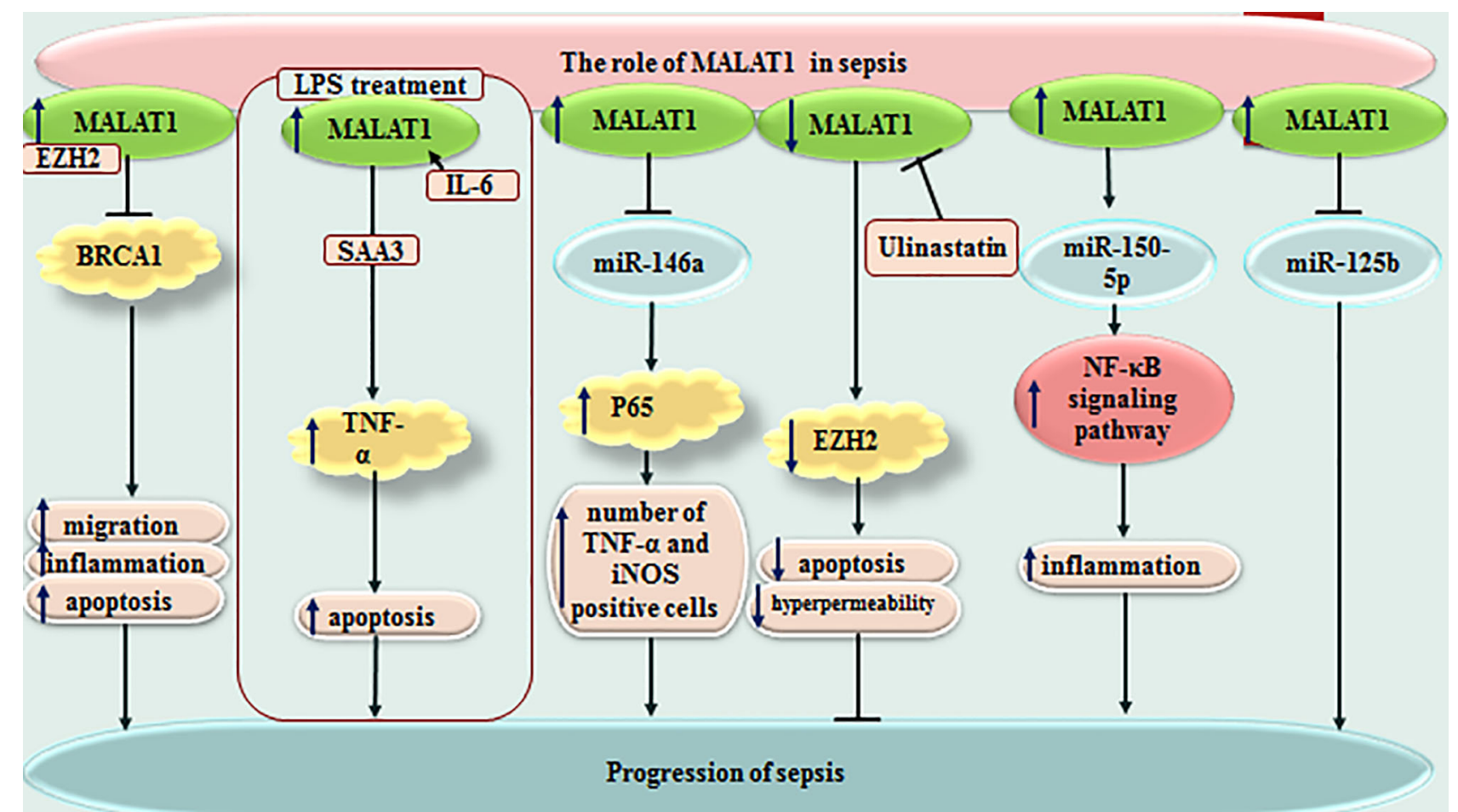

FIGURE 1 | Function of MALAT1 in sepsis-related events.

The role of NEATl in sepsis

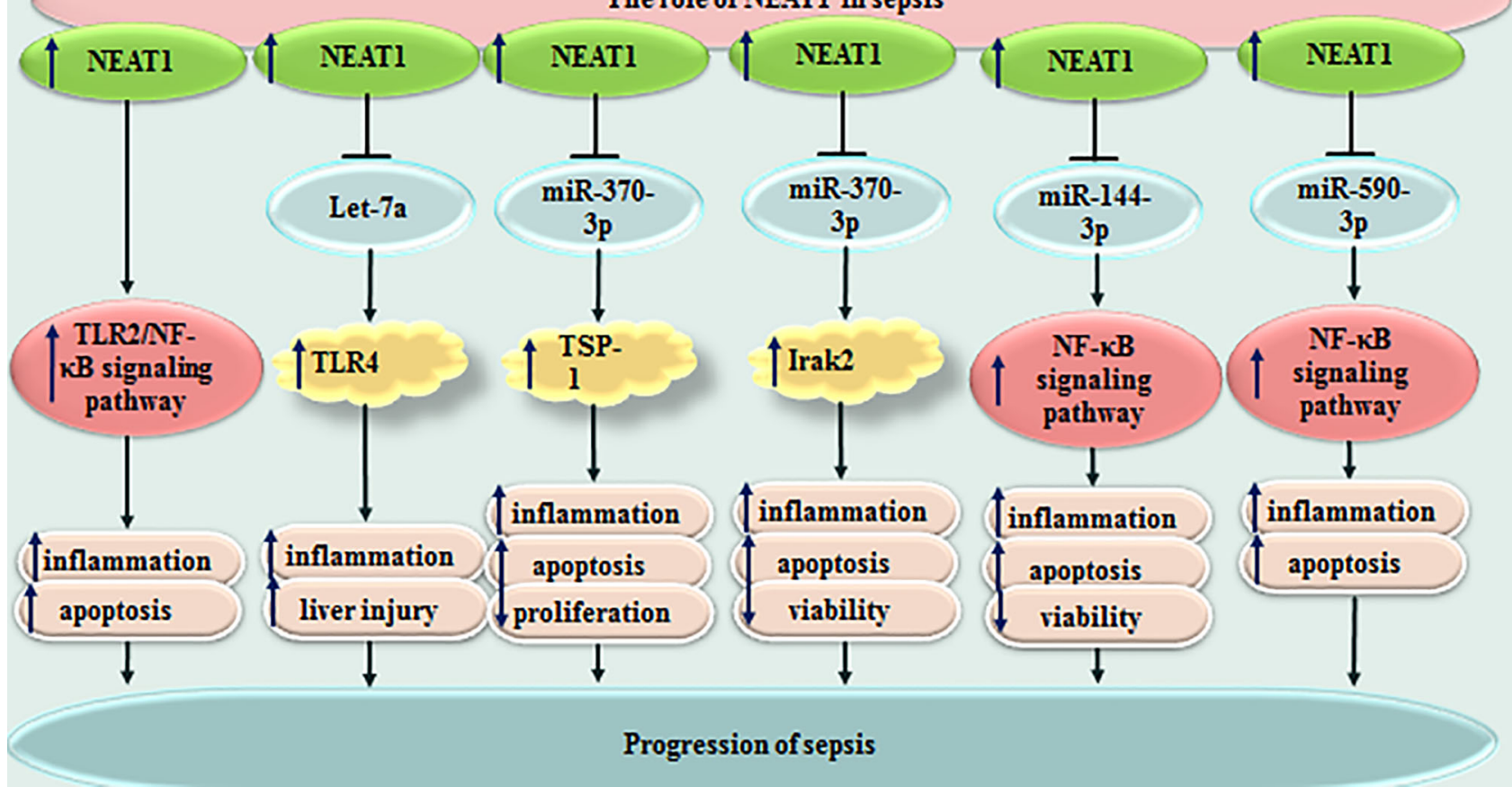

FIGURE 2 | Function of NEAT1 in sepsis-related events. Several other IncRNAs have also been found to influence course of sepsis through modulation of immune responses (Table 1). 
TLR6 has been shown to be targeted by miR-494-3p. Taken together, miR-494-3p could attenuate sepsis-associated inflammatory responses through influencing expression of TLR6 (132). miR-218 is another miRNA which participates in the pathoetiology of sepsis. This miRNA could reduce inflammatory responses in the sepsis through decreasing expression of VOPP1 via JAK/STAT axis (133).

miR-122 is another important miRNA in the sepsis which has superior diagnostic power compared with CRP and total leucocytes count for distinguishing sepsis from wound infection. miR-122 has also been found to be a prognostic marker for sepsis, albeit with poor specificity and accuracy values (134).

In the mice model of sepsis, decreased levels of miR-208a-5p and increased levels of SOCS2 has been associated with enhanced activity of SOD, while reduction in $\mathrm{LDH}$ and MDA activities. Moreover, down-regulation of miR-208a-5p has been associated with low levels TNF- $\alpha$, IL-6, NF- $\mathrm{KB}$ p65 and HIF- $1 \alpha$ in this animal model. miR-208a-5p silencing could decrease the extent of mitochondria swelling, and inhibit apoptosis of cardiomyocytes in animal model of sepsis. Taken together, miR-208a-5p suppression has been suggested as a modality to attenuate sepsis-related myocardial damage. This function is mediated through NF- $\kappa \mathrm{B} / \mathrm{HIF}-1 \alpha$ axis (135).

miR-21 is another miRNA whose role in sepsis has been investigated by several groups. Down-regulation of miR-21 has been shown to inhibit inflammasome activation, ASC pyroptosome, LPS-induced pyroptosis and septic shock in one study (136). On the other hand, another study in animal models of sepsis has shown that up-regulation of miR-21 reduced inflammation and apoptosis (137). Similarly, $\beta$ MSCs-derived exosomes have been shown to reduce symptoms in septic mice and improve their survival rate through up-regulation of miR-21 (138).

miR-328 is another miRNA which is dysregulated in sepsis patients as well as animal models of sepsis. Serum levels of this miRNA could properly differentiate sepsis from normal conditions. Thus, miR-328 has been suggested as a diagnostic biomarker for sepsis. Moreover, down-regulation of miR-328 could amend sepsis-related heart dysfunction and inflammatory responses in this tissue (139). miR-452 is another miRNA with diagnostic applications in sepsis. Notably, serum and urinary levels of this miRNA have been suggested as possible markers for early diagnosis of sepsis-associated acute kidney injury, since expression of this miRNA has been higher in sepsis patients with acute kidney injury compared with those without this condition (140) (Table 2). Figure 3 depicts miRNAs that are downregulated in sepsis.

\section{CircRNAs AND SEPSIS}

CircRNAs are a recently appreciated group of non-coding RNAs with enclosed circular configuration formed by covalent bonds between two ends of linear transcripts. However, some of these transcripts have been shown to produce proteins. They mostly exert regulatory functions in the transcriptome. Impact of circRNAs in the sepsis has been assessed by several groups (303). For instance, circC3P1 has been shown to attenuate production of inflammatory cytokines and decrease cell apoptosis in sepsis-associated acute lung injury via influencing expression of miR-21 (304).

A microarray-based has shown differential expression of 132 circRNAs between sepsis patients and healthy controls among them have been hsa_circRNA_104484 and hsa_circRNA_104670 whose up-regulation in sepsis serum exosomes has been verified been RT-PCR. Expression levels of these two circRNAs have been suggested as diagnostic biomarkers for sepsis (305).

CircVMA21 is another circRNA that has been shown to ameliorate sepsis-related acute kidney injury through modulation of oxidative stress and inflammatory responses via miR-9-3p/SMG1 axis (306). Circ_0114428/miR-495-3p/CRBN axis is another molecular axis which is involved in the pathoetiology of sepsis-related acute kidney injury (307). Moreover, expression levels of circPRKCI have been correlated with sepsis risk, severity of sepsis and mortality during a period of 28 days (308). Table 3 summarizes the role of circRNAs in sepsis.

\section{DISCUSSION}

A vast body of literature points to the involvement of lncRNAs, miRNAs and circRNAs in the pathoetiology of sepsis-related complications. NEAT1, MALAT1, MEG3, THRIL, XIST, CRNDE, ZFAS1, HULC, MIAT and TUG1 are among lncRNAs with the strongest evidence for their participation in this process. NEAT1 as the mostly assessed lncRNA in this regard has been shown to act as a molecular sponge for let-7a, let-7b-5p, miR-370-3p, miR-124, miR-125, miR-17-5p, miR-165p, miR-93-5p, miR-370-3p, miR-144-3p, miR-944, miR495-3p, miR-22-3p, miR-31-5p and miR-590-3p. Through sequestering these miRNAs, NEAT1 can affect several molecular pathways in the course of sepsis. It can enhance immune responses and the related injury in target organs, thus participating in sepsis-related multiple organ damage.

Similar to lncRNAs, circRNAs influence course of sepsis mainly through acting as molecular sponges for miRNAs. circC3P1/miR-21, circVMA21/miR-9, circVMA21/miR-199a5p, circ-PRKCI/miR-545, circPRKCI/miR-106b-5p, circDNMT3B/miR-20b-5p, circ_0114428/miR-495-3p, circ_Ttc3/miR-148a, circPRKCI/miR-454, circ-Fryl/miR-490$3 \mathrm{p}$, circ_0091702/miR-182, circTLK1/miR-106a-5p, circFADS2/miR-15a-5p, circ_0091702/miR-545-3p, hsa_circ_0068,888/miR-21-5p, circPTK2/miR-181c-5p, circFANCA/miR-93-5p and circANKRD36/miR-330 are among circRNA/miRNA axes which are involved in the pathophysiology of sepsis-related conditions. 
TABLE 1 | LncRNAs and Sepsis.

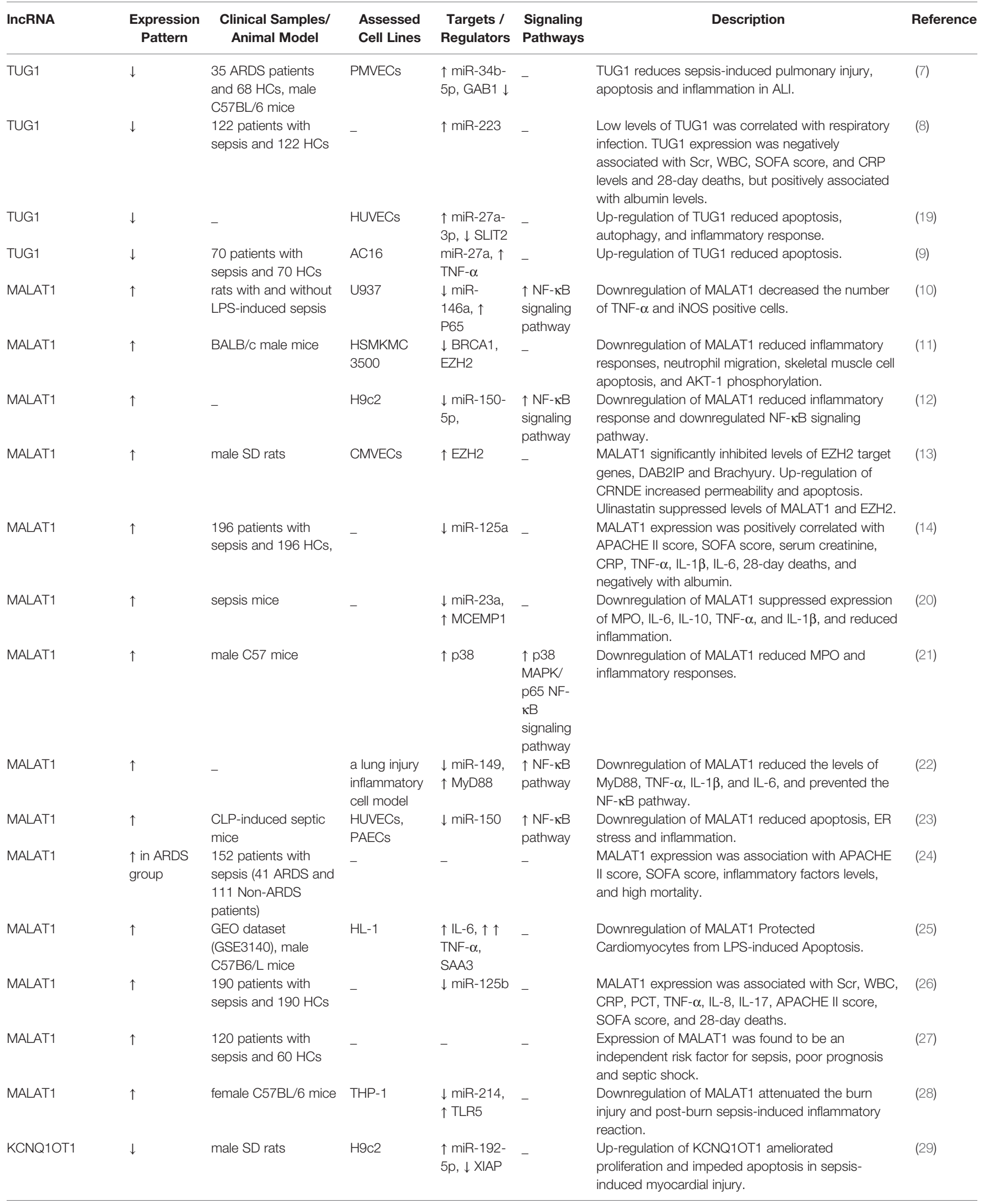


TABLE 1 | Continued

\begin{tabular}{|c|c|c|c|c|c|c|c|}
\hline IncRNA & $\begin{array}{l}\text { Expression } \\
\text { Pattern }\end{array}$ & $\begin{array}{l}\text { Clinical Samples/ } \\
\text { Animal Model }\end{array}$ & $\begin{array}{l}\text { Assessed } \\
\text { Cell Lines }\end{array}$ & $\begin{array}{c}\text { Targets / } \\
\text { Regulators }\end{array}$ & $\begin{array}{l}\text { Signaling } \\
\text { Pathways }\end{array}$ & Description & Reference \\
\hline CYTOR & $\downarrow$ & male SD rats & $\mathrm{H} 9 \mathrm{c} 2$ & $\begin{array}{l}\uparrow \operatorname{miR}-24, \downarrow \\
\text { XIAP }\end{array}$ & - & $\begin{array}{l}\text { Up-regulation of CYTOR ameliorated viability and } \\
\text { inhibited apoptosis in sepsis-induced myocardial } \\
\text { injury. }\end{array}$ & (30) \\
\hline IncRNA-5657 & $\uparrow$ & $\begin{array}{l}15 \text { patients with } \\
\text { sepsis-induced ARDS } \\
\text { and } 15 \text { non-septic } \\
\text { and non-ARDS } \\
\text { patients, SD rats }\end{array}$ & NR8383 & $\uparrow$ Spns2 & - & $\begin{array}{l}\text { Downregulation of IncRNA-5657 } 7 \text { prevented } \\
\text { sepsis-induced lung injury and LPS-induced } \\
\text { inflammation. }\end{array}$ & (31) \\
\hline RMRP & $\downarrow$ & male C57BL/6 mice & $\mathrm{HL}-1$ & $\begin{array}{l}\uparrow \operatorname{miR}-1-5 p \\
\downarrow \text { HSPA4 }\end{array}$ & $\begin{array}{l}\uparrow \mathrm{NF}-\kappa \mathrm{B} \\
\text { Pathway }\end{array}$ & $\begin{array}{l}\text { Up-regulation of RMRP reduced LPS-induced } \\
\text { damage, apoptosis and mitochondrial damage and } \\
\text { LPS-induced sepsis. }\end{array}$ & (32) \\
\hline NEAT1 & $\uparrow$ & $\begin{array}{l}15 \text { patients with } \\
\text { sepsis-induced liver } \\
\text { injury and } 15 \mathrm{HCs}\end{array}$ & $\begin{array}{l}\text { Kupffer, } \\
\text { Raw264.7 }\end{array}$ & $\begin{array}{l}\downarrow \text { Let-7a, } \uparrow \\
\text { TLR4 }\end{array}$ & - & $\begin{array}{l}\text { Downregulation of NEAT1 reduced expression of } \\
\text { inflammatory factors in sepsis-induced liver injury. }\end{array}$ & (15) \\
\hline NEAT1 & $\uparrow$ & $\begin{array}{l}25 \text { Sepsis patients } \\
\text { and } 25 \mathrm{HCs}\end{array}$ & RAW 264.7 & $\begin{array}{l}\downarrow \mathrm{miR}-370- \\
3 \mathrm{p}, \uparrow \mathrm{TSP}- \\
1\end{array}$ & - & $\begin{array}{l}\text { Downregulation of NEAT1 prevented LPS-mediated } \\
\text { inflammation and apoptosis and ameliorated } \\
\text { proliferation. }\end{array}$ & (16) \\
\hline NEAT1 & $\uparrow$ & $\begin{array}{l}\text { male pathogen-free } \\
\text { C57BL/6 mice }\end{array}$ & - & $\begin{array}{l}\downarrow \mathrm{miR}-125 \\
\uparrow \mathrm{MCEMP1}\end{array}$ & - & $\begin{array}{l}\text { Downregulation of NEAT1 suppressed inflammation } \\
\text { and T lymphocyte apoptosis. }\end{array}$ & (18) \\
\hline NEAT1 & $\uparrow$ & $\begin{array}{l}68 \text { patients with } \\
\text { sepsis and } 32 \mathrm{HCs}\end{array}$ & $\begin{array}{l}\text { THP-1 } \\
\text { macrophages }\end{array}$ & $\begin{array}{l}\downarrow \mathrm{miR}-17- \\
5 \mathrm{p}, \uparrow \mathrm{TLR} 4\end{array}$ & - & $\begin{array}{l}\text { Downregulation of NEAT1 prevented LPS-induced } \\
\text { inflammatory responses in macrophages. }\end{array}$ & $(17)$ \\
\hline NEAT1 & $\uparrow$ & $\begin{array}{l}\text { mouse with sepsis- } \\
\text { induced lung injury }\end{array}$ & - & $\begin{array}{l}\downarrow \mathrm{miR}-16- \\
5 p, \uparrow \mathrm{BRD} 4\end{array}$ & - & $\begin{array}{l}\text { Downregulation of NEAT1 inhibited inflammation, } \\
\text { apoptosis, pulmonary edema, MPO activity, } \\
\text { pathological changes, promoted viability. }\end{array}$ & (33) \\
\hline NEAT1 & $\uparrow$ & male C57 mice & - & - & $\begin{array}{l}\uparrow \mathrm{TLR} 2 / \\
\mathrm{NF}-\kappa \mathrm{B} \\
\text { signaling } \\
\text { pathway }\end{array}$ & $\begin{array}{l}\text { Downregulation of NEAT1 reduced LPS-induced } \\
\text { myocardial pathological injury, apoptosis, oxidative } \\
\text { stress, inflammatory responses. }\end{array}$ & (34) \\
\hline NEAT1 & $\uparrow$ & male C57BL/6 mice & A549 & - & $\begin{array}{l}\uparrow \text { HMGB1/ } \\
\text { RAGE } \\
\text { signaling }\end{array}$ & $\begin{array}{l}\text { Downregulation of NEAT1 increased viability } \\
\text { attenuated LPS-induced apoptosis and suppressed } \\
\text { inflammation. }\end{array}$ & (35) \\
\hline NEAT1 & $\uparrow$ & $\begin{array}{l}30 \text { patients with } \\
\text { sepsis and } 30 \mathrm{HCs}\end{array}$ & $\mathrm{HK}-2$ & $\begin{array}{l}\downarrow \text { let-7b-5p, } \\
\text { TRAF6 }\end{array}$ & - & $\begin{array}{l}\text { Downregulation of NEAT1 increased proliferation } \\
\text { and inhibited apoptosis and inflammation. }\end{array}$ & (36) \\
\hline NEAT1 & $\uparrow$ & - & RAW264.7 & $\begin{array}{l}\downarrow \text { miR- } \\
125 a-5 p, \uparrow \\
\text { TRAF6, } \uparrow \\
\text { P-TAK1 }\end{array}$ & - & $\begin{array}{l}\text { Downregulation of NEAT1 decreased inflammation } \\
\text { by promoting macrophage M2 polarization. }\end{array}$ & (37) \\
\hline NEAT1 & $\uparrow$ & _patients with sepsis & HK2 & $\begin{array}{l}\downarrow \mathrm{miR}-93- \\
5 \mathrm{p}, \uparrow \\
\text { TXNIP }\end{array}$ & - & $\begin{array}{l}\text { Downregulation of NEAT1 inhibited apoptosis, } \\
\text { inflammation and oxidative stress. }\end{array}$ & (38) \\
\hline NEAT1 & $\uparrow$ & $\begin{array}{l}\text { _ sepsis tissues } \\
\text { and ANCTs }\end{array}$ & $\begin{array}{l}\text { AW } 264.7 \\
\text { and } H L-1\end{array}$ & $\begin{array}{l}\downarrow \mathrm{miR}-370- \\
3 p, \uparrow \text { Irak2 }\end{array}$ & - & $\begin{array}{l}\text { Downregulation of NEAT1 ameliorated viability, } \\
\text { prevented apoptosis and the expression of } \\
\text { inflammatory cytokines. }\end{array}$ & (39) \\
\hline NEAT1 & $\uparrow$ & - & $\mathrm{HL}-1$ & $\begin{array}{l}\downarrow \mathrm{miR}-144- \\
3 p\end{array}$ & $\begin{array}{l}\mathrm{NF}-\kappa \mathrm{B} \\
\text { signaling } \\
\text { pathway }\end{array}$ & $\begin{array}{l}\text { Downregulation of NEAT1 ameliorated viability, } \\
\text { prevented apoptosis and inflammatory response in } \\
\text { LPS-induced myocardial cell injury. }\end{array}$ & $(40)$ \\
\hline NEAT1 & $\uparrow$ & $\begin{array}{l}152 \text { patients with } \\
\text { sepsis and } 150\end{array}$ & - & - & - & $\begin{array}{l}\text { Up-regulation of NEAT1 was positively associated } \\
\text { with Acute Physiology and Chronic Health Evaluation } \\
\text { II score, inflammatory responses, while negatively } \\
\text { associated with IL-10. }\end{array}$ & $(41)$ \\
\hline NEAT1 & $\uparrow$ & C57BL/6 mice & WI-38 & $\begin{array}{l}\downarrow \mathrm{miR}-944 \\
\uparrow \mathrm{TRIM} 37\end{array}$ & - & $\begin{array}{l}\text { Downregulation of NEAT1 inhibited inflammatory } \\
\text { responses and apoptosis. Overexpression of } \\
\text { TRIM37 rescued influence of downregulation of } \\
\text { NEAT1 on cell s. }\end{array}$ & $(42)$ \\
\hline NEAT1 & $\uparrow$ & $\begin{array}{l}59 \text { patients with } \\
\text { sepsis, } 52 \text { patients } \\
\text { with noninfectious } \\
\text { SIRS, and } 56 \text { HCs }\end{array}$ & PBMCs & - & - & $\begin{array}{l}\text { Levels of NEAT1 could be considered as a good } \\
\text { predictor for the diagnosis of sepsis. }\end{array}$ & (43) \\
\hline NEAT1 & $\uparrow$ & $\begin{array}{l}127 \text { patients with } \\
\text { sepsis and } 50 \mathrm{HCs}\end{array}$ & - & $\begin{array}{l}\uparrow \text { Th1, } \uparrow \\
\text { Th17 }\end{array}$ & - & $\begin{array}{l}\text { Overexpression of NEAT1 was associated with } \\
\text { chronic health evaluation II score, CRP level, acute } \\
\text { physiology, and SOFA score. }\end{array}$ & (44) \\
\hline
\end{tabular}


TABLE 1 | Continued

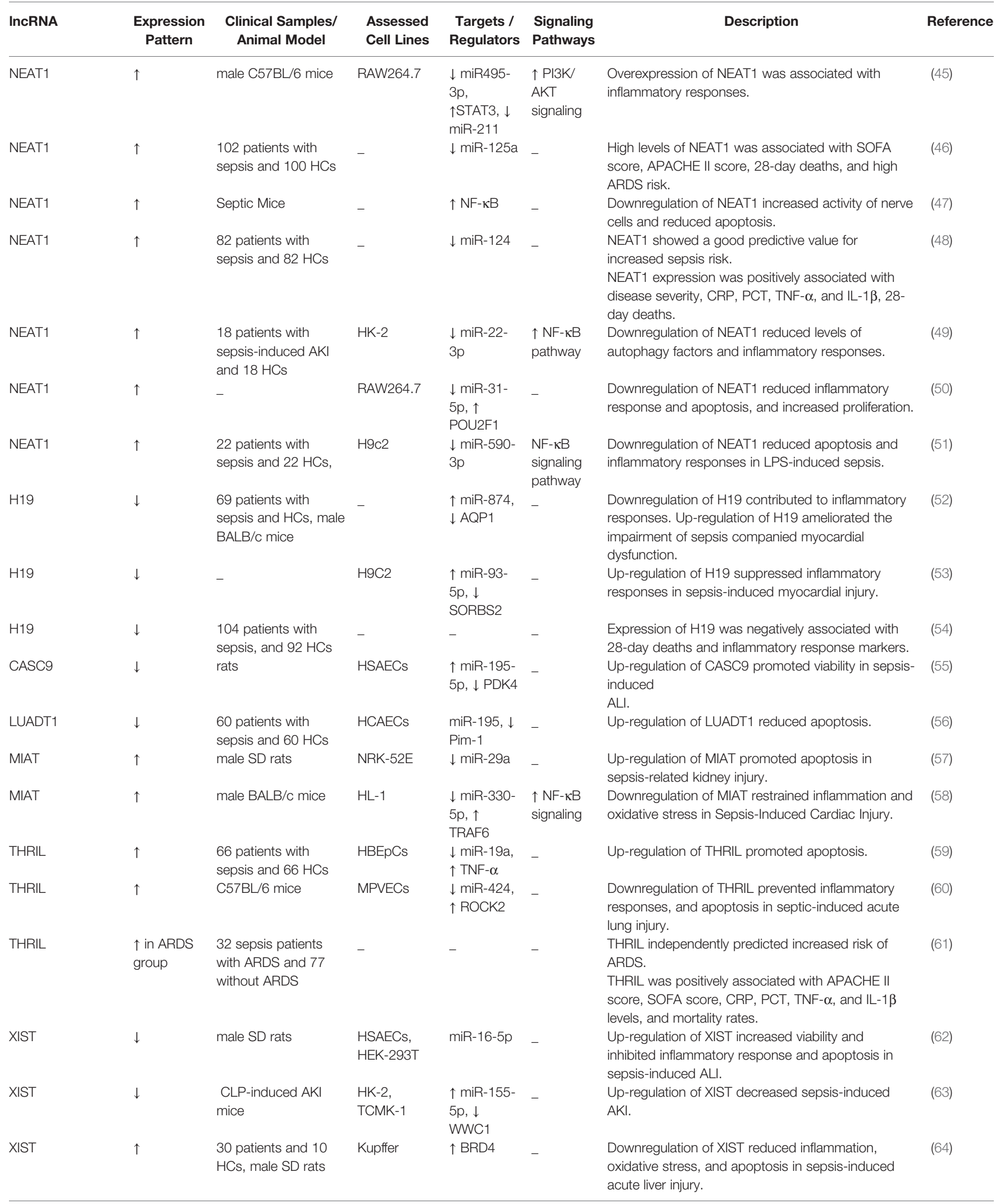


TABLE 1 | Continued

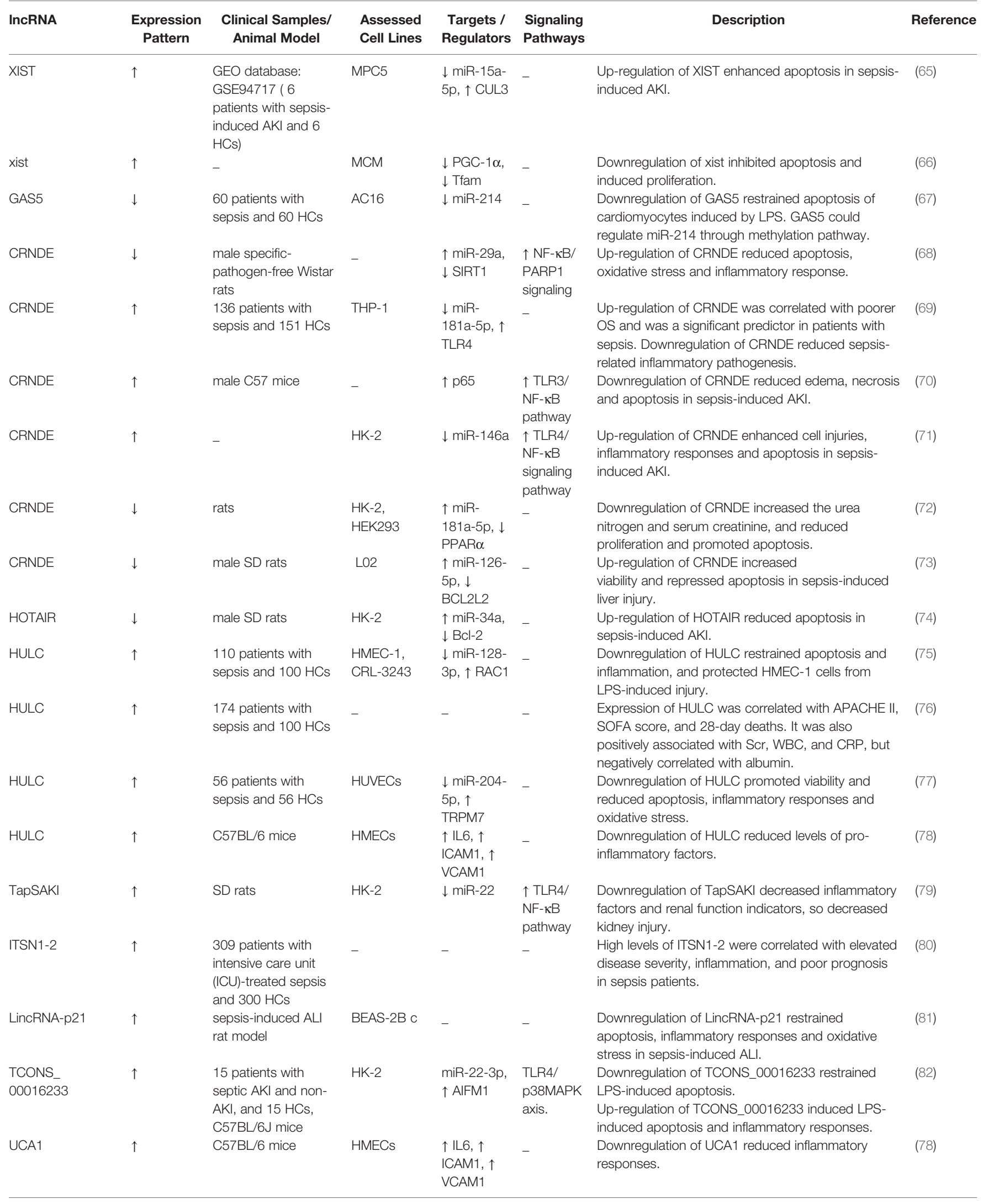


TABLE 1 | Continued

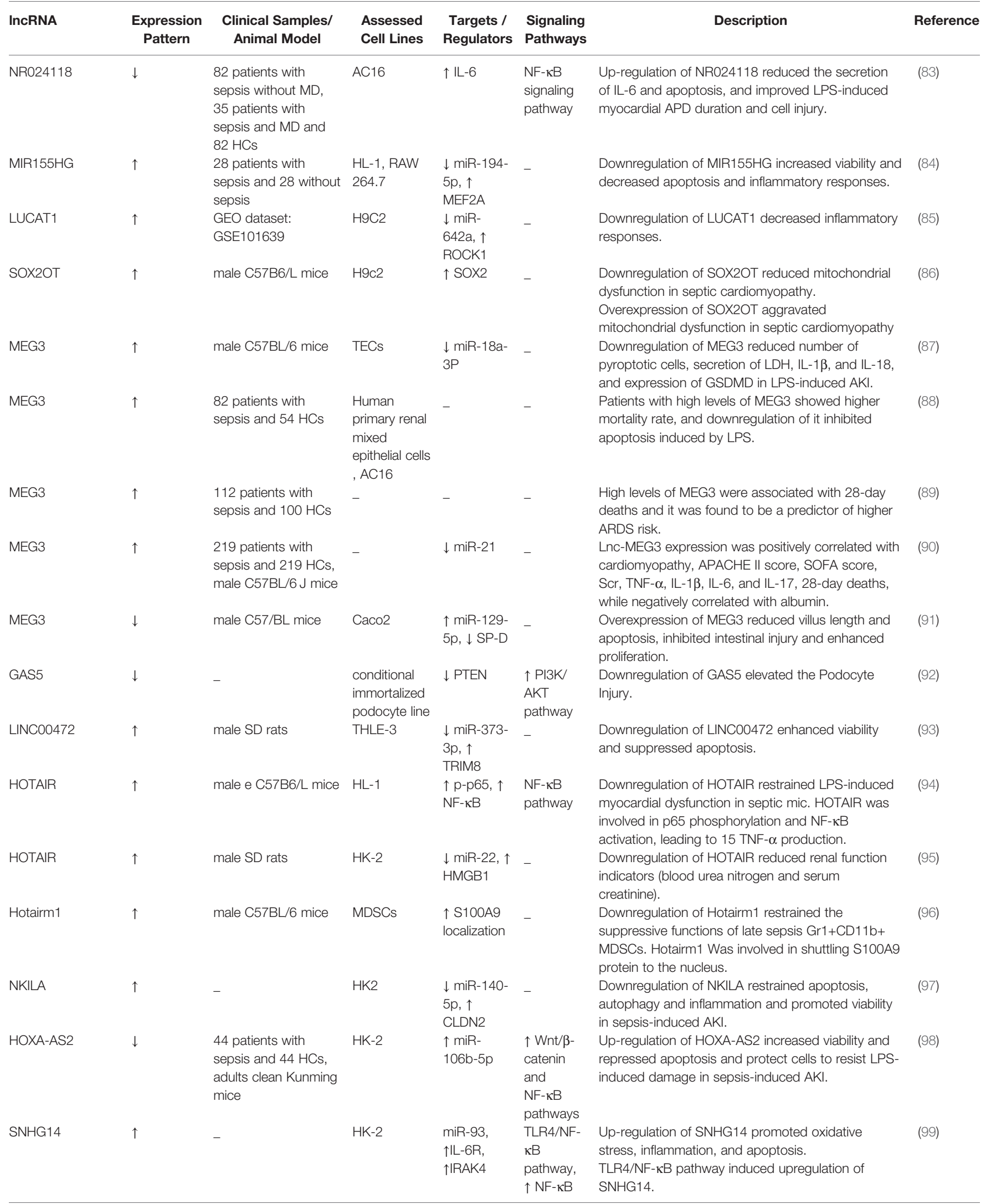


TABLE 1 | Continued

\begin{tabular}{|c|c|c|c|c|c|c|c|}
\hline IncRNA & $\begin{array}{l}\text { Expression } \\
\text { Pattern }\end{array}$ & $\begin{array}{l}\text { Clinical Samples/ } \\
\text { Animal Model }\end{array}$ & $\begin{array}{l}\text { Assessed } \\
\text { Cell Lines }\end{array}$ & $\begin{array}{l}\text { Targets / } \\
\text { Regulators }\end{array}$ & $\begin{array}{l}\text { Signaling } \\
\text { Pathways }\end{array}$ & Description & Reference \\
\hline & & & & & $\begin{array}{l}\text { and } \\
\text { STAT3 } \\
\text { signaling }\end{array}$ & & \\
\hline IncRNA-CCL2 & $\uparrow$ & male C57BL/6 mice & - & $\downarrow$ SIRT1 & - & $\begin{array}{l}\text { Expression of IncRNA-CCL2 was inhibited by SIRT1 } \\
\text { through maintaining a more repressive chromatin } \\
\text { state in IncRNA-CCL2 locus. } \\
\text { Downregulation of SIRT1 induced inflammatory } \\
\text { response. }\end{array}$ & $(100)$ \\
\hline DLX6-AS1 & $\uparrow$ & $\begin{array}{l}\text { patients with septic } \\
\text { AKI }\end{array}$ & $\mathrm{HK}-2$ & $\begin{array}{l}\downarrow \mathrm{miR}-223- \\
3 \mathrm{p}, \uparrow \\
\text { NLRP3 }\end{array}$ & - & $\begin{array}{l}\text { Downregulation of DLX6-AS1 suppressed LPS- } \\
\text { induced cytotoxicity and pyroptosis. } \\
\text { Expression of DLX6-AS1 was positively correlated } \\
\text { with levels of creatinine in the serum of patients. }\end{array}$ & $(101)$ \\
\hline CASC2 & $\downarrow$ & $\begin{array}{l}\text { _ patients with sepsis } \\
\text { and HCs }\end{array}$ & HK-2 & $\uparrow \mathrm{miR}-155$ & $\begin{array}{l}\uparrow \mathrm{NF}-\kappa \mathrm{B} \\
\text { signaling } \\
\text { pathway }\end{array}$ & $\begin{array}{l}\text { The levels of CASC2 were negatively correlated with } \\
\text { the severity of AKI. } \\
\text { CASC2 expression induced cell viability and inhibited } \\
\text { inflammatory response, apoptosis and oxidative } \\
\text { stress. }\end{array}$ & (102) \\
\hline CASC2 & $\downarrow$ & $\begin{array}{l}\text { patients with sepsis } \\
\text { and } \mathrm{HCs}\end{array}$ & HPAEpiC & $\begin{array}{l}\uparrow \mathrm{miR}-152- \\
3 p, \downarrow \text { PDK4 }\end{array}$ & - & $\begin{array}{l}\text { Up-regulation of CASC2 increased viability and } \\
\text { restrained apoptosis, inflammatory and oxidative } \\
\text { damages. }\end{array}$ & (103) \\
\hline ZFAS1 & $\downarrow$ & $\begin{array}{l}202 \text { patients with } \\
\text { sepsis and } 200 \mathrm{HCs}\end{array}$ & - & - & - & $\begin{array}{l}\text { Expression of ZFAS1 } \\
\text { was negatively associated with APACHE II, level of } \\
\text { CRP, TNF- } \alpha, \text { IL-6 and positively with IL- } 10 \text {. }\end{array}$ & (104) \\
\hline ZFAS1 & $\downarrow$ & male SD rats & $\mathrm{H} 9 \mathrm{C} 2$ & $\begin{array}{l}\uparrow \mathrm{miR}-34 \mathrm{~b}- \\
5 \mathrm{p}, \downarrow \mathrm{SIRT} 1\end{array}$ & - & $\begin{array}{l}\text { Up-regulation of ZFAS1 decreased inflammatory } \\
\text { responses and apoptosis. }\end{array}$ & (105) \\
\hline ZFAS1 & $\uparrow$ & male C57BL/6 mice & - & $\begin{array}{l}\downarrow \mathrm{miR}-590- \\
3 p, \text { SP1 }\end{array}$ & $\begin{array}{l}\text { AMPK } \\
\text { mTOR } \\
\text { signaling }\end{array}$ & $\begin{array}{l}\text { Downregulation of ZFAS1 reduced LPS-induced } \\
\text { pyroptosis and enhanced LPS-suppressed } \\
\text { autophagy in sepsis-induced cardiac dysfunction. }\end{array}$ & $(106)$ \\
\hline ZFAS1 & $\downarrow$ & $\begin{array}{l}22 \text { patients with SIMI } \\
\text { and } 24 \mathrm{HCs} \text {, rats } \\
\text { treated by LPS }\end{array}$ & $\mathrm{H} 9 \mathrm{C} 2$ & $\begin{array}{l}\uparrow \mathrm{miR}-138- \\
5 \mathrm{p}, \downarrow \\
\text { SESN2 }\end{array}$ & - & $\begin{array}{l}\text { Up-regulation of ZFAS1 attenuated myocardial injury } \\
\text { and inflammatory response. }\end{array}$ & (107) \\
\hline Mirt2 & $\downarrow$ & male SD rats & - & $\uparrow \mathrm{MiR}-101$ & $\begin{array}{l}\downarrow P I 3 K \\
\text { AKT } \\
\text { Signaling } \\
\text { Pathway }\end{array}$ & $\begin{array}{l}\text { Up-regulation of Mirt2 inhibited inflammatory } \\
\text { responses and improved cardiac function. }\end{array}$ & $(108)$ \\
\hline Mirt2 & $\downarrow$ & $\begin{array}{l}40 \text { patients with } \\
\text { sepsis, } 40 \text { patients } \\
\text { with sepsis-ALI, } 40 \\
\text { HCs }\end{array}$ & HBEpCs & $\downarrow \mathrm{miR}-1246$ & - & $\begin{array}{l}\text { Up-regulation of Mirt2 inhibited LPS-induced } \\
\text { inflammatory response, apoptosis, and promoted } \\
\text { miR-1246 expression but reduced its gene } \\
\text { methylation. }\end{array}$ & (109) \\
\hline TCONS_00016406 & $\downarrow$ & male C57BL/6 mice & PTEC & $\begin{array}{l}\uparrow \operatorname{miR}-687 \\
\downarrow \mathrm{PTEN}\end{array}$ & - & $\begin{array}{l}\text { Up-regulation of IncRNA } 6406 \text { inhibited inflammatory } \\
\text { responses, apoptosis and oxidative stress in LPS- } \\
\text { induced AKI. }\end{array}$ & $(110)$ \\
\hline NORAD & $\begin{array}{l}\uparrow \text { in NS } \\
\text { patients }\end{array}$ & $\begin{array}{l}88 \text { patients with late- } \\
\text { onset NS and } 86 \\
\text { patients with } \\
\text { pneumonia neonates }\end{array}$ & RAW264.7 & $\begin{array}{l}\downarrow \mathrm{miR}-410- \\
3 \mathrm{p}\end{array}$ & - & $\begin{array}{l}\text { Expression of NORAD was closely correlated with } \\
\text { WBC, PCT, IL-6, IL-8, and TNF- } \alpha \text {. }\end{array}$ & (111) \\
\hline GAS5 & $\uparrow$ & - & THP-1 & $\begin{array}{l}\downarrow \mathrm{miR}-23 \mathrm{a}- \\
3 \mathrm{p}, \uparrow \text { TLR4 }\end{array}$ & - & $\begin{array}{l}\text { Downregulation of GAS5 inhibited inflammation and } \\
\text { apoptosis. }\end{array}$ & $(112)$ \\
\hline Inc-ANRIL & $\uparrow$ & $\begin{array}{l}126 \text { patients with } \\
\text { sepsis and } 125 \mathrm{HCs}\end{array}$ & - & $\downarrow \mathrm{miR}-125 \mathrm{a}$ & - & $\begin{array}{l}\text { Inc-ANRIL showed good predictive values for sepsis } \\
\text { risk. } \\
\text { Inc-ANRIL was positively associated with CRP and } \\
\text { PCT levels, disease severity scale scores, and pro- } \\
\text { inflammatory cytokine levels, 28-day deaths in } \\
\text { sepsis patients, }\end{array}$ & $(113)$ \\
\hline PVT1 & $\uparrow$ & $\begin{array}{l}109 \text { patients with } \\
\text { sepsis and } 100 \mathrm{HCs}\end{array}$ & - & - & - & $\begin{array}{l}\text { PVT1 was found to be an independent risk factor for } \\
\text { sepsis ARDS. And PVT1 expression positively } \\
\text { associated with disease severity and } 28 \text {-day deaths. }\end{array}$ & $(114)$ \\
\hline PVT1 & $\uparrow$ & - & THP-1 & - & $\begin{array}{l}\uparrow \mathrm{p} 38 \\
\text { MAPK } \\
\text { signaling } \\
\text { pathway }\end{array}$ & $\begin{array}{l}\text { Downregulation of PVT1 reduced levels of IL-1 } \beta \text { and } \\
\text { TNF- } \alpha \text { mRNA and inhibited the p38 MAPK signaling } \\
\text { pathway, }\end{array}$ & (115) \\
\hline
\end{tabular}


TABLE 1 | Continued

\begin{tabular}{|c|c|c|c|c|c|c|c|}
\hline IncRNA & $\begin{array}{l}\text { Expression } \\
\text { Pattern }\end{array}$ & $\begin{array}{l}\text { Clinical Samples/ } \\
\text { Animal Model }\end{array}$ & $\begin{array}{l}\text { Assessed } \\
\text { Cell Lines }\end{array}$ & $\begin{array}{l}\text { Targets / } \\
\text { Regulators }\end{array}$ & $\begin{array}{l}\text { Signaling } \\
\text { Pathways }\end{array}$ & Description & Reference \\
\hline PVT1 & $\uparrow$ & sepsis model mice & $\mathrm{HK}-2$ & $\begin{array}{l}\downarrow \mathrm{miR}-20 \mathrm{a}- \\
5 \mathrm{p}, \uparrow \\
\text { NLRP3 }\end{array}$ & - & $\begin{array}{l}\text { Downregulation of PVT1 inhibited pyroptosis in } \\
\text { septic AKI. }\end{array}$ & $(116)$ \\
\hline PVT1 & $\uparrow$ & $\begin{array}{l}\text { Mice model with } \\
\text { sepsis }\end{array}$ & - & $\begin{array}{l}\downarrow \mathrm{miR}-29 \mathrm{a}, \\
\uparrow \mathrm{HMGB1}\end{array}$ & - & $\begin{array}{l}\text { Downregulation of PVT1 reduced LPS-induced } \\
\text { myocardial injury and alleviated M1 macrophage } \\
\text { polarization. }\end{array}$ & $(117)$ \\
\hline HOTAIR & $\uparrow$ & C57BL/6 mice & Monocytes & $\downarrow \mathrm{miR}-211$ & - & $\begin{array}{l}\text { Overexpression of HOTAIR suppressed proliferation } \\
\text { and promoted apoptosis. }\end{array}$ & (118) \\
\hline HOTAIR & $\uparrow$ & $\begin{array}{l}\text { LPS-induced septic } \\
\text { cardiomyopathy mice }\end{array}$ & $\mathrm{H} 9 \mathrm{C} 2$ & $\begin{array}{l}\uparrow \text { PDCD4, } \\
\text { Lin28 }\end{array}$ & - & $\begin{array}{l}\text { Downregulation of HOTAIR inhibited inflammatory } \\
\text { responses and apoptosis. }\end{array}$ & (119) \\
\hline DILC & $\downarrow$ & $\begin{array}{l}18 \text { patients with } \\
\text { sepsis and } 18 \mathrm{HCs}\end{array}$ & $\begin{array}{l}\text { PBMCs, } \\
\text { THP-1 }\end{array}$ & $\uparrow \mathbb{I L}-6$ & - & $\begin{array}{l}\text { DILC suppressed the transcription of IL-6, } \\
\text { DILC decreased levels of STAT3, p-STAT3, TLR4, } \\
\text { TNF- } \alpha \text {, CCL5, E-selectin and CXCR1. }\end{array}$ & $(120)$ \\
\hline RMRP & $\uparrow$ & C57BL/6 mice & $\mathrm{HK}-2$ & $\begin{array}{l}\downarrow \mathrm{miR}-206, \\
\uparrow \mathrm{DDX} 5\end{array}$ & - & $\begin{array}{l}\text { Downregulation of RMRP inhibited inflammatory } \\
\text { response and apoptosis in sepsis-induced AKI. }\end{array}$ & $(121)$ \\
\hline GAS5 & $\uparrow$ & C57BL/6 mice & - & $\begin{array}{l}\downarrow \mathrm{miR}- \\
449 \mathrm{~b}, \uparrow \\
\text { HMGB1 }\end{array}$ & $\begin{array}{l}\uparrow \mathrm{HMGB1/} \\
\mathrm{NF}-\kappa \mathrm{B} \\
\text { pathway }\end{array}$ & $\begin{array}{l}\text { Downregulation of GAS5 inhibited pro-inflammatory } \\
\text { reaction and alleviated } \\
\text { myocardial injury. }\end{array}$ & $(122)$ \\
\hline TapSAKI & $\uparrow$ & - & $\mathrm{HK}-2$ & $\begin{array}{l}\downarrow \text { miR-205, } \\
\uparrow \text { IRF3 }\end{array}$ & - & $\begin{array}{l}\text { Downregulation of TapSAKI alleviated LPS-induced } \\
\text { damage. }\end{array}$ & (123) \\
\hline SNHG16 & $\uparrow$ & male SD rats & BEAS-2B & $\begin{array}{l}\downarrow \mathrm{miR}-128- \\
3 p, \uparrow \\
\text { HMGB3 }\end{array}$ & - & $\begin{array}{l}\text { Downregulation of SNHG16 reduced the apoptosis } \\
\text { and inflammation in sepsis-induced ALI. }\end{array}$ & $(124)$ \\
\hline DANCR & $\downarrow$ & $\begin{array}{l}20 \text { patients with } \\
\text { sepsis-induced } \mathrm{AKI} \\
\text { and } 20 \mathrm{HCs}\end{array}$ & $\mathrm{HK}-2$ & $\begin{array}{l}\uparrow \operatorname{miR}-214, \\
\uparrow \mathrm{KLF6}\end{array}$ & - & $\begin{array}{l}\text { Up-regulation of DANCR promoted viability and } \\
\text { suppressed cell apoptosis and inflammatory } \\
\text { responses. }\end{array}$ & $(125)$ \\
\hline CASC2 & $\downarrow$ & - & $\begin{array}{l}\text { HK2, } \\
\text { HEK293 }\end{array}$ & $\begin{array}{l}\uparrow \text { miR-545- } \\
3 p \text { to } \\
\text { regulate, } \downarrow \\
\text { PPARA }\end{array}$ & - & $\begin{array}{l}\text { Up-regulation of CASC2 increased viability and } \\
\text { inhibited apoptosis, migration, epithelial- } \\
\text { mesenchymal transition and oxidative stress. }\end{array}$ & (126) \\
\hline SNHG1 & $\downarrow$ & - & $\mathrm{H} 9 \mathrm{c} 2$ & $\begin{array}{l}\uparrow \mathrm{miR}- \\
181 \mathrm{a}-5 \mathrm{p}, \downarrow \\
\text { XIAP }\end{array}$ & - & $\begin{array}{l}\text { Up-regulation of SNHG1 increased viability and } \\
\text { inhibited inflammatory responses and oxidative } \\
\text { stress. }\end{array}$ & $(127)$ \\
\hline SNHG14 & $\uparrow$ & _patients with sepsis & HK-2 & $\begin{array}{l}\downarrow \mathrm{miR}-495- \\
3 p, \uparrow \\
\text { HIPK1 }\end{array}$ & - & $\begin{array}{l}\text { SNHG14 is upregulated in patients. SNHG14 } \\
\text { prevented proliferation and autophagy and boosted } \\
\text { apoptosis and inflammatory responses. }\end{array}$ & (128) \\
\hline Linc-KIAA1737-2 & $\uparrow$ & - & $\mathrm{HK}-2$ & $\begin{array}{l}\downarrow \text { MiR-27a- } \\
3 p\end{array}$ & - & $\begin{array}{l}\text { Downregulation of Linc-KIAA1737-2 reduced } \\
\text { apoptosis. }\end{array}$ & (129) \\
\hline PlncRNA-1 & $\downarrow$ & $\begin{array}{l}6 \text { patients with septic } \\
\mathrm{AKI} \text { and } 6 \mathrm{HCs}\end{array}$ & NRK-52E & $\downarrow \mathrm{BCL} 2$ & - & $\begin{array}{l}\text { Up-regulation of PIncRNA-1 meliorated proliferation } \\
\text { and prevented apoptosis and autophagy. }\end{array}$ & (130) \\
\hline CDKN2B-AS1 & $\uparrow$ & $\begin{array}{l}\text { sepsis patients } 47 \\
\text { and } 55 \mathrm{HCs}\end{array}$ & BEAS-2B & $\begin{array}{l}\downarrow \mathrm{miR}-140- \\
5 p, \uparrow \\
\text { TGFBR2 }\end{array}$ & $\begin{array}{l}\uparrow \\
\text { TGFBR2/ } \\
\text { smad3 } \\
\text { pathway }\end{array}$ & $\begin{array}{l}\text { Downregulation of CDKN2B-AS1 promoted viability } \\
\text { reduced apoptosis and inflammation. }\end{array}$ & (131) \\
\hline
\end{tabular}

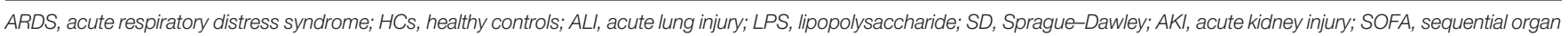

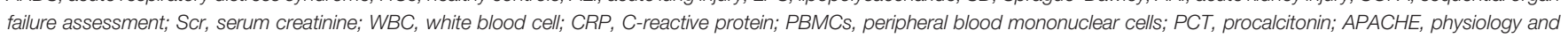
chronic health evaluation; MPO, Myeloperoxidase; NS, Neonatal sepsis; SIMI, sepsis-induced myocardial injury.

NF-אB, PI3K/AKT, JAK/STAT and Wnt/ $\beta$-catenin pathways are the most important pathways being regulated by lncRNAs, circRNAs and miRNAs in the context of sepsis. These transcripts, particularly miRNAs can be used as diagnostic or prognostic markers in sepsis. Expression levels of these regulatory transcripts might be used for diagnosis of organ specific damages during the course of sepsis.

In general, the pathophysiology of sepsis is considered as an initial hyperinflammatory phase ("cytokine storm") followed by a protracted immunosuppressive phase. Since no data is available about the differential expression of non-coding RNAs during these two distinct phases, future studies are needed to evaluate expression patterns of non-coding RNAs in these two phases. It is possible that some of the non-coding RNAs that suppress the immune response could be used as biomarkers to indicate the immunoparalysis in sepsis.

From a therapeutic point of view, several in vitro and in vivo studies have shown that up-regulation/silencing of circRNAs, 
TABLE 2 | Lists the function of miRNAs in the course of sepsis.

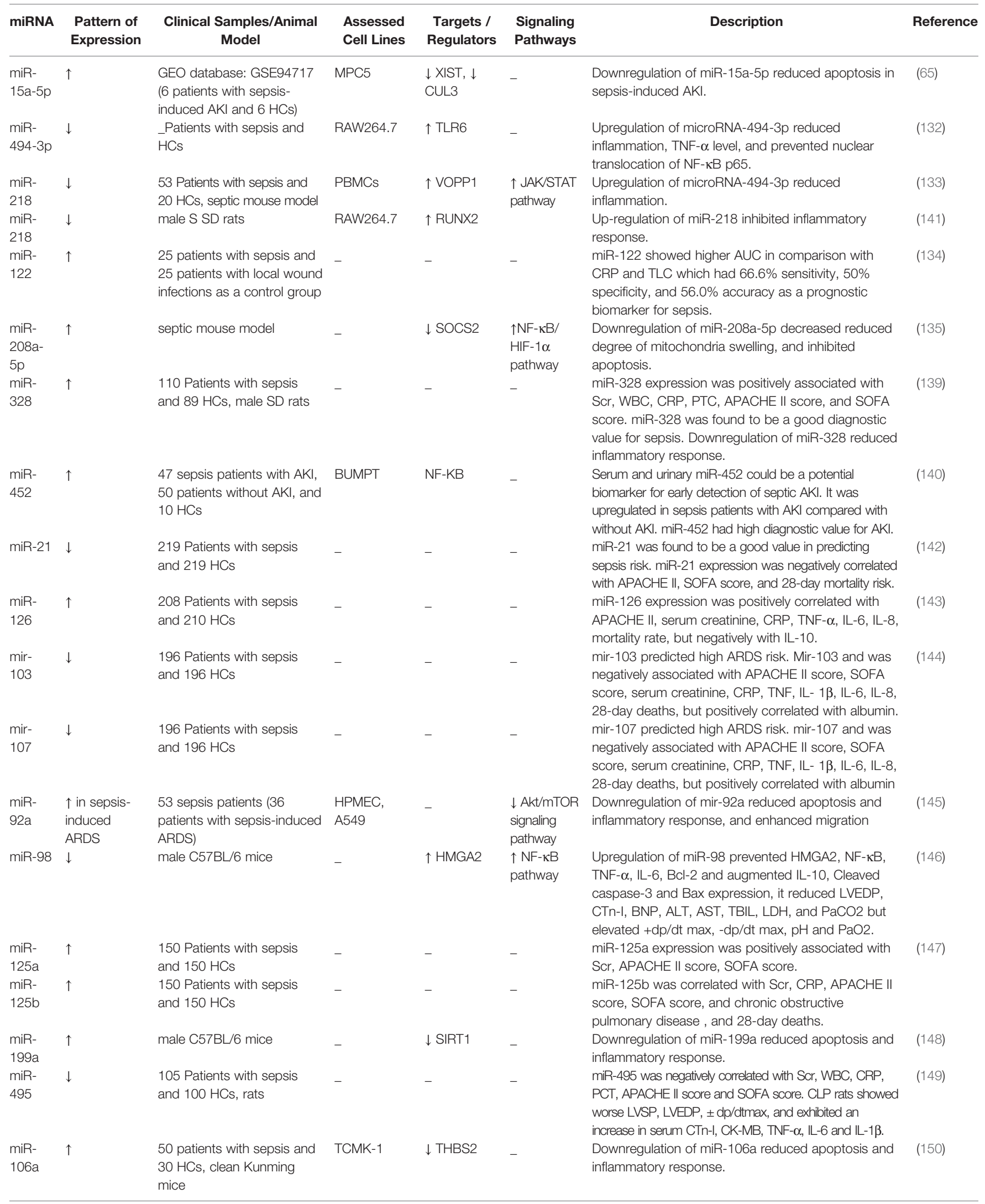


TABLE 2 | Continued

\begin{tabular}{|c|c|c|c|c|c|c|c|}
\hline miRNA & $\begin{array}{l}\text { Pattern of } \\
\text { Expression }\end{array}$ & $\begin{array}{l}\text { Clinical Samples/Animal } \\
\text { Model }\end{array}$ & $\begin{array}{l}\text { Assessed } \\
\text { Cell Lines }\end{array}$ & $\begin{array}{c}\text { Targets / } \\
\text { Regulators }\end{array}$ & $\begin{array}{l}\text { Signaling } \\
\text { Pathways }\end{array}$ & Description & Reference \\
\hline $\begin{array}{l}\text { miR- } \\
146 a\end{array}$ & - & male C57BL/6 mice & MSCs & $\mathrm{IL}-1 \beta$ & - & $\begin{array}{l}\text { IL-1 } 1 \beta \text { stimulation resulted in packaging miR-146a into } \\
\text { exosomes. The exosomal miR-146a was transferred to } \\
\text { macrophages, yielded to M2 polarization, and finally led } \\
\text { to high survival in septic mice. }\end{array}$ & $(151)$ \\
\hline $\begin{array}{l}\mathrm{miR}- \\
574\end{array}$ & $\downarrow$ & CLP-treated mice & $\mathrm{HBE}$ & $\uparrow \mathrm{C} 3$ & - & $\begin{array}{l}\text { Upregulation of mir-574 increased viability, inhibited } \\
\text { apoptosis, and reduced sepsis-induced ERS. }\end{array}$ & $(152)$ \\
\hline $\begin{array}{l}\text { miR- } \\
195\end{array}$ & - & wistar rats with sepsis & & - & $\begin{array}{l}\text { TGF- } \beta 1 / \\
\text { Smads } \\
\text { signaling } \\
\text { pathway, }\end{array}$ & $\begin{array}{l}\text { MicroRNA-195 could promote cardiac remodeling by } \\
\text { up-regulating the nanoantibiotics signaling pathway in } \\
\text { sepsis rats. }\end{array}$ & $(153)$ \\
\hline $\begin{array}{l}\text { miR- } \\
133 a\end{array}$ & $\uparrow$ & septic mouse model & RAW264.7 & $\downarrow \mathrm{SIRT} 1$ & - & $\begin{array}{l}\text { Downregulation of miR-133a prevented inflammatory } \\
\text { response, sepsis-induced lung, liver and kidney injuries. }\end{array}$ & (154) \\
\hline $\begin{array}{l}\text { miR- } \\
191-5 p\end{array}$ & $\downarrow$ & female Wistar rats & - & $\uparrow$ OXSR1 & $\begin{array}{l}\uparrow p 38 \\
\text { MAPK/NF- } \\
\text { кB signaling } \\
\text { pathway }\end{array}$ & $\begin{array}{l}\text { Upregulation of miR-191-5p prevented inflammatory } \\
\text { response and apoptosis in }\end{array}$ & $(155)$ \\
\hline $\begin{array}{l}\mathrm{miR}- \\
146 \mathrm{a}\end{array}$ & $\uparrow$ & $\begin{array}{l}180 \text { patients with sepsis and } \\
180 \mathrm{HCs}\end{array}$ & - & - & - & $\begin{array}{l}\text { MiR-146a was of good value in predicting high sepsis } \\
\text { risk and 28-day mortality risk. MiR-146a was } \\
\text { positively associated with biochemical indices, } \\
\text { inflammatory cytokines, overall disease severity. }\end{array}$ & (156) \\
\hline $\begin{array}{l}\text { miR- } \\
146 b\end{array}$ & $\uparrow$ & $\begin{array}{l}180 \text { patients with sepsis and } \\
180 \mathrm{HCs}\end{array}$ & - & - & - & $\begin{array}{l}\text { miR-146b was of good value in predicting high } \\
\text { sepsis risk and } 28 \text {-day mortality risk. MiR-146a was } \\
\text { positively associated with biochemical indices, } \\
\text { inflammatory cytokines, and overall disease severity. } \\
\text {. }\end{array}$ & \\
\hline $\begin{array}{l}\text { miR- } \\
126\end{array}$ & $\downarrow$ & $\begin{array}{l}20 \text { patients with sepsis and } \\
30 \text { patients with general } \\
\text { infection }\end{array}$ & - & - & - & $\begin{array}{l}\text { miR-126 was negatively associated with the levels of } \\
\text { caspase- } 3 \text {, APACHE II score, and positively with } 28 \text { - } \\
\text { day cumulative survival rate. AUC for predicting the } \\
\text { prognosis by miR-126 was } 0.823 \text {. }\end{array}$ & $(157)$ \\
\hline $\begin{array}{l}\mathrm{miR}- \\
223\end{array}$ & - & C57BL/6 mice & RAW264.7 & - & - & $\begin{array}{l}\text { Upregulation of mir-223 impelled M2 macrophage } \\
\text { through lower activity of glycolysis Pathway. the } \\
\text { Implementation of } \\
\text { miR-223 over-expressed macrophages with IL-4 pre- } \\
\text { conditioning alleviated sepsis severity. }\end{array}$ & (158) \\
\hline $\begin{array}{l}\mathrm{miR}- \\
146 b\end{array}$ & $\downarrow$ & septic mouse model & $\mathrm{HK}-2$ & $\uparrow \operatorname{IRAK} 1$ & $\begin{array}{l}\uparrow \mathrm{NF}-\kappa \mathrm{B} \\
\text { pathway }\end{array}$ & $\begin{array}{l}\text { Treatment with hucMSC-Ex improved survival in mice } \\
\text { with sepsis by reducing levels of IRAK1, increasing of } \\
\text { miR-146b level, and inhibition of NF- KB activity. }\end{array}$ & $(159)$ \\
\hline $\begin{array}{l}\operatorname{miR}-1- \\
3 p\end{array}$ & $\uparrow$ & male SD rats & HUVECS & $\downarrow$ SERP1 & - & $\begin{array}{l}\text { miR-1-3p decreased proliferation, and increased apoptosis, } \\
\text { and permeability and HUVECs membrane injury. }\end{array}$ & $(160)$ \\
\hline miR-25 & $\downarrow$ & $\begin{array}{l}70 \text { patients with sepsis and } \\
30 \text { patients with SIRS }\end{array}$ & - & - & - & $\begin{array}{l}\text { Levels of miR-25 was negatively associated with the } \\
\text { severity of sepsis, SOFA score, CRP and PCT level, 28- } \\
\text { day deaths, and levels of oxidative stress indicators. }\end{array}$ & $(161)$ \\
\hline $\begin{array}{l}\text { miR- } \\
370-3 p\end{array}$ & $\uparrow$ in SAE & $\begin{array}{l}12 \text { patients with sepsis } \\
\text { without encephalopathy, } 17 \\
\text { patients with SAE, } 20 \\
\text { patients with severe uremia } \\
\text { and } 12 \mathrm{HCs} \text {, male C57BL/6 } \\
\text { mice }\end{array}$ & - & - & - & $\begin{array}{l}\text { miR-370-3p was associated with TNF- } \alpha \text { and } \\
\text { increased brain apoptosis in SAE mice. }\end{array}$ & $(162)$ \\
\hline miR-21 & $\uparrow$ & $\begin{array}{l}\text { GEO database: GSE26440 } \\
\text { (88 children with septic shock } \\
\text { and } 26 \text { HCs), C57BL/6 mice }\end{array}$ & - & $\begin{array}{l}\downarrow \mathrm{A} 20, \uparrow \\
\mathrm{NLRP3}\end{array}$ & $\begin{array}{l}\uparrow \mathrm{NF}-\kappa \mathrm{B} \\
\text { pathway }\end{array}$ & $\begin{array}{l}\text { Downregulation of miR-21 inhibited inflammasome } \\
\text { activation, ASC pyroptosome, LPS-induced } \\
\text { pyroptosis and septic shock. }\end{array}$ & $(136)$ \\
\hline miR-21 & $\downarrow$ & CLP mouse model & - & $\begin{array}{l}\uparrow \text { PDCD4, } \uparrow \\
\text { PTEN }\end{array}$ & $\begin{array}{l}\text { PDCD4/NF- } \\
\kappa B \text { and } \\
\text { PTEN/AKT } \\
\text { pathways }\end{array}$ & $\begin{array}{l}\text { rIPC protected kidneys from injury by miR- } 21 \text {. miR- } \\
21 \text { was transported from ischemic limbs to the } \\
\text { kidneys by exosomes. }\end{array}$ & $(163)$ \\
\hline miR-21 & $\downarrow$ & septic mouse model & MTEC & $\uparrow \mathrm{PDCD} 4$ & $\begin{array}{l}\uparrow \mathrm{NF}-\kappa \mathrm{B} \\
\text { pathway }\end{array}$ & $\begin{array}{l}\text { Upregulation of miR-21 reduced inflammation and } \\
\text { apoptosis. }\end{array}$ & $(137)$ \\
\hline miR-21 & - & septic mice & - & - & - & $\begin{array}{l}\text { Hyperoside decreased miR-21 levels so reduced } \\
\text { inflammatory responses and increased viability. }\end{array}$ & $(164)$ \\
\hline miR-21 & $\downarrow$ & - & MSCs & $\uparrow \mathrm{PDCD} 4$ & - & $\begin{array}{l}\text { BMSCs-derived exosomes reduced symptoms in } \\
\text { septic mice and improved their survival rate through } \\
\text { miR-21 upregulation. }\end{array}$ & $(138)$ \\
\hline
\end{tabular}


TABLE 2 | Continued

\begin{tabular}{|c|c|c|c|c|c|c|c|}
\hline miRNA & $\begin{array}{l}\text { Pattern of } \\
\text { Expression }\end{array}$ & $\begin{array}{l}\text { Clinical Samples/Animal } \\
\text { Model }\end{array}$ & $\begin{array}{l}\text { Assessed } \\
\text { Cell Lines }\end{array}$ & $\begin{array}{c}\text { Targets / } \\
\text { Regulators }\end{array}$ & $\begin{array}{l}\text { Signaling } \\
\text { Pathways }\end{array}$ & Description & Reference \\
\hline miR-21 & $\uparrow$ & septic C57BL/6J mice & - & $\begin{array}{l}\downarrow \text { PGE2, } \\
\downarrow \| \text { L-10 }\end{array}$ & - & $\begin{array}{l}\text { Downregulation of miR-21 reduced bacterial growth, } \\
\text { systemic inflammation, organ damage, macrophage } \\
\text { glycolysis, and increased animal survival. }\end{array}$ & $(165)$ \\
\hline $\begin{array}{l}\mathrm{miR}- \\
21-3 p\end{array}$ & $\uparrow$ & SD rats & TECs & $\begin{array}{l}\downarrow \mathrm{AKT} \\
\downarrow \mathrm{CDK} 2 \\
\uparrow \mathrm{FOXO} 1\end{array}$ & - & $\begin{array}{l}\text { miR-21-3p regulated lipid metabolism and increased } \\
\text { cell cycle arrest and apoptosis. }\end{array}$ & $(166)$ \\
\hline miR-34 & $\uparrow$ & $\begin{array}{l}\text { male C57BL/6 mice ( } 15 \\
\text { control group and } 15 \text { sepsis } \\
\text { model group) }\end{array}$ & - & $\downarrow \mathrm{KLF} 4$ & - & $\begin{array}{l}\text { Plasma miR-34a was positively associated with SCr } \\
\text { and BUN. }\end{array}$ & $(167)$ \\
\hline $\begin{array}{l}\text { miR- } \\
483-5 p\end{array}$ & $\uparrow$ & CLP-treated mice & PMVECs & $\downarrow \mathrm{PIAS} 1$ & - & $\begin{array}{l}\text { Downregulation of miR-483-5p reduced inflammation } \\
\text { and apoptosis and improved lung injury in mice with } \\
\text { sepsis-induced ALI. }\end{array}$ & (168) \\
\hline $\begin{array}{l}\mathrm{miR}- \\
181-5 p\end{array}$ & $\downarrow$ & CLP- treated mice & - & $\uparrow \mathrm{HMGB1}$ & - & $\begin{array}{l}\text { Upregulation of miR-181-5p reduced inflammatory } \\
\text { response, and sepsis-induced renal and hepatic } \\
\text { dysfunction. }\end{array}$ & $(169)$ \\
\hline $\begin{array}{l}\text { miR- } \\
20 a\end{array}$ & - & SD rats & - & - & - & $\begin{array}{l}\text { miR-20a could deteriorated AKI via activating } \\
\text { autophagy in sepsis rats. }\end{array}$ & $(170)$ \\
\hline $\begin{array}{l}\text { hsa- } \\
\text { miR- } \\
92 a-3 p\end{array}$ & $\begin{array}{l}\downarrow \text { in sepsis- } \\
\text { induced } \\
\text { coagulopathy } \\
\text { group }\end{array}$ & 116 patients with sepsis & - & - & - & $\begin{array}{l}\text { AUC of hsa-mir-92a-3p was 0.660. Levels of plasma } \\
\text { hsa-mir-92a-3p were related to plasma lipocalin-2 } \\
\text { level, activated partial thromboplastin time, and } \\
\text { prothrombin activity. }\end{array}$ & $(171)$ \\
\hline $\begin{array}{l}\mathrm{miR}- \\
93-5 p\end{array}$ & $\downarrow$ & septic mouse model & HK2 & $\begin{array}{l}\uparrow \mathrm{KDM} 6 \mathrm{~B}, \downarrow \\
\mathrm{H} 3 \mathrm{~K} 27 \mathrm{me} 3\end{array}$ & - & $\begin{array}{l}\text { Extracellular vesicles containing miR-93-5p reduced } \\
\text { inflammation, apoptosis, multiple organ injury, and } \\
\text { vascular leakage in septic mice. }\end{array}$ & $(172)$ \\
\hline $\begin{array}{l}\mathrm{miR}- \\
223\end{array}$ & $\downarrow$ & $\begin{array}{l}143 \text { patients with sepsis and } \\
44 \mathrm{HCs}\end{array}$ & - & - & - & $\begin{array}{l}\text { Expression of miR-223 was negatively correlated with } \\
\text { SOFA scores and positively with survival rate. } \\
\text { Upregulation of miR-223 decreased apoptosis and } \\
\text { increased proliferation and G1/S transition. }\end{array}$ & $(173)$ \\
\hline $\begin{array}{l}\mathrm{miR}- \\
34 \mathrm{a}\end{array}$ & $\uparrow$ & male C57BL/6 mice & - & $\begin{array}{l}\downarrow \text { SIRT1, } \downarrow \\
\text { ATG4B }\end{array}$ & - & $\begin{array}{l}\text { Downregulation of miR-34a reduced inflammatory } \\
\text { response and pyroptosis, apoptosis and enhanced } \\
\text { autophagy. }\end{array}$ & $(174)$ \\
\hline $\begin{array}{l}\text { miR- } \\
30 a\end{array}$ & $\uparrow$ & septic rats & - & $\downarrow$ SOCS- 1 & $\begin{array}{l}\uparrow \text { JAK } \\
\text { STAT } \\
\text { signaling } \\
\text { pathway }\end{array}$ & $\begin{array}{l}\text { Upregulation of miR-30a promoted apoptosis and } \\
\text { inhibited proliferation. }\end{array}$ & $(175)$ \\
\hline $\begin{array}{l}\operatorname{miR}- \\
150-5 p\end{array}$ & $\downarrow$ & rat septic shock model & $\mathrm{H} 9 \mathrm{C} 2$ & $\uparrow \mathrm{Akt} 2$ & - & Upregulation of miR-150-5p inhibited apoptosis. & $(176)$ \\
\hline $\begin{array}{l}\text { miR- } \\
140\end{array}$ & $\downarrow$ & SPF male BALB/c mice & - & - & $\begin{array}{l}\uparrow \text { WNT } \\
\text { signaling } \\
\text { pathway }\end{array}$ & $\begin{array}{l}\text { Upregulation of miR-140 inhibited apoptosis and } \\
\text { inflammation, skeletal muscle glycolysis and atrophy. }\end{array}$ & (177) \\
\hline $\begin{array}{l}\mathrm{miR}- \\
22-3 p\end{array}$ & $\downarrow$ & male SD rats & $\mathrm{HK}-2$ & $\begin{array}{l}\uparrow \mathrm{HMGB} 1, \uparrow \\
\mathrm{PTEN}\end{array}$ & - & $\begin{array}{l}\text { Upregulation of miR-22-3p inhibited apoptosis and } \\
\text { inflammatory response }\end{array}$ & $(178)$ \\
\hline $\begin{array}{l}\text { miR- } \\
205-5 b\end{array}$ & $\uparrow$ & BALB/c mice & RAW264.7 & HMGB1 & - & $\begin{array}{l}\text { Down regulation of miR-205-5b increased HMGB1 } \\
\text { expression in LPS-induced sepsis. }\end{array}$ & (179) \\
\hline $\begin{array}{l}\mathrm{miR}- \\
526 \mathrm{~b}\end{array}$ & $\downarrow$ & BALB/c mice & HK2 & $\uparrow$ ATG7 & - & $\begin{array}{l}\text { Upregulation of miR-526b increased viability by } \\
\text { inhibiting autophagy. }\end{array}$ & (180) \\
\hline $\begin{array}{l}\text { miR- } \\
145 a\end{array}$ & $\downarrow$ & septic mouse model & - & $\uparrow \mathrm{Fli}-1$ & $\begin{array}{l}\uparrow \mathrm{NF}-\kappa \mathrm{B} \\
\text { signaling }\end{array}$ & $\begin{array}{l}\text { Upregulation of miR-526b reduced levels of } \\
\text { proinflammatory cytokines. }\end{array}$ & $(181)$ \\
\hline $\begin{array}{l}\text { miR- } \\
125 a\end{array}$ & $\uparrow$ & $\begin{array}{l}150 \text { patients with sepsis and } \\
150 \mathrm{HCs}\end{array}$ & - & - & - & $\begin{array}{l}\text { AUC of miR-125a: } 0.749 \\
\text { miR-125a was positively correlated with APACHE ॥ } \\
\text { score and SOFA score. }\end{array}$ & (182) \\
\hline $\begin{array}{l}\mathrm{miR}- \\
125 b\end{array}$ & $\uparrow$ & $\begin{array}{l}150 \text { patients with sepsis and } \\
150 \mathrm{HCs}\end{array}$ & - & - & - & $\begin{array}{l}\text { AUC of miR-125b: } 0.839 \\
\text { miR-125b was positively correlated with APACHE II } \\
\text { score, SOFA score CRP, TNF- } \alpha, I L-6, I L-17, I L-23 \text {, } \\
\text { and 28-day mortality risk. }\end{array}$ & \\
\hline $\begin{array}{l}\text { miR- } \\
122\end{array}$ & $\uparrow$ & $\begin{array}{l}108 \text { patients with sepsis and } \\
20 \text { patients with infections } \\
\text { without sepsis as controls }\end{array}$ & - & - & - & $\begin{array}{l}\text { AUC of miR-122: } 0.760 \\
\text { miR-122 was found as independent prognostic factor } \\
\text { for } 30 \text {-day mortality. }\end{array}$ & (183) \\
\hline $\begin{array}{l}\text { miR- } \\
135 a\end{array}$ & $\uparrow$ & $\begin{array}{l}\text { _patients with sepsis and } \\
\text { HCs, BALB/c mice }\end{array}$ & - & - & $\begin{array}{l}\uparrow \mathrm{p} 38 \\
\text { MAPK/NF- } \\
\text { кB pathway }\end{array}$ & $\begin{array}{l}\text { Upregulation of } \\
\text { miR-135a exacerbated inflammation and myocardial } \\
\text { dysfunction. }\end{array}$ & (184) \\
\hline $\begin{array}{l}\text { miR- } \\
133 a\end{array}$ & $\downarrow$ & - & TCMK-1 & $\uparrow \mathrm{BNIP3L}$ & $\begin{array}{l}\uparrow \mathrm{NF}-\kappa \mathrm{B} \\
\text { pathway }\end{array}$ & $\begin{array}{l}\text { Upregulation of miR-133a reduced inflammation and } \\
\text { apoptosis. }\end{array}$ & (185) \\
\hline
\end{tabular}


TABLE 2 | Continued

\begin{tabular}{|c|c|c|c|c|c|c|c|}
\hline miRNA & $\begin{array}{l}\text { Pattern of } \\
\text { Expression }\end{array}$ & $\begin{array}{l}\text { Clinical Samples/Animal } \\
\text { Model }\end{array}$ & $\begin{array}{l}\text { Assessed } \\
\text { Cell Lines }\end{array}$ & $\begin{array}{c}\text { Targets / } \\
\text { Regulators }\end{array}$ & $\begin{array}{l}\text { Signaling } \\
\text { Pathways }\end{array}$ & Description & Reference \\
\hline $\begin{array}{l}\mathrm{miR}- \\
223\end{array}$ & - & male C57BL/6 mice & - & - & - & $\begin{array}{l}\text { In multiple models of experimental sepsis, miR-223 } \\
\text { showed the complex role in the pathogenesis of } \\
\text { septic kidney injury. }\end{array}$ & $(186)$ \\
\hline $\begin{array}{l}\mathrm{miR}- \\
155\end{array}$ & $\uparrow$ & $\begin{array}{l}44 \text { patients with severe } \\
\text { sepsis, } 102 \text { patients with } \\
\text { sepsis, and } 19 \mathrm{HCs}\end{array}$ & $\uparrow$ & $\uparrow$ & $\uparrow$ & $\begin{array}{l}\text { AUC of miR-155: } 0.782 \text { (for predicting 30-day } \\
\text { mortality in ALI) }\end{array}$ & $(187)$ \\
\hline $\begin{array}{l}\mathrm{miR-} \\
146 a\end{array}$ & $\uparrow$ & $\begin{array}{l}44 \text { patients with severe } \\
\text { sepsis, } 102 \text { patients with } \\
\text { sepsis, and } 19 \mathrm{HCs}\end{array}$ & $\uparrow$ & $\uparrow$ & $\uparrow$ & $\begin{array}{l}\text { AUC of miR-146a: } 0.733 \\
\text { (for predicting 30-day mortality in ALI), } \\
\text { CC genotype of rs } 2910164 \text { in miR-146a was } \\
\text { correlated with worse treatment result. }\end{array}$ & \\
\hline $\begin{array}{l}\text { miR- } \\
194\end{array}$ & $\uparrow$ & - & $\mathrm{H} 9 \mathrm{c} 2$ & $\downarrow$ Slc7a5 & $\begin{array}{l}\uparrow \text { Wnt// - } \\
\text { catenin } \\
\text { pathway }\end{array}$ & $\begin{array}{l}\text { Upregulation of } \\
\text { miR-194 increased apoptosis. }\end{array}$ & (188) \\
\hline $\begin{array}{l}\text { miR- } \\
30 a\end{array}$ & $\uparrow$ & male C57BL/6 mice & RAW 264.7 & $\begin{array}{l}\downarrow \text { ADAR } 1, \downarrow \\
\text { SOCS3 }\end{array}$ & - & $\begin{array}{l}\text { Upregulation of ADAR1 (a target of miR-30a) reduced } \\
\text { inflammation and organ damage. }\end{array}$ & (189) \\
\hline $\begin{array}{l}\mathrm{miR-} \\
27 \mathrm{~b}\end{array}$ & $\downarrow$ & male C57BL/6 mice & BMMSCs & $\uparrow$ JMJD3 & $\begin{array}{l}\uparrow \mathrm{NF}-\kappa \mathrm{B} \\
\text { signaling } \\
\text { pathway }\end{array}$ & $\begin{array}{l}\text { Upregulation of miR-27b MSC-derived exosomes } \\
\text { reduced pro-inflammatory cytokines. }\end{array}$ & $(190)$ \\
\hline $\begin{array}{l}\mathrm{miR}- \\
155\end{array}$ & $\uparrow$ & BALB/c mice & - & $\downarrow$ SOCS1 & $\begin{array}{l}\uparrow \text { JAK } \\
\text { STAT } \\
\text { signaling }\end{array}$ & $\begin{array}{l}\text { Downregulation of miR-155 alleviated LPS-induced } \\
\text { mortality and liver injury }\end{array}$ & $(191)$ \\
\hline $\begin{array}{l}\mathrm{miR}- \\
155\end{array}$ & $\downarrow$ & C57BL/6 mice & - & $\uparrow$ Arrb2 & $\begin{array}{l}\uparrow \text { JNK } \\
\text { signaling } \\
\text { pathway }\end{array}$ & $\begin{array}{l}\text { Upregulation of miR-155 ameliorated late sepsis } \\
\text { survival and its cardiac dysfunction, and reduced pro- } \\
\text { inflammatory responses. }\end{array}$ & (192) \\
\hline $\begin{array}{l}\mathrm{miR}- \\
155\end{array}$ & $\uparrow$ & $\begin{array}{l}\text { _patients with sepsis and } \\
\text { HCs, mouse septic shock } \\
\text { model }\end{array}$ & - & $\downarrow$ CD47 & - & $\begin{array}{l}\text { Downregulation of microRNA-155 reduced sepsis- } \\
\text { associated cardiovascular dysfunction and mortality. }\end{array}$ & (193) \\
\hline $\begin{array}{l}\mathrm{miR}- \\
155\end{array}$ & $\uparrow$ & $\begin{array}{l}60 \text { patients with sepsis and } \\
20 \mathrm{HCs}\end{array}$ & - & $\uparrow$ Foxp3 & - & $\begin{array}{l}\text { Expression of miR-155 was correlated with APACHEll } \\
\text { score, it was significantly higher in non-survival group. }\end{array}$ & (194) \\
\hline $\begin{array}{l}\mathrm{miR}- \\
155\end{array}$ & $\begin{array}{l}\uparrow \text { in sepsis } \\
\text { and ALI/ } \\
\text { ARDS than } \\
\text { sepsis but no } \\
\text { ALI/ARDS }\end{array}$ & $\begin{array}{l}156 \text { patients with sepsis ( } 41 \\
\text { with ALI and } 32 \text { with ARDS) }\end{array}$ & - & - & - & $\begin{array}{l}\text { AUC of miR-155: } 0.87 \\
\text { miR-155 was positively associated with IL-1 } \beta, \text { TNF- } \alpha \\
\text { levels, and ALI/ARDS score, but negatively with } \\
\text { PaO2/FiO2. }\end{array}$ & $(195)$ \\
\hline $\begin{array}{l}\mathrm{miR}- \\
29 c-3 p\end{array}$ & $\uparrow$ & $\begin{array}{l}86 \text { patients with sepsis and } \\
85 \mathrm{HCs} \text {, male SD rats }\end{array}$ & - & - & - & $\begin{array}{l}\text { AUC of miR-29c-3p: } 0.872 \\
\text { miR-29c-3p expression was positively correlated with } \\
\text { APACHE II score, SOFA score, levels of CRP and } \\
\text { PCT. } \\
\text { miR-29c-3p was found to be an independent factor } \\
\text { in the occurrence of cardiac dysfunction. }\end{array}$ & (196) \\
\hline $\begin{array}{l}\text { miR- } \\
125 b\end{array}$ & $\downarrow$ & $\begin{array}{l}40 \text { patients with sepsis and } \\
\text { HCs, female and male } \\
\text { C57BL/ } 6 \text { mice }\end{array}$ & - & $\begin{array}{l}\downarrow \text { PTEN, } \uparrow \\
\text { MyD88 }\end{array}$ & - & $\begin{array}{l}\text { PTEN increased miR125 production through } \\
\text { associating with the nuclear localization of Drosha- } \\
\text { Dgcr8. } \\
\text { Downregulation of PTEN resulted in cytokine } \\
\text { production, MyD88 abundance and mortality. }\end{array}$ & $(197)$ \\
\hline $\begin{array}{l}\text { miR- } \\
203 b\end{array}$ & $\downarrow$ & $\begin{array}{l}40 \text { patients with sepsis and } \\
\text { HCs, female and male } \\
\text { C57BL/6 mice }\end{array}$ & - & $\begin{array}{l}\downarrow \text { PTEN, } \uparrow \\
\text { MyD } 88\end{array}$ & - & $\begin{array}{l}\text { PTEN increased miR203b production through } \\
\text { associating with the nuclear localization of Drosha- } \\
\text { Dgcr8. } \\
\text { Downregulation of PTEN resulted in cytokine } \\
\text { production, MyD88 abundance and mortality. }\end{array}$ & \\
\hline $\begin{array}{l}\mathrm{miR}- \\
146\end{array}$ & $\downarrow$ & - & EA. hy926 & - & $\begin{array}{l}\uparrow \mathrm{NF}-\kappa \mathrm{B} \\
\text { signaling } \\
\text { pathway }\end{array}$ & $\begin{array}{l}\text { Upregulation of reduced levels inflammatory } \\
\text { cytokines. }\end{array}$ & (198) \\
\hline $\begin{array}{l}\mathrm{miR}- \\
140-5 p\end{array}$ & $\downarrow$ & male SPF rats & MLE-12 & $\begin{array}{l}\uparrow \mathrm{TLR} 4, \uparrow \\
\text { MyD88 }\end{array}$ & $\begin{array}{l}\uparrow \mathrm{NF}-\kappa \mathrm{B} \\
\text { signaling } \\
\text { pathway }\end{array}$ & $\begin{array}{l}\text { Shikonin could alleviated sepsis- induced ALI by } \\
\text { increasing the levels of miRA-140-5p and decreasing } \\
\text { the levels of TLR4. }\end{array}$ & (199) \\
\hline $\begin{array}{l}\text { miR- } \\
125 b\end{array}$ & $\downarrow$ & male C57BL/6 mice & HUVECs & $\begin{array}{l}\uparrow \text { ICAM- } 1, \uparrow \\
\text { VCAM- } 1, \uparrow \\
\text { TRAF6 }\end{array}$ & $\begin{array}{l}\uparrow \mathrm{NF}-\kappa \mathrm{B} \\
\text { signaling } \\
\text { pathway }\end{array}$ & $\begin{array}{l}\text { Upregulation of miR-125b alleviated } \\
\text { sepsis-induced cardiac dysfunction and ameliorated } \\
\text { survival. }\end{array}$ & $(200)$ \\
\hline $\begin{array}{l}\mathrm{miR}- \\
494\end{array}$ & $\uparrow$ & ARDS rat models & - & - & $\begin{array}{l}\downarrow \text { Nif2 } \\
\text { signaling } \\
\text { pathway }\end{array}$ & $\begin{array}{l}\text { Upregulation of miR-494 increased inflammatory } \\
\text { response, oxidative stress and ALI. }\end{array}$ & (201) \\
\hline
\end{tabular}


TABLE 2 | Continued

\begin{tabular}{|c|c|c|c|c|c|c|c|}
\hline miRNA & $\begin{array}{l}\text { Pattern of } \\
\text { Expression }\end{array}$ & $\begin{array}{c}\text { Clinical Samples/Animal } \\
\text { Model }\end{array}$ & $\begin{array}{l}\text { Assessed } \\
\text { Cell Lines }\end{array}$ & $\begin{array}{c}\text { Targets / } \\
\text { Regulators }\end{array}$ & $\begin{array}{l}\text { Signaling } \\
\text { Pathways }\end{array}$ & Description & Reference \\
\hline $\begin{array}{l}\mathrm{miR}- \\
146 a\end{array}$ & $\downarrow$ & male C57BL/6 mice & H9C2, J774 & $\begin{array}{l}\uparrow \text { IRAK, } \\
\uparrow \text { TRAF6 }\end{array}$ & $\begin{array}{l}\uparrow \mathrm{NF}-\kappa \mathrm{B} \\
\text { signaling } \\
\text { pathway }\end{array}$ & $\begin{array}{l}\text { Upregulation of miR-146 reduced levels of } \\
\text { inflammatory cytokines and sepsis-induced cardiac } \\
\text { dysfunction }\end{array}$ & $(202)$ \\
\hline $\begin{array}{l}\text { miR- } \\
223\end{array}$ & - & $\begin{array}{l}221 \text { patients with sepsis and } \\
75 \mathrm{HCs} \text {, male C57BI/6 mice }\end{array}$ & - & - & - & $\begin{array}{l}\text { Levels of serum miR-223 did not differ between } \\
\text { critically ill patients and HCs, but ICU patients with } \\
\text { APACHE-Il score had moderately decreased } \\
\text { circulating miR-223. }\end{array}$ & (203) \\
\hline $\begin{array}{l}\text { miR- } \\
300\end{array}$ & $\downarrow$ & septic mouse model & - & $\uparrow$ NAMPT & $\begin{array}{l}\downarrow \text { AMPK } \\
\text { mTOR } \\
\text { signaling } \\
\text { pathway }\end{array}$ & $\begin{array}{l}\text { Upregulation of miR-300 increased autophagy, cell } \\
\text { cycle entry and reduced apoptosis and inflammatory } \\
\text { response. }\end{array}$ & $(204)$ \\
\hline $\begin{array}{l}\text { miR- } \\
126\end{array}$ & $\downarrow$ & male C57BL/6 mice & - & $\downarrow$ HSPA12B & - & $\begin{array}{l}\text { Upregulation of HSPA12B increased levels of miR- } \\
\text { 126, upregulation of miR-126 reduced levels of } \\
\text { dhesion molecules and improved sepsis-induced } \\
\text { cardiac dysfunction. }\end{array}$ & $(205)$ \\
\hline $\begin{array}{l}\text { miR- } \\
10 a\end{array}$ & $\downarrow$ & $\begin{array}{l}62 \text { patients with sepsis and } \\
20 \mathrm{HCs}\end{array}$ & - & $\uparrow \mathrm{MAP} 3 \mathrm{~K} 7$ & $\begin{array}{l}\uparrow \mathrm{NF}-\kappa \mathrm{B} \\
\text { pathway }\end{array}$ & $\begin{array}{l}\text { miR-10a expression was negatively association with } \\
\text { disease severity scores, levels of c-reactive protein, } \\
\text { procalcitonin, and } 28 \text {-day death. }\end{array}$ & $(206)$ \\
\hline $\begin{array}{l}\text { miR- } \\
146 a\end{array}$ & $\downarrow$ & mice & - & $\uparrow$ Notch1 & $\begin{array}{l}\uparrow \mathrm{NF}-\kappa \mathrm{B} \\
\text { signaling }\end{array}$ & $\begin{array}{l}\text { Upregulation of miR-146a reduced inflammatory } \\
\text { responses of macrophages and protected mice from } \\
\text { organ damage }\end{array}$ & $(207)$ \\
\hline $\begin{array}{l}\text { miR- } \\
19 a\end{array}$ & $\downarrow$ & CLP mice & RAW 264.7 & $\uparrow \mathrm{Fn} 14$ & - & $\begin{array}{l}\text { Upregulation of miR-19a reduced LPS-Induced } \\
\text { Tubular Damage, it was found to protected mice } \\
\text { from sepsis-induced AKI. }\end{array}$ & $(208)$ \\
\hline $\begin{array}{l}\text { miR- } \\
214\end{array}$ & - & male Kunming mice & - & - & - & $\begin{array}{l}\text { Upregulation of miR-214 reduced apoptosis, } \\
\text { inflammatory response, myocardial injury, and } \\
\text { improved cardiac function in SIMI. }\end{array}$ & (209) \\
\hline $\begin{array}{l}\text { miR- } \\
539-5 p\end{array}$ & $\downarrow$ & male C57BL/6 mice & MPVECs & $\uparrow \mathrm{ROCK} 1$ & - & $\begin{array}{l}\text { Upregulation of miR-539-5p reduced apoptosis, } \\
\text { inflammatory response, sepsis-induced pulmonary } \\
\text { injury. }\end{array}$ & $(210)$ \\
\hline $\begin{array}{l}\text { miR- } \\
155\end{array}$ & $\uparrow$ & $\begin{array}{l}60 \text { patients with sepsis and } \\
30 \mathrm{HCs}\end{array}$ & - & - & - & $\begin{array}{l}\text { miR-155 was positively correlated with a higher } \\
\text { SOFA score and a greater severity. AUC of miR-155 } \\
\text { for } 28 \text {-day survival was } 0.763 \text {. miR-155 derived } \\
\text { immunosuppression through CD39(+) Tregs. }\end{array}$ & $(211)$ \\
\hline $\begin{array}{l}\text { miR- } \\
146 a\end{array}$ & $\begin{array}{l}\uparrow \text { in sepsis } \\
\text { group } \\
\text { compared to } \\
\text { shame group }\end{array}$ & male BALB/C mice & - & - & - & $\begin{array}{l}\text { Up-regulation of miR-146a reduced levels of } \\
\text { inflammatory cytokine TNF- } \alpha \text { and mitigated } \\
\text { inflammatory reaction and lung tissue injury in sepsis- } \\
\text { induced ALI. }\end{array}$ & $(212)$ \\
\hline $\begin{array}{l}\text { miR- } \\
7110- \\
5 p\end{array}$ & $\uparrow$ & $\begin{array}{l}52 \text { patients with pneumonia, } \\
44 \text { patients with sepsis and } \\
21 \mathrm{HCs}\end{array}$ & - & - & - & $\begin{array}{l}\text { The sensitivity and specificity of miR-7110-5p were } \\
84.2 \text { and } 90.5 \% \text { respectively. (sepsis vs HCs) }\end{array}$ & $(213)$ \\
\hline $\begin{array}{l}\text { miR- } \\
223-3 p\end{array}$ & $\uparrow$ & $\begin{array}{l}52 \text { patients with pneumonia, } \\
44 \text { patients with sepsis and } \\
21 \text { HCs }\end{array}$ & - & - & - & $\begin{array}{l}\text { The sensitivity and specificity of miR-223-3p were } \\
82.9 \text { and } 100 \% \text { respectively. (sepsis vs HCs) }\end{array}$ & \\
\hline $\begin{array}{l}\text { miR- } \\
19 a\end{array}$ & $\uparrow$ & patients with sepsis & $\begin{array}{l}\text { B cells from } \\
\text { patients with } \\
\text { sepsis }\end{array}$ & CD22 & - & $\begin{array}{l}\text { Expression of CD22 initially increased but } \\
\text { subsequently reduced. Upregulation of miR-19a } \\
\text { resulted in an increased BCR signaling, while } \\
\text { overexpression of CD22 reduced the effect of miR- } \\
19 a \text { and promoted its expression. }\end{array}$ & $(214)$ \\
\hline $\begin{array}{l}\mathrm{miR}- \\
206\end{array}$ & $\uparrow$ & $\begin{array}{l}63 \text { patients with sepsis, } 30 \\
\text { patients with septic shock } \\
\text { and HCs }\end{array}$ & - & - & - & $\begin{array}{l}\text { miR-206 was positively associated with SOFA sore } \\
\text { and APACHE-II score. It was observed an activated } \\
\text { partial thromboplastin time and notably longer } \\
\text { prothrombin time. }\end{array}$ & $(215)$ \\
\hline $\begin{array}{l}\text { miR- } \\
146 a\end{array}$ & $\downarrow$ & male C57BL/6 mice & RAW264.7 & - & $\begin{array}{l}\uparrow \mathrm{NF}-\kappa \mathrm{B} \\
\text { signaling }\end{array}$ & $\begin{array}{l}\text { Up-regulation of miR-146a reduced apoptosis, } \\
\text { inflammatory response, and weakened organ injury in } \\
\text { splenic macrophages. }\end{array}$ & $(216)$ \\
\hline $\begin{array}{l}\text { miR- } \\
19 b-3 p\end{array}$ & $\downarrow$ & $\begin{array}{l}103 \text { patients with sepsis and } \\
98 \mathrm{HCs}\end{array}$ & HUVECS & - & - & $\begin{array}{l}\text { Up-regulation of miR-19b-3p reduced inflammatory } \\
\text { response. miR-19b-3p was found to be an } \\
\text { independent prognostic factor for } 28 \text {-day survival. }\end{array}$ & $(217)$ \\
\hline $\begin{array}{l}\text { miR- } \\
129-5 p\end{array}$ & $\downarrow$ & CLP mice & MLE-12 & $\uparrow \mathrm{HMGB1}$ & - & $\begin{array}{l}\text { Up-regulation of miR-129-5p reduced apoptosis, } \\
\text { inflammatory response, , lung wet/dry weight ratio, } \\
\text { and myeloperoxidase activity. }\end{array}$ & $(218)$ \\
\hline
\end{tabular}


TABLE 2 | Continued

\begin{tabular}{|c|c|c|c|c|c|c|c|}
\hline miRNA & $\begin{array}{l}\text { Pattern of } \\
\text { Expression }\end{array}$ & $\begin{array}{l}\text { Clinical Samples/Animal } \\
\text { Model }\end{array}$ & $\begin{array}{l}\text { Assessed } \\
\text { Cell Lines }\end{array}$ & $\begin{array}{l}\text { Targets / } \\
\text { Regulators }\end{array}$ & $\begin{array}{l}\text { Signaling } \\
\text { Pathways }\end{array}$ & Description & Reference \\
\hline $\begin{array}{l}\mathrm{miR}- \\
23 \mathrm{~b}\end{array}$ & $\downarrow$ & $\begin{array}{l}30 \text { patients with sepsis and } \\
30 \mathrm{HCs}\end{array}$ & THP-1 & $\uparrow$ ADAM10 & - & $\begin{array}{l}\text { Up-regulation of miR-23b reduced apoptosis and } \\
\text { inflammatory response. }\end{array}$ & (219) \\
\hline $\begin{array}{l}\mathrm{miR}- \\
150\end{array}$ & $\downarrow$ & $\begin{array}{l}140 \text { patients multiple trauma } \\
\text { and } 10 \mathrm{HCs}\end{array}$ & MDSCs & $\uparrow A R G 1$ & - & $\begin{array}{l}\text { Up-regulation of miR-150 reduced IL-6, TGF- } \beta \text { and } \\
\mathrm{IL}-10 \text {. }\end{array}$ & $(220)$ \\
\hline $\begin{array}{l}\mathrm{miR}- \\
375\end{array}$ & $\downarrow$ & $\begin{array}{l}\text { _ patients with sepsis, } \\
\text { septic mice }\end{array}$ & MDSCs & $\uparrow \mathrm{miR}-21$ & $\begin{array}{l}\uparrow \text { JAK2/ } \\
\text { STAT3 } \\
\text { pathway }\end{array}$ & $\begin{array}{l}\text { Up-regulation of miR-375 reduced the number of } \\
\text { sepsis Gr1+CD11b+ MDSCs in mice. }\end{array}$ & $(221)$ \\
\hline miR-31 & $\uparrow$ & male SD rats & CACO-2 & $\downarrow \mathrm{HMOX} 1$ & $\begin{array}{l}\uparrow \mathrm{NF}-\kappa \mathrm{B} / \\
\mathrm{HIF-1}-1 \alpha \\
\text { pathway }\end{array}$ & $\begin{array}{l}\text { Downregulation of miR-31 reduced intestinal barrier } \\
\text { function, intestinal mucosal permeability, oxidative } \\
\text { damage and inflammation level. }\end{array}$ & $(222)$ \\
\hline $\begin{array}{l}\text { miR-21 } \\
\text { and } \\
\text { miR- } \\
181 b\end{array}$ & $\begin{array}{l}\uparrow \text { (in early } \\
\text { sepsis) } \\
\text { sustained (in } \\
\text { late sepsis) }\end{array}$ & male BALB/c mice & MDSCs & $\uparrow \mathrm{NFI}-\mathrm{A}$ & - & $\begin{array}{l}\text { Down regulation of miR-21 and miR-181b } \\
\text { decreased, immunosuppression, reprograming } \\
\text { myeloid cells, late-sepsis mortality, and improved } \\
\text { bacterial clearance. }\end{array}$ & $(223)$ \\
\hline $\begin{array}{l}\text { miR- } \\
150\end{array}$ & $\downarrow$ slightly & $\begin{array}{l}223 \text { critically ill patients } \\
\text { (including } 138 \text { fulfilled sepsis } \\
\text { criteria) and } 76 \mathrm{HCs}\end{array}$ & - & - & - & $\begin{array}{l}\text { serum levels of miR-150 were associated with } \\
\text { hepatic or renal dysfunction. Low levels were } \\
\text { correlated with an unfavorable prognosis of patients. } \\
\text { serum levels of miR-150 were not suitable for } \\
\text { predicting of sepsis. }\end{array}$ & $(224)$ \\
\hline $\begin{array}{l}\text { miR- } \\
10 a\end{array}$ & $\uparrow$ & $\mathrm{SD}$ rats & - & - & $\begin{array}{l}\uparrow \text { TGF- } \beta 1 / \\
\text { Smad } \\
\text { pathway }\end{array}$ & $\begin{array}{l}\text { Up-regulation of miR-10a increased ROS, TNF- } \alpha \text {, IL- } \\
6 \text {, and MPO, and downregulation reduced sepsis- } \\
\text { induced liver injury. }\end{array}$ & $(225)$ \\
\hline $\begin{array}{l}\text { miR- } \\
145\end{array}$ & $\downarrow$ & septic mice & HUVECs & $\begin{array}{l}\uparrow \text { TGFBR2, } \\
\uparrow \mathrm{SMAD} 2, \uparrow \\
\text { DNMT1 }\end{array}$ & - & $\begin{array}{l}\text { Up-regulation of miR-145 reduced LPS-induced } \\
\text { sepsis and improved the overall survival of septic } \\
\text { mice. }\end{array}$ & $(226)$ \\
\hline $\begin{array}{l}\mathrm{miR}- \\
150\end{array}$ & $\downarrow$ & $\begin{array}{l}17 \text { patients with sepsis and } \\
32 \mathrm{HCs}\end{array}$ & - & - & - & $\begin{array}{l}\text { Levels of miR-150 were negatively correlated with the } \\
\text { level of disease severity, TNF- } \alpha, \mathrm{IL}-10 \text {, and IL-18. }\end{array}$ & $(227)$ \\
\hline $\begin{array}{l}\text { miR- } \\
103 a- \\
3 p\end{array}$ & $\uparrow$ & $\begin{array}{l}30 \text { patients with sepsis and } \\
30 \mathrm{HCs} \text {, male C57 BL/6 } \\
\text { mice }\end{array}$ & AML12, LO2 & $\downarrow$ FBXW7 & - & $\begin{array}{l}\text { Downregulation of miR-103a-3p reduced apoptosis, } \\
\text { and inflammatory response. }\end{array}$ & $(228)$ \\
\hline $\begin{array}{l}\mathrm{miR}- \\
143\end{array}$ & $\uparrow$ & $\begin{array}{l}103 \text { patients with sepsis, } 95 \\
\text { patients with SIRS and } 16 \\
\text { HCs }\end{array}$ & - & - & - & $\begin{array}{l}\text { miR-143 was positively correlated with SOFA score } \\
\text { and APACHE II score in patients with sepsis. For } \\
\text { distinguishing between sepsis and SIRS, miR-143 } \\
\text { showed a sensitivity of } 78.6 \% \text { and specificity of } \\
91.6 \% \text {. }\end{array}$ & $(229)$ \\
\hline $\begin{array}{l}\mathrm{miR}- \\
145\end{array}$ & $\downarrow$ & $\begin{array}{l}33 \text { patients with sepsis and } \\
22 \mathrm{HCs} \text {, septic mice }\end{array}$ & BEAS-2B & $\uparrow$ TGFBR2 & - & $\begin{array}{l}\text { Up-regulation of miR-145 reduced inflammatory } \\
\text { response and improved the overall survival of septic } \\
\text { mice. }\end{array}$ & (230) \\
\hline $\begin{array}{l}\mathrm{miR}- \\
150\end{array}$ & $\downarrow$ & C57Blk/6J mice & HPAECs & $\uparrow$ Ang2 & - & $\begin{array}{l}\text { Downregulation of miR-150 damaged adherens } \\
\text { junctions reannealing after injury, which caused an } \\
\text { irreversible increase in vascular permeability. Up- } \\
\text { regulation of miR-150 reduced vascular injury and } \\
\text { mortality. }\end{array}$ & $(231)$ \\
\hline $\begin{array}{l}\operatorname{miR}- \\
34 b-3 p\end{array}$ & $\downarrow$ & CLP mice & RMCs & $\uparrow \cup B L 4 A$ & $\begin{array}{l}\uparrow N F-\kappa B \\
\text { signaling }\end{array}$ & $\begin{array}{l}\text { Up-regulation of MiR-34b-3p reduced inflammatory } \\
\text { response and } A K I \text { in sepsis mice }\end{array}$ & $(232)$ \\
\hline $\begin{array}{l}\mathrm{miR}- \\
21-3 p\end{array}$ & $\uparrow$ & $\begin{array}{l}\text { _patients with sepsis, } \\
\text { C57BL/6 mice }\end{array}$ & - & $\downarrow$ SORBS2 & - & $\begin{array}{l}\text { Downregulation of miR-21-3p induced mitochondria } \\
\text { ultrastructural damage and autophagy in LPS-treated } \\
\text { mice. Levels of miR-21-3p increased in patients with } \\
\text { cardiac dysfunction than without cardiac dysfunction. }\end{array}$ & (233) \\
\hline $\begin{array}{l}\text { miR- } \\
199 a- \\
5 p\end{array}$ & $\uparrow$ & C57BL/6 mice & HEK-293T & $\downarrow$ SP-D & $\begin{array}{l}\uparrow \mathrm{NF}-\kappa \mathrm{B} \\
\text { signaling }\end{array}$ & $\begin{array}{l}\text { Down regulation of miR-199a-5p reduced D-lactic } \\
\text { acid, DAO, FD-40, oxidative damage and } \\
\text { inflammation. }\end{array}$ & $(234)$ \\
\hline $\operatorname{miR}-17$ & $\downarrow$ & mice & $\begin{array}{l}\text { BMSCs, } \\
\text { RAW264.7 }\end{array}$ & $\begin{array}{l}\uparrow \mathrm{BDR} 4, \uparrow \\
\mathrm{EZH} 2, \uparrow \\
\text { TRAIL }\end{array}$ & - & $\begin{array}{l}\text { MiR-17 carried by BMSC-EVs reduced inflammation } \\
\text { and apoptosis. }\end{array}$ & (235) \\
\hline $\begin{array}{l}\mathrm{miR}- \\
125 \mathrm{~b}\end{array}$ & $\uparrow$ & $\begin{array}{l}120 \text { patients with sepsis and } \\
120 \mathrm{HCs}\end{array}$ & - & - & - & $\begin{array}{l}\text { AUC of miR-125b: } 0.658 \\
\text { MiR-125b was positively associated with APACHE II } \\
\text { score, SOFA score, Scr, CRP, PCT, TNF- } \alpha \text {, and IL-6 } \\
\text { levels. } \\
\text { miR-125b Was found to be an independent risk } \\
\text { factor for mortality risk. }\end{array}$ & (236) \\
\hline
\end{tabular}


TABLE 2 | Continued

\begin{tabular}{|c|c|c|c|c|c|c|c|}
\hline miRNA & $\begin{array}{l}\text { Pattern of } \\
\text { Expression }\end{array}$ & $\begin{array}{l}\text { Clinical Samples/Animal } \\
\text { Model }\end{array}$ & $\begin{array}{l}\text { Assessed } \\
\text { Cell Lines }\end{array}$ & $\begin{array}{c}\text { Targets / } \\
\text { Regulators }\end{array}$ & $\begin{array}{l}\text { Signaling } \\
\text { Pathways }\end{array}$ & Description & Reference \\
\hline $\begin{array}{l}\text { miR- } \\
30 e\end{array}$ & $\downarrow$ & septic rats & - & $\uparrow$ FOSL2 & $\begin{array}{l}\uparrow \text { JAK/STAT } \\
\text { signaling }\end{array}$ & $\begin{array}{l}\text { Up-regulation of miR-30e increased proliferation and } \\
\text { reduced apoptosis. }\end{array}$ & $(237)$ \\
\hline $\begin{array}{l}\text { miR- } \\
20 b-5 p\end{array}$ & $\uparrow$ & $\mathrm{SD}$ rats & HEK-293T & $\begin{array}{l}\downarrow \\
\text { circDMNT3B }\end{array}$ & - & $\begin{array}{l}\text { Downregulation of miR-20b-5p reduced level of d- } \\
\text { lactic acid, FD-40, MDA, diamine oxidase, IL-10, IL-6, } \\
\text { oxidative damage and inflammatory factors level. }\end{array}$ & $(238)$ \\
\hline $\begin{array}{l}\mathrm{miR}- \\
146 b\end{array}$ & $\downarrow$ & CLP mice & - & $\uparrow$ Notch1 & - & $\begin{array}{l}\text { Up-regulation of miR-146b reduced apoptosis and } \\
\text { inflammatory response. }\end{array}$ & $(239)$ \\
\hline miR-25 & $\downarrow$ & SD rats & $\mathrm{H} 9 \mathrm{C} 2$ & $\begin{array}{l}\uparrow \text { PTEN, } \uparrow \\
\text { TLR4 }\end{array}$ & $\begin{array}{l}\uparrow N F-\kappa B \\
\text { signaling }\end{array}$ & $\begin{array}{l}\text { Up-regulation of miR-25 reduced apoptosis and } \\
\text { enhanced survival rate. }\end{array}$ & $(240)$ \\
\hline $\begin{array}{l}\text { miR-21 } \\
\text { and } \\
\text { miR- } \\
181 b\end{array}$ & $\uparrow$ & septic mice & $\begin{array}{l}\text { MDSCs, Gr1 } \\
+ \text { CD11b } \\
+ \text { cells }\end{array}$ & $\begin{array}{l}\uparrow \mathrm{C} / \mathrm{EBP} \beta, \uparrow \\
\text { Stat3 }\end{array}$ & - & $\begin{array}{l}\text { Stat3 and C/EBP } \beta \text { increased miR-21 and miR-181b } \\
\text { expression by binding to their promoters during } \\
\text { sepsis. }\end{array}$ & $(241)$ \\
\hline $\begin{array}{l}\mathrm{miR}- \\
17-5 p\end{array}$ & $\downarrow$ & septic mice & $\begin{array}{l}\text { LPS-induced } \\
\text { macrophages }\end{array}$ & $\uparrow$ TLR4 & - & $\begin{array}{l}\text { Sch B increased miR-17-5p expression and reduced } \\
\text { inflammation. }\end{array}$ & $(242)$ \\
\hline $\begin{array}{l}\text { miR- } \\
200 a- \\
3 p\end{array}$ & $\uparrow$ & male C57BL/6J mice & HBMECs & $\begin{array}{l}\uparrow \mathrm{NLRP3}, \\
\downarrow \text { Keap1, } \\
\downarrow \mathrm{Nrf} 2 \\
\downarrow \mathrm{HO}-1\end{array}$ & - & $\begin{array}{l}\text { Up-regulation of miR-200a-3p induced inflammatory } \\
\text { response in sepsis-induced brain injury. }\end{array}$ & $(243)$ \\
\hline $\begin{array}{l}\text { miR- } \\
26 b\end{array}$ & $\downarrow$ & $\begin{array}{l}14 \text { patients with sepsis and } \\
7 \text { patients with septic shock } \\
\text { and } 21 \mathrm{HCs}\end{array}$ & MEG-01 & $\begin{array}{l}\uparrow \text { SELP, } \\
\downarrow \text { Dicer1 }\end{array}$ & - & $\begin{array}{l}\text { Low levels of miR-26b was correlated with the } \\
\text { severity and mortality of sepsis. }\end{array}$ & $(244)$ \\
\hline $\begin{array}{l}\mathrm{miR}- \\
96-5 p\end{array}$ & $\downarrow$ & - & RAW264.7 & $\uparrow$ NAMPT & $\begin{array}{l}\uparrow \mathrm{NF}-\kappa \mathrm{B} \\
\text { pathway }\end{array}$ & $\begin{array}{l}\text { Up-regulation of miR-96-5p reduced inflammatory } \\
\text { response. }\end{array}$ & $(245)$ \\
\hline $\begin{array}{l}\mathrm{miR}- \\
27 \mathrm{a}\end{array}$ & $\uparrow$ & septic mice & - & - & $\begin{array}{l}\uparrow \mathrm{NF}-\kappa \mathrm{B} \\
\text { pathway }\end{array}$ & $\begin{array}{l}\text { Downregulation of miR-27a reduced inflammatory } \\
\text { response and promoted survival of septic mice. }\end{array}$ & $(246)$ \\
\hline $\begin{array}{l}\mathrm{miR}- \\
21 \mathrm{a}-3 \mathrm{p}\end{array}$ & $\uparrow$ & $\begin{array}{l}\text { specific pathogen-free SD } \\
\text { rats }\end{array}$ & NRK52E & $\begin{array}{l}\uparrow \text { Ago } 2, \uparrow \\
\text { Nrp-1 }\end{array}$ & - & $\begin{array}{l}\text { miR-21a-3p was found to be internalized by TECs via } \\
\text { Nrp-1 and Ago2. }\end{array}$ & $(247)$ \\
\hline $\begin{array}{l}\operatorname{miR}- \\
574-5 p\end{array}$ & $\uparrow$ & 118 patients with sepsis & - & - & - & $\begin{array}{l}\text { miR-574-5p was associated with the death of sepsis } \\
\text { patients. }\end{array}$ & $(248)$ \\
\hline $\begin{array}{l}\mathrm{miR}- \\
181 \mathrm{~b}\end{array}$ & $\downarrow$ & $\begin{array}{l}26 \text { patients with sepsis, } 36 \\
\text { patients with sepsis plus } \\
\text { sepsis/ARDS and } 16 \mathrm{HCs} \text {, } \\
\text { male C57BL/ } 6 \text { mice }\end{array}$ & $\begin{array}{l}\text { THP-1, } \\
\text { HUVECS }\end{array}$ & $\begin{array}{l}\uparrow \text { importin- } \\
\alpha 3\end{array}$ & $\begin{array}{l}\uparrow \mathrm{NF}-\kappa \mathrm{B} \\
\text { signaling } \\
\text { pathway }\end{array}$ & $\begin{array}{l}\text { Up-regulation of miR-181b reduced mortality rate, } \\
\text { inflammation response, LPS-induced EC activation, } \\
\text { leukocyte accumulation. }\end{array}$ & $(249)$ \\
\hline $\begin{array}{l}\mathrm{miR}- \\
182-5 p\end{array}$ & $\uparrow$ & pneumonia mice models & - & - & - & $\begin{array}{l}\text { Downregulation of miR-182-5p reduced apoptosis, } \\
\text { inflammation response and promoted viability and } \\
\text { proliferation. }\end{array}$ & $(250)$ \\
\hline $\begin{array}{l}\text { miR- } \\
195\end{array}$ & $\uparrow$ & C57BL/6 mice & $\begin{array}{l}\text { endothelial } \\
\text { cells }\end{array}$ & $\begin{array}{l}\downarrow \mathrm{BCL}-2, \downarrow \\
\text { Sirt1, } \downarrow \text { Pim- } \\
1\end{array}$ & - & $\begin{array}{l}\text { Downregulation of miR-182-5p reduced apoptosis, } \\
\text { and improved survival. }\end{array}$ & (251) \\
\hline $\begin{array}{l}\mathrm{miR}- \\
205\end{array}$ & $\downarrow$ & male SD rats & - & - & $\begin{array}{l}\uparrow \text { HMGB1- } \\
\text { PTEN } \\
\text { signaling } \\
\text { pathway }\end{array}$ & $\begin{array}{l}\text { Up-regulation of miR-205 reduced apoptosis and } \\
\text { renal injury. }\end{array}$ & (252) \\
\hline $\begin{array}{l}\mathrm{miR}- \\
21-3 p\end{array}$ & $\begin{array}{l}\uparrow \text { in } \mathrm{AKI} \\
\text { group }\end{array}$ & $\begin{array}{l}49 \text { patients with sepsis- } \\
\text { induced } \mathrm{AKI} \text { and } 93 \text { sepsis } \\
\text { patients with non-AKI }\end{array}$ & - & $\begin{array}{l}\uparrow \mathrm{Scr} \\
\uparrow \mathrm{Cys}-\mathrm{C} \\
\uparrow \mathrm{KIM}-1\end{array}$ & - & $\begin{array}{l}\text { Levels of miR-21-3p was positively associated with } \\
\text { Scr, Cys-C, and KIM-1 in the AKI group. }\end{array}$ & (253) \\
\hline $\begin{array}{l}\text { miR- } \\
181 a- \\
2-3 p\end{array}$ & $\downarrow$ & $\begin{array}{l}\text { GSE46955 data set, CLP } \\
\text { mouse model }\end{array}$ & TCMK-1 & $\uparrow$ GJB2 & - & $\begin{array}{l}\text { Up-regulation of miR-181a-2-3p reduced apoptosis } \\
\text { and inflammatory response. }\end{array}$ & $(254)$ \\
\hline miR-21 & $\downarrow$ & female Wistar rats & $\mathrm{HK}-2$ & $\begin{array}{l}\uparrow \mathrm{PTEN}, \downarrow \\
\mathrm{PIOK}, \downarrow \mathrm{AKT}\end{array}$ & - & $\begin{array}{l}\text { Up-regulation of miR-21 suppressed apoptosis and } \\
\text { kidney injury. }\end{array}$ & $(255)$ \\
\hline $\begin{array}{l}\text { miR- } \\
146 a\end{array}$ & $\downarrow$ & female ICR mice & Raw264.7 & $\begin{array}{l}\uparrow \mathrm{JMJD3} \\
\mathrm{NF}-\mathrm{kB} \text { p65 }\end{array}$ & - & $\begin{array}{l}\text { GSKJ4 reduced inflammatory response by increasing } \\
\text { miR-146a levels. } \\
\text { Transcription of miR-146a was negatively regulated } \\
\text { by JMJD3 through epigenetic mechanism. }\end{array}$ & $(256)$ \\
\hline $\begin{array}{l}\mathrm{miR}- \\
294\end{array}$ & - & - & RAW264.7 & TREM-1 & - & miR-294 reduced TNF- $\alpha$ and IL-6 secretion. & $(257)$ \\
\hline $\begin{array}{l}\mathrm{miR}- \\
128-3 p\end{array}$ & $\uparrow$ & CLP mouse model & TCMK-1 & $\downarrow N R P 1$ & - & $\begin{array}{l}\text { Up-regulation of miR-128-3p promoted apoptosis } \\
\text { and inflammatory response and reduced viability. }\end{array}$ & $(258)$ \\
\hline
\end{tabular}


TABLE 2 | Continued

\begin{tabular}{|c|c|c|c|c|c|c|c|}
\hline miRNA & $\begin{array}{l}\text { Pattern of } \\
\text { Expression }\end{array}$ & $\begin{array}{l}\text { Clinical Samples/Animal } \\
\text { Model }\end{array}$ & $\begin{array}{l}\text { Assessed } \\
\text { Cell Lines }\end{array}$ & $\begin{array}{c}\text { Targets / } \\
\text { Regulators }\end{array}$ & $\begin{array}{l}\text { Signaling } \\
\text { Pathways }\end{array}$ & Description & Reference \\
\hline $\begin{array}{l}\mathrm{miR-} \\
146 \mathrm{a}\end{array}$ & $\downarrow$ & - & H9C2 & $\begin{array}{l}\downarrow \text { ErbB4, } \\
\uparrow \text { TRAF6, } \\
\uparrow \text { IRAK1 }\end{array}$ & - & $\begin{array}{l}\text { Up-regulation of miR-146a reduced apoptosis and } \\
\text { inflammatory response and promoted viability. }\end{array}$ & $(259)$ \\
\hline $\begin{array}{l}\mathrm{miR}- \\
511\end{array}$ & $\uparrow$ in S mice & $\begin{array}{l}\text { C57BL/6J (B) mice, SPRET/ } \\
\text { Ei (S) mice, }\end{array}$ & - & $\begin{array}{l}\text { Low protein } \\
\text { expression } \\
\text { of TNFR1 in } \\
\text { S mice }\end{array}$ & - & $\begin{array}{l}\text { miR-511 was induced by glucocorticoids. miR-511 } \\
\text { inhibited endotoxemia and experimental hepatitis. }\end{array}$ & $(260)$ \\
\hline $\begin{array}{l}\text { miR- } \\
376 b\end{array}$ & $\begin{array}{l}\downarrow \text { in sepsis } \\
\text { with AKI } \\
\text { group }\end{array}$ & $\begin{array}{l}20 \text { Patients with sepsis with } \\
\mathrm{AKI}, 20 \text { patients with sepsis } \\
\text { without } \mathrm{AKI} \text { and } 10 \mathrm{HCs} \text {, } \\
\text { male C57BL/ } 6 \text { mice }\end{array}$ & BUMPT & $\begin{array}{l}\text { NF- } \kappa B \text {, } \\
\text { NFKBIZ }\end{array}$ & - & 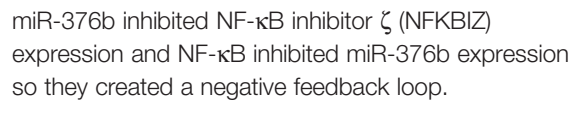 & $(261)$ \\
\hline $\begin{array}{l}\text { miR- } \\
155\end{array}$ & $\uparrow$ & female BALB/c mice & - & - & - & $\begin{array}{l}\text { DXM treatment } \\
\text { suppressed the expression of miRNA-155. }\end{array}$ & $(262)$ \\
\hline $\begin{array}{l}\text { miR- } \\
133 a\end{array}$ & $\uparrow$ & $\begin{array}{l}223 \text { patients with sepsis and } \\
76 \mathrm{HCs}, \mathrm{C} 57 \mathrm{BI} / 6 \text { mice }\end{array}$ & - & - & - & $\begin{array}{l}\text { High levels of miR-133a was correlated with disease } \\
\text { severity, inflammatory response, bacterial infection, } \\
\text { and organ failure and predicted an unfavorable } \\
\text { outcome of patients. }\end{array}$ & $(263)$ \\
\hline $\begin{array}{l}\mathrm{miR}- \\
203\end{array}$ & $\downarrow$ & clean grade Kunming mice & HEK-293T & $\uparrow$ VNN1 & $\begin{array}{l}\downarrow \text { AKT } \\
\text { signaling } \\
\text { pathway }\end{array}$ & $\begin{array}{l}\text { Up-regulation of miR-203 reduced apoptosis, } \\
\text { inflammatory response, MDA, ALT, and AST in lung } \\
\text { tissues, PMN and PAM levels in BALF and increased } \\
\text { SOD activity. }\end{array}$ & $(264)$ \\
\hline $\begin{array}{l}\text { miR- } \\
223\end{array}$ & $\uparrow$ & $\begin{array}{l}187 \text { patients with sepsis and } \\
186 \mathrm{HCs}\end{array}$ & - & - & - & $\begin{array}{l}\text { AUC for miR-223: } 0.754 \text {, } \\
\text { Plasma miR-223 was associated with disease } \\
\text { severity and inflammatory factor levels. miR-223 was } \\
\text { found to predict sepsis risk independently. }\end{array}$ & $(265)$ \\
\hline $\begin{array}{l}\text { miR- } \\
146 a\end{array}$ & $\downarrow$ & $\begin{array}{l}\text { patients with sepsis and } \\
\text { HCs }\end{array}$ & $\begin{array}{l}\text { Human } \\
\text { primary } T \\
\text { cells }\end{array}$ & $\uparrow P R K C \epsilon$ & - & $\begin{array}{l}\text { Reduced levels of miR-146a contributes to the } \\
\text { pathogenesis of sepsis. }\end{array}$ & $(266)$ \\
\hline $\begin{array}{l}\mathrm{miR}- \\
146-\mathrm{a}\end{array}$ & $\downarrow$ & $\begin{array}{l}55 \text { patients with sepsis and } \\
60 \mathrm{HCs}\end{array}$ & - & - & - & $\begin{array}{l}\text { AUC for miR-146-a: } 0.803 \\
\text { Serum levels of miR-146-a was negatively correlated } \\
\text { with C-reactive protein, pro-calcitonin, IL-6 and TNF- } \\
\alpha .\end{array}$ & $(267)$ \\
\hline $\begin{array}{l}\text { miR- } \\
34 a\end{array}$ & $\uparrow$ & CLP-induced suckling rats & U937 & - & $\begin{array}{l}\uparrow \text { STAT3 } \\
\text { pathway }\end{array}$ & $\begin{array}{l}\text { Up-regulation of miR-34a promoted iNOS secretion } \\
\text { from pulmonary macrophages. }\end{array}$ & $(268)$ \\
\hline $\begin{array}{l}\text { hsa- } \\
\text { miR- } \\
346\end{array}$ & $\downarrow$ & - & RAW264.7 & $\begin{array}{l}\uparrow \operatorname{IncRNA} \\
\text { MALAT1, } \uparrow \\
\text { SMAD3 }\end{array}$ & - & Up-regulation of hsa-miR-346 promoted proliferation. & $(269)$ \\
\hline $\begin{array}{l}\mathrm{miR}- \\
214\end{array}$ & $\downarrow$ & male Kunming mice & - & $\uparrow$ PTEN & $\begin{array}{l}\downarrow \text { AKT/ } \\
\text { mTOR } \\
\text { pathway }\end{array}$ & $\begin{array}{l}\text { Up-regulation of miR-214 reduced oxidative stress } \\
\text { and autophagy, so ameliorated CLP-induced AKI. }\end{array}$ & $(270)$ \\
\hline $\begin{array}{l}\text { miR- } \\
27 a\end{array}$ & $\uparrow$ & $\begin{array}{l}\text { LPS induced sepsis mice } \\
\text { model }\end{array}$ & H9C2 & $\begin{array}{l}\downarrow \text { rhTNFR: } \\
\text { Fc, } \downarrow \text { Nrf2 }\end{array}$ & - & $\begin{array}{l}\text { rhTNFR:Fc elevated viability and reduced apoptosis } \\
\text { by increasing Nrf2 levels and reducing miR-27a } \\
\text { levels. }\end{array}$ & (271) \\
\hline $\begin{array}{l}\text { miR- } \\
150\end{array}$ & $\begin{array}{l}\downarrow \text { in non- } \\
\text { survival group }\end{array}$ & $\begin{array}{l}48 \text { patients with septic } \\
\text { shock ( } 23 \text { survival patients } \\
\text { and } 25 \text { non-survival } \\
\text { patients) }\end{array}$ & - & - & - & $\begin{array}{l}\text { MiR-150 level was positively associated with cardiac } \\
\text { index and negatively with EVLWI and PVPI. }\end{array}$ & $(272)$ \\
\hline $\begin{array}{l}\text { miR- } \\
148 a- \\
3 p\end{array}$ & $\uparrow$ & $\begin{array}{l}\text { male adult wild-type mice } \\
\text { and myeloid-specific RBP-J- } \\
\text { deficient mice }\end{array}$ & RAW264.7 & - & $\begin{array}{l}\text { Notch } \\
\text { signaling } \\
\text { and NF-кB } \\
\text { pathway }\end{array}$ & $\begin{array}{l}\text { Up-regulation of miR-148a-3p increased } \\
\text { proinflammatory cytokines and decreased protective } \\
\text { effect of EVs in LPS induced sepsis. }\end{array}$ & (273) \\
\hline $\begin{array}{l}\operatorname{miR}- \\
218-5 p\end{array}$ & $\uparrow$ & male ICR mice & GMCs & $\downarrow \mathrm{HO}-1$ & - & $\begin{array}{l}\text { miR-218-5p was reduced in honokiol-treated septic } \\
\text { mice, so the survival rate was increased. }\end{array}$ & $(274)$ \\
\hline $\begin{array}{l}\mathrm{miR}- \\
425-5 p\end{array}$ & $\downarrow$ & C57BL/6 mice & hepatocytes & $\uparrow \mathrm{RIP1}$ & - & $\begin{array}{l}\text { Up-regulation of miR-425-5p reduced inflammatory } \\
\text { response and sepsis-related liver damage. }\end{array}$ & $(275)$ \\
\hline $\begin{array}{l}\mathrm{miR}- \\
122\end{array}$ & $\uparrow$ in CA group & $\begin{array}{l}168 \text { patients with sepsis (CA } \\
\text { group and } \mathrm{CN} \text { group) }\end{array}$ & - & - & - & $\begin{array}{l}\text { Serum levels of miR-122 were associated with APTT } \\
\text { ratios, FIB and antithrombin III levels. }\end{array}$ & $(275)$ \\
\hline $\begin{array}{l}\text { miR- } \\
101-3 p\end{array}$ & $\uparrow$ & $\begin{array}{l}27 \text { patients with SIC and } 15 \\
\text { HCs, male SD rats }\end{array}$ & H9C2 & $\downarrow$ DUSP1 & $\begin{array}{l}\uparrow \mathrm{MAPK} \\
\text { p38 and } \\
\mathrm{NF}-\mathrm{KB} \\
\text { pathways. }\end{array}$ & $\begin{array}{l}\text { Downregulation of reduced apoptosis and } \\
\text { inflammatory response. }\end{array}$ & $(276)$ \\
\hline
\end{tabular}


TABLE 2 | Continued

\begin{tabular}{|c|c|c|c|c|c|c|c|}
\hline miRNA & $\begin{array}{l}\text { Pattern of } \\
\text { Expression }\end{array}$ & $\begin{array}{l}\text { Clinical Samples/Animal } \\
\text { Model }\end{array}$ & $\begin{array}{l}\text { Assessed } \\
\text { Cell Lines }\end{array}$ & $\begin{array}{l}\text { Targets / } \\
\text { Regulators }\end{array}$ & $\begin{array}{l}\text { Signaling } \\
\text { Pathways }\end{array}$ & Description & Reference \\
\hline $\begin{array}{l}\mathrm{miR}- \\
124\end{array}$ & $\downarrow$ & mouse model of ALI & - & $\uparrow \mathrm{MAPK} 14$ & $\begin{array}{l}\uparrow \text { MAPK } \\
\text { signaling } \\
\text { pathway }\end{array}$ & $\begin{array}{l}\text { Up-regulation of miR-124 reduced apoptosis and } \\
\text { inflammatory response and promoted proliferation. }\end{array}$ & $(277)$ \\
\hline $\begin{array}{l}\mathrm{miR}- \\
942-5 p\end{array}$ & $\downarrow$ & - & $\mathrm{HK}-2$ & $\uparrow \mathrm{FOXO3}$ & - & $\begin{array}{l}\text { Up-regulation of miR-942-5p reduced apoptosis and } \\
\text { inflammatory response and promoted viability. }\end{array}$ & $(278)$ \\
\hline $\begin{array}{l}\mathrm{miR}- \\
23 a-5 p\end{array}$ & $\uparrow$ & $\mathrm{SD}$ rats & NR8383 & - & - & - & $(279)$ \\
\hline $\begin{array}{l}\operatorname{miR-} \\
1298- \\
5 p\end{array}$ & $\uparrow$ & - & BEAS-2B & $\begin{array}{l}\downarrow \text { SOCS6, } \\
\uparrow \text { STAT3 }\end{array}$ & - & $\begin{array}{l}\text { Up-regulation of miR-1298-5p induced cell } \\
\text { permeability and inflammatory response and reduced } \\
\text { proliferation. }\end{array}$ & $(280)$ \\
\hline $\begin{array}{l}\mathrm{miR}- \\
290-5 p\end{array}$ & $\downarrow$ & male C57BL/6J mice & MPC5 & $\uparrow \mathrm{CCL}-2$ & - & $\begin{array}{l}\text { Propofol increased levels of miR-290-5p and } \\
\text { decreased CCL-2 and inflammatory response. }\end{array}$ & $(281)$ \\
\hline $\begin{array}{l}\mathrm{miR}- \\
146 \mathrm{a}\end{array}$ & $\downarrow$ & C57BL/6 mice & BMDMs & - & - & $\begin{array}{l}\text { Rg6 increased IL-10 and miR-146a levels so inhibited } \\
\text { inflammatory responses. }\end{array}$ & $(282)$ \\
\hline $\begin{array}{l}\mathrm{miR}- \\
223\end{array}$ & - & C57BL/6 mice & MSCs & $\begin{array}{l}\text { Sema3A, } \\
\text { Stat3 }\end{array}$ & - & $\begin{array}{l}\text { WT-exosomes encased high miR-223 levels induced } \\
\text { cardio-protection in sepsis. }\end{array}$ & $(283)$ \\
\hline $\begin{array}{l}\mathrm{miR}- \\
608\end{array}$ & - & - & $\begin{array}{l}\text { U937, } \\
\text { HEK293T }\end{array}$ & ELANE & - & $\begin{array}{l}\text { miR-608 played an important role in } \\
\text { posttranscriptional regulation of ELANE expression } \\
\text { and upregulation of miR- } 608 \text { reduced inflammation. }\end{array}$ & $(284)$ \\
\hline $\begin{array}{l}\mathrm{miR}- \\
124\end{array}$ & $\downarrow$ & BALB/c and C57BL/6 mice & RAW264.7 & $\begin{array}{l}\downarrow \alpha 7 \mathrm{nAChR} \\
\uparrow \mathrm{STAT3}\end{array}$ & - & $\begin{array}{l}\text { miR-124 was found to be a critical mediator for the } \\
\text { cholinergic anti-inflammatory effect. }\end{array}$ & $(285)$ \\
\hline $\begin{array}{l}\mathrm{miR-} \\
26 \mathrm{~b}\end{array}$ & $\begin{array}{l}\uparrow \text { in } \mathrm{AKI} \\
\text { group }\end{array}$ & $\begin{array}{l}155 \text { patients with sepsis (68 } \\
\mathrm{AKI} \text { and } 87 \text { non-AKI) and } \\
57 \text { patients with non- } \\
\text { infectious SIRS }\end{array}$ & - & - & - & $\begin{array}{l}\text { Urinary miR-26b levels showed an elevated mortality } \\
\text { rate and was correlated with the severity of the } \\
\text { disease. }\end{array}$ & $(286)$ \\
\hline $\begin{array}{l}\text { miR- } \\
146 a\end{array}$ & - & Rat model of SAKI & - & - & - & $\begin{array}{l}\text { DEX pretreatment could increase the expression level } \\
\text { of miR-146a and reduce oxidative stress and } \\
\text { inflammatory responses. }\end{array}$ & $(287)$ \\
\hline $\begin{array}{l}\mathrm{miR-} \\
29 \mathrm{a}\end{array}$ & $\begin{array}{l}\uparrow \text { in } \mathrm{AKI} \\
\text { group }\end{array}$ & $\begin{array}{l}74 \text { patients with } \mathrm{AKI} \text { and } 41 \\
\text { without } \mathrm{AKI}\end{array}$ & - & - & - & $\begin{array}{l}\text { AUC for miR-29a: } 0.82 \\
\text { miR-29a was found to be an independent risk factor } \\
\text { for mortality in the septic patients. }\end{array}$ & $(288)$ \\
\hline $\begin{array}{l}\text { miR- } \\
10 a-5 p\end{array}$ & $\begin{array}{l}\uparrow \text { in } \mathrm{AKI} \\
\text { group }\end{array}$ & $\begin{array}{l}74 \text { patients with } \mathrm{AKI} \text { and } 41 \\
\text { without } \mathrm{AKI}\end{array}$ & - & - & - & $\begin{array}{l}\text { AUC for miR-10a- } 5 p: 0.75 \\
\text { miR-10a-5p was found to be an independent risk } \\
\text { factor for mortality in the septic patients. }\end{array}$ & \\
\hline $\begin{array}{l}\text { miR- } \\
155\end{array}$ & $\uparrow$ & septic mice & NCM460 & - & $\begin{array}{l}\uparrow \mathrm{NF}-\kappa \mathrm{B} \\
\text { signaling }\end{array}$ & $\begin{array}{l}\text { Up-regulation of miR-155 increased } \\
\text { hyperpermeability to FITC-dextran, TNF- } \alpha \text { and IL-6 } \\
\text { levels, and decreased ZO-1 and Occludin expression. }\end{array}$ & (289) \\
\hline $\begin{array}{l}\text { miR- } \\
155\end{array}$ & $\uparrow$ & male C57BL/6 mice & $\begin{array}{l}\text { Raw264.7, } \\
\text { THP-1 }\end{array}$ & - & $\begin{array}{l}\uparrow \mathrm{PI} 3 \mathrm{~K} / \mathrm{AKT} \\
\text { signalling } \\
\text { pathways }\end{array}$ & $\begin{array}{l}\text { Curcumin inhibited inflammatory responses and miR- } \\
155 \text { expression. }\end{array}$ & (290) \\
\hline $\begin{array}{l}\text { miR- } \\
497\end{array}$ & $\begin{array}{l}\uparrow \text { in } \\
\text { myocardial } \\
\text { injury group }\end{array}$ & $\begin{array}{l}148 \text { patients with sepsis (58 } \\
\text { myocardial injury group and } \\
90 \text { non-myocardial injury } \\
\text { group) }\end{array}$ & - & - & - & $\begin{array}{l}\text { Plasma miRNA- } 497 \text { was correlated with cTnl in } \\
\text { patients with myocardial injury. }\end{array}$ & (291) \\
\hline $\begin{array}{l}\text { miR- } \\
497-5 p\end{array}$ & $\uparrow$ & $\begin{array}{l}\text { GEO database, male } \\
\text { C57BL/6 mice }\end{array}$ & BEAS-2B & $\downarrow \|\llcorner 2 R B$ & - & $\begin{array}{l}\text { Downregulation of miR-497-5p reduced apoptosis } \\
\text { and inflammatory responses. }\end{array}$ & (292) \\
\hline $\begin{array}{l}\mathrm{miR}- \\
30 \mathrm{a}\end{array}$ & $\downarrow$ & - & monocytes & $\begin{array}{l}\uparrow \text { STAT1, } \uparrow \\
\text { MD-2 }\end{array}$ & - & $\begin{array}{l}\text { miR-30a could inhibit STAT1-MD-2 in monocytes of } \\
\text { sepsis. }\end{array}$ & $(293)$ \\
\hline $\begin{array}{l}\mathrm{miR}- \\
150\end{array}$ & $\downarrow$ & C57BL/6 mice & HUVECS & $\uparrow N F-\kappa B 1$ & - & $\begin{array}{l}\text { miR-150 increased survival in patients and inhibited } \\
\text { apoptosis and inflammatory responses. }\end{array}$ & $(294)$ \\
\hline $\begin{array}{l}\text { miR- } \\
146 a\end{array}$ & - & - & THP-1 & $\begin{array}{l}\text { RBM4, } \\
\text { Ago2, p38 }\end{array}$ & - & $\begin{array}{l}\text { Up-regulation of miR-146a inhibited p38 activation } \\
\text { and increased Ago2-RBM4 protein interaction, so } \\
\text { reduced inflammatory responses. }\end{array}$ & $(295)$ \\
\hline $\begin{array}{l}\text { miR- } \\
146 a\end{array}$ & - & C57BL/6 mice & $\begin{array}{l}\text { HEK293TN, } \\
\text { J774.1 }\end{array}$ & - & - & $\begin{array}{l}\text { Up-regulation of miR-146a reduced morphine } \\
\text { mediated hyper-inflammation. }\end{array}$ & $(296)$ \\
\hline $\begin{array}{l}\mathrm{miR-} \\
27 \mathrm{a}\end{array}$ & $\downarrow$ & septic mice & - & $\uparrow \mathrm{TAB} 3$ & $\begin{array}{l}\uparrow \mathrm{NF}-\kappa \mathrm{B} \\
\text { signaling } \\
\text { pathway }\end{array}$ & $\begin{array}{l}\text { Paclitaxel pretreatment increased miR-27a levels, so } \\
\text { decreased inflammatory responses. }\end{array}$ & $(297)$ \\
\hline $\begin{array}{l}\text { miR- } \\
146 a\end{array}$ & $\begin{array}{l}\downarrow \text { in septic } \\
\text { patients than } \\
\text { SIRS and } \\
\text { HCs groups }\end{array}$ & $\begin{array}{l}50 \text { patients with sepsis, } 30 \\
\text { patients with SIRS and } 20 \\
\text { HCs }\end{array}$ & - & - & - & AUC for miR-146a: 0.858 & $(298)$ \\
\hline
\end{tabular}


TABLE 2 | Continued

\begin{tabular}{|c|c|c|c|c|c|c|c|}
\hline miRNA & $\begin{array}{l}\text { Pattern of } \\
\text { Expression }\end{array}$ & $\begin{array}{l}\text { Clinical Samples/Animal } \\
\text { Model }\end{array}$ & $\begin{array}{l}\text { Assessed } \\
\text { Cell Lines }\end{array}$ & $\begin{array}{c}\text { Targets / } \\
\text { Regulators }\end{array}$ & $\begin{array}{l}\text { Signaling } \\
\text { Pathways }\end{array}$ & Description & Reference \\
\hline $\begin{array}{l}\mathrm{miR}- \\
223\end{array}$ & $\begin{array}{l}\downarrow \text { in septic } \\
\text { patients than } \\
\text { SIRS and } \\
\text { HCs groups }\end{array}$ & $\begin{array}{l}50 \text { patients with sepsis, } 30 \\
\text { patients with SIRS and } 20 \\
\text { HCs }\end{array}$ & - & - & - & AUC for miR-223: 0.804 & \\
\hline $\begin{array}{l}\text { miR- } \\
339-5 p\end{array}$ & $\downarrow$ & septic mice & RAW264.7 & $\begin{array}{l}\uparrow \mathrm{HMGB} 1, \uparrow \\
\mathrm{IKK}-\beta\end{array}$ & - & $\begin{array}{l}\text { Paeonol could reduce inflammatory responses by } \\
\text { upregulating miR-339-5p expression. }\end{array}$ & (299) \\
\hline $\begin{array}{l}\text { miR- } \\
99 b\end{array}$ & $\uparrow$ & male C57BL/6 J mice & RAW264.7 & $\downarrow$ MFG-E8 & - & $\begin{array}{l}\text { Spherical nucleic acid increased migration by } \\
\text { inhibiting miR-99b. }\end{array}$ & $(300)$ \\
\hline $\begin{array}{l}\mathrm{miR}- \\
215-5 p\end{array}$ & $\downarrow$ & - & $\mathrm{H} 9 \mathrm{c} 2$ & $\begin{array}{l}\uparrow \text { LRRFIP1, } \\
\uparrow I L F 3\end{array}$ & - & miR-215-5p reduced inflammatory responses. & $(301)$ \\
\hline $\begin{array}{l}\text { miR- } \\
15 a\end{array}$ & $\begin{array}{l}\uparrow \text { in sepsis } \\
\text { and SIRS } \\
\text { than HCs }\end{array}$ & $\begin{array}{l}166 \text { patients with sepsis, } 32 \\
\text { patients with SIRS, and } 24 \\
\text { HCs }\end{array}$ & - & - & - & miR-15a could distinguish sepsis/SIRS from HCs. & $(302)$ \\
\hline $\mathrm{miR}-16$ & $\begin{array}{l}\uparrow \text { in sepsis } \\
\text { and SIRS } \\
\text { than HCs }\end{array}$ & $\begin{array}{l}166 \text { patients with sepsis, } 32 \\
\text { patients with SIRS, and } 24 \\
\text { HCs }\end{array}$ & - & - & - & miR-16 could distinguish sepsis/SIRS from HCs. & \\
\hline
\end{tabular}

miRNAs and Sepsis. AKI, Acute kidney injury; HCs, healthy controls; AUC, significant higher area under curve; CRP, C-reactive protein; TLC, total leucocytes count; SD,

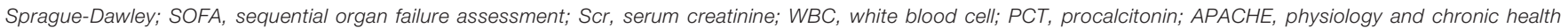

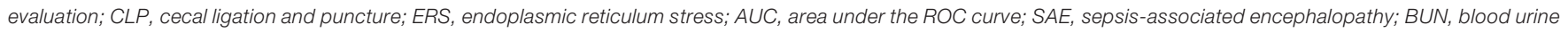

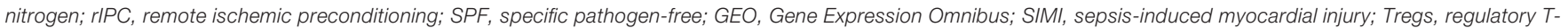

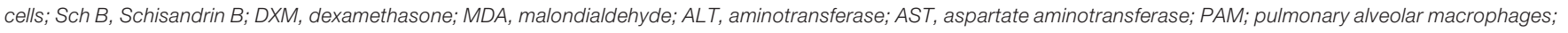

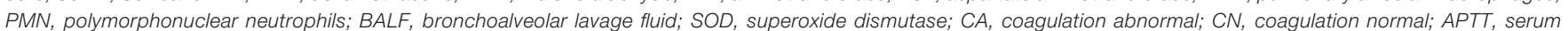

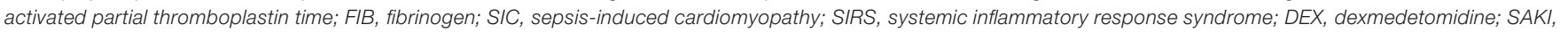
sepsis-induced acute kidney injury).

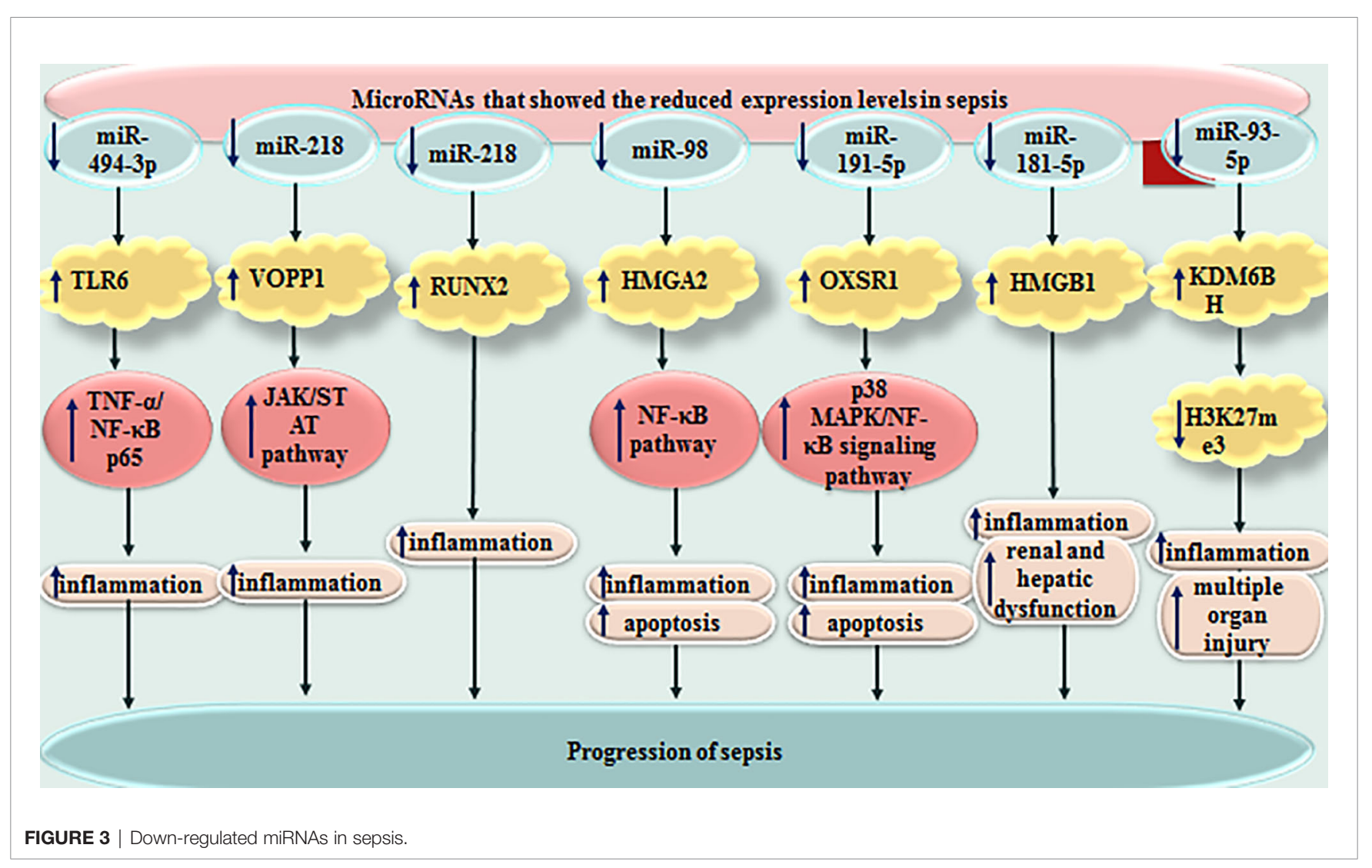


TABLE 3 | CircRNAs and Sepsis.

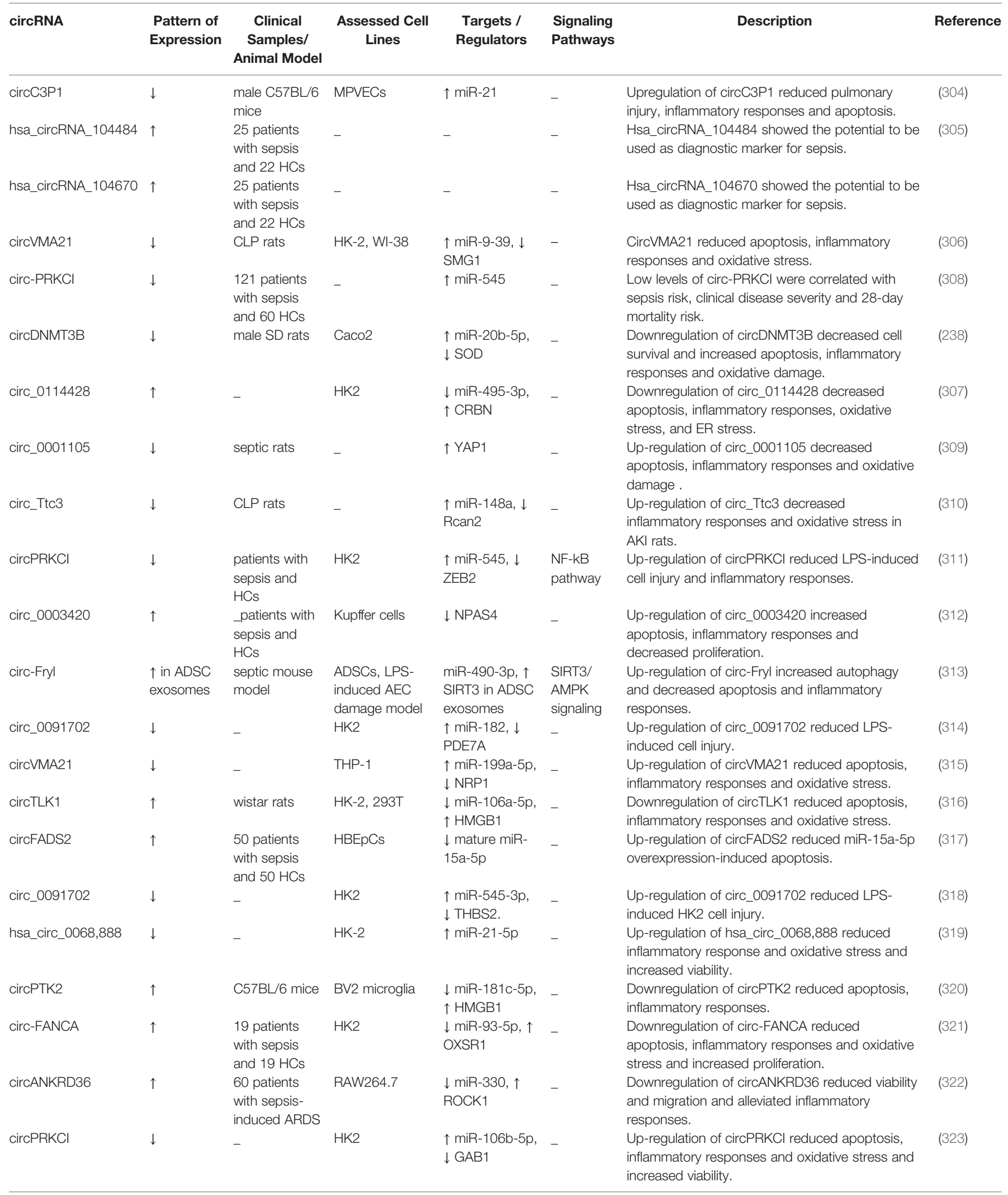

HCs, healthy controls; AKI, acute kidney injury; ARDS, acute respiratory distress syndrome. 
lncRNAs and miRNAs can ameliorate the pathologic events in the target organs, particularly heart and kidney during sepsis. Yet, this field is still in its infancy needing verification in additional animal models and cell lines. Moreover, since sepsis is an emergency situation, any therapeutic option should be verified in terms of bioavailability, efficiency and instant amelioration of pathological events.

Since the pathoetiology of sepsis-related complications is not completely understood, high throughput sequencing strategies focusing on different classes of non-coding as well coding RNAs

\section{REFERENCES}

1. Zarjou A, Agarwal A. Sepsis and Acute Kidney Injury. J Am Soc Nephrol (2011) 22(6):999-1006. doi: 10.1681/ASN.2010050484

2. Rossaint J, Zarbock A. Pathogenesis of Multiple Organ Failure in Sepsis. Crit Rev Immunol (2015) 35(4):277-91. doi: 10.1615/CritRevImmunol.2015015461

3. Li C, Wu J, Li Y, Xing G. Cytoprotective Effect of Heat Shock Protein 27 Against Lipopolysaccharide-Induced Apoptosis of Renal Epithelial HK-2 Cells. Cell Physiol Biochem (2017) 41(6):2211-20. doi: 10.1159/000475636

4. Ye H-Y, Jin J, Jin L-W, Chen Y, Zhou Z-H, Li Z-Y. Chlorogenic Acid Attenuates Lipopolysaccharide-Induced Acute Kidney Injury by Inhibiting TLR4/NF-kb Signal Pathway. Inflammation (2017) 40(2):523-9. doi: 10.1007/s10753-016-0498-9

5. Zhang X, Wang W, Zhu W, Dong J, Cheng Y, Yin Z, et al. Mechanisms and Functions of Long Non-Coding Rnas at Multiple Regulatory Levels. Int $J$ Mol Sci (2019) 20(22):5573. doi: 10.3390/ijms20225573

6. Flores-Concha M, Oñate N. Long Non-Coding Rnas in the Regulation of the Immune Response and Trained Immunity. Front Genet (2020) 11:718. doi: 10.3389/fgene.2020.00718

7. Qiu N, Xu X, He Y. Lncrna TUG1 Alleviates Sepsis-Induced Acute Lung Injury by Targeting Mir-34b-5p/GAB1. BMC Pulmonary Med (2020) 20 (1):1-12. doi: 10.1186/s12890-020-1084-3

8. Li N, Wu S, Yu L. The Associations of Long Non-Coding RNA Taurine Upregulated Gene 1 and Microrna-223 With General Disease Severity and Mortality Risk in Sepsis Patients. Med (2020) 99(50). doi: 10.1097/ MD.0000000000023444

9. Ge X, Liu W, Zhao W, Feng S, Duan A, Ji C, et al. Exosomal Transfer of LCP1 Promotes Osteosarcoma Cell Tumorigenesis and Metastasis by Activating the JAK2/STAT3 Signaling Pathway. Mol Ther Nucleic Acids (2020) 21:900-15. doi: 10.1016/j.omtn.2020.07.025

10. Zhou Y-L, Yang S-H, Zhang C, Zhang B, Yang X-J. Lncrna MALAT1 Modulates the Immunoreaction of Rats With Lipopolysaccharide-Induced Sepsis by Targeting the Mir-146a/NF-kb P65 Pathway. Sichuan da xue xue bao Yi xue ban= J Sichuan Univ Med Sci Ed (2018) 49(6):865-70.

11. Li Z, Liu S, Li X, Zhao W, Li J, Xu Y. Circular RNA in Schizophrenia and Depression. Front Psychiatry (2020) 11. doi: 10.3389/fpsyt.2020.00392

12. Wei S, Liu Q. Long Noncoding RNA MALAT1 Modulates Sepsis-Induced Cardiac Inflammation Through the Mir-150-5p/NF-kb Axis. Int J Clin Exp Pathol (2019) 12(9):3311.

13. Yu Z, Rayile A, Zhang X, Li Y, Zhao Q. Ulinastatin Protects Against Lipopolysaccharide-Induced Cardiac Microvascular Endothelial Cell Dysfunction via Downregulation of Lncrna MALAT1 and EZH2 in Sepsis. Int J Mol Med (2017) 39(5):1269-76. doi: 10.3892/ijmm.2017.2920

14. Liu W, Geng F, Yu L. Long Non-Coding RNA MALAT1/Microrna 125a Axis Presents Excellent Value in Discriminating Sepsis Patients and Exhibits Positive Association With General Disease Severity, Organ Injury, Inflammation Level, and Mortality in Sepsis Patients. J Clin Lab Anal (2020) 34(6):e23222. doi: 10.1002/jcla.23222

15. Zhang C-C, Niu F. Lncrna NEAT1 Promotes Inflammatory Response in Sepsis-Induced Liver Injury via the Let-7a/TLR4 Axis. Int Immunopharmacol (2019) 75:105731. doi: 10.1016/j.intimp.2019.105731

16. Wu X, Fang Y, Zheng F, Zhang Y, Li Q. Lncrna NEAT1 Facilitates the Progression of Sepsis Through Up-Regulating TSP-1 via Sponging Mir-370- are necessary to find the complicated networks between these transcripts in the context of sepsis.

\section{AUTHOR CONTRIBUTIONS}

SG-F wrote the draft and revised it. MT designed and supervised the study. NA, BH, and TK collected the data and designed the figures and tables. All authors contributed to the article and approved the submitted version.

3p. Eur Rev Med Pharmacol Sci (2020) 24(1):333-44. doi: 10.26355/ eurrev_202001_19931

17. Li Y, Guo W, Cai Y. NEAT1 Promotes LPS-Induced Inflammatory Injury in Macrophages by Regulating Mir-17-5p/TLR4. Open Med (2020) 15(1):3849. doi: 10.1515/med-2020-0007

18. Chen JX, Xu X, Zhang S. Silence of Long Noncoding RNA NEAT1 Exerts Suppressive Effects on Immunity During Sepsis by Promoting Microrna125-Dependent MCEMP1 Downregulation. IUBMB Life (2019) 71(7):95668. doi: $10.1002 /$ iub. 2033

19. Dong Y, Fan G, Li Y, Zhou Q. TUG1 Represses Apoptosis, Autophagy, and Inflammatory Response by Regulating Mir-27a-3p/SLIT2 in LPS-Treated Vascular Endothelial Cells. J Surg Res (2020) 256:345-54. doi: 10.1016/ j.jss.2020.05.102

20. Xie W, Chen L, Chen L, Kou Q. Silencing of Long Non-Coding RNA MALAT1 Suppresses Inflammation in Septic Mice: Role of Microrna-23a in the Down-Regulation of MCEMP1 Expression. Inflamm Res (2020) 69 (2):179-90. doi: 10.1007/s00011-019-01306-z

21. Lin L, Niu G, Zhang X. Influence of Lncrna MALAT1 on Septic Lung Injury in Mice Through P38 MAPK/P65 NF-kb Pathway. Eur Rev Med Pharmacol Sci (2019) 23(3):1296-304. doi: 10.26355/eurrev_201902_17025

22. Liang WJ, Zeng XY, Jiang SL, Tan HY, Yan MY, Yang HZ. Long NonCoding RNA MALAT1 Sponges Mir-149 to Promote Inflammatory Responses of LPS-Induced Acute Lung Injury by Targeting Myd88. Cell Biol Int (2020) 44(1):317-26. doi: 10.1002/cbin.11235

23. Liu L, Yan L-N, Sui Z. Microrna-150 Affects Endoplasmic Reticulum Stress via MALAT1-Mir-150 Axis-Mediated NF-kb Pathway in LPS-Challenged Huvecs and Septic Mice. Life Sci (2021) 265:118744. doi: 10.1016/ j.lfs.2020.118744

24. Huang X, Zhao M. High Expression of Long Non-Coding RNA MALAT1 Correlates With Raised Acute Respiratory Distress Syndrome Risk, Disease Severity, and Increased Mortality in Sepstic Patients. Int J Clin Exp Pathol (2019) 12(5):1877.

25. Zhuang Y, Xu D, Wang G, Sun J, Huang Y, Wang S. IL-6 Induced Lncrna MALAT1 Enhances TNF- $\alpha$ Expression in LPS-Induced Septic Cardiomyocytes via Activation of SAA3. Eur Rev Med Pharmacol Sci (2017) 21(2):302-9.

26. Geng F, Liu W, Yu L. Potential Role of Circulating Long Noncoding RNA MALAT1 in Predicting Disease Risk, Severity, and Patients' Survival in Sepsis. J Clin Lab Anal (2019) 33(8):e22968. doi: 10.1002/jcla.22968

27. Chen J, He Y, Zhou L, Deng Y, Si L. Long Non-Coding RNA MALAT1 Serves as an Independent Predictive Biomarker for the Diagnosis, Severity and Prognosis of Patients With Sepsis. Mol Med Rep (2020) 21(3):1365-73. doi: $10.3892 / \mathrm{mmr} .2020 .10923$

28. Gao F, Chen R, Xi Y, Zhao Q, Gao H. Long Noncoding RNA MALAT1 Regulates Sepsis in Patients With Burns by Modulating Mir-214 With TLR5. Mol Med Rep (2019) 19(5):3756-66. doi: 10.3892/mmr.2019.10028

29. Sun F, Yuan W, Wu H, Chen G, Sun Y, Yuan L, et al. Lncrna KCNQ1OT1 Attenuates Sepsis-Induced Myocardial Injury via Regulating Mir-192-5p/ XIAP Axis. Exp Biol Med (2020) 245(7):620-30. doi: 10.1177/ 1535370220908041

30. Chen T, Zhu C, Ye C. Lncrna CYTOR Attenuates Sepsis-Induced Myocardial Injury via Regulating Mir-24/XIAP. Cell Biochem Funct (2020) 38(7):976-85. doi: 10.1002/cbf.3524 
31. Liu F, Hu S, Zhao N, Shao Q, Li Y, Jiang R, et al. Lncrna-5657 Silencing Alleviates Sepsis-Induced Lung Injury by Suppressing the Expression of Spinster Homology Protein 2. Int Immunopharmacol (2020) 88:106875. doi: 10.1016/j.intimp.2020.106875

32. Han Y, Cai Y, Lai X, Wang Z, Wei S, Tan K, et al. Lncrna RMRP Prevents Mitochondrial Dysfunction and Cardiomyocyte Apoptosis via the Mir-1-5p/ Hsp70 Axis in LPS-Induced Sepsis Mice. Inflammation (2020) 43(2):605-18. doi: 10.1007/s10753-019-01141-8

33. Yin J, Han B, Shen Y. Lncrna NEAT1 Inhibition Upregulates Mir-16-5p to Restrain the Progression of Sepsis-Induced Lung Injury via Suppressing BRD4 in a Mouse Model. Int Immunopharmacol (2021) 97:107691. doi: 10.1016/j.intimp.2021.107691

34. Wang S, Liu G, Xian H, Si J, Qi S, Yu Y. Lncrna NEAT1 Alleviates SepsisInduced Myocardial Injury by Regulating the TLR2/NF- $\kappa b$ Signaling Pathway. Eur Rev Med Pharmacol Sci (2019) 23(11):4898-907. doi: 10.26355/eurrev_201906_18078

35. Zhou H, Wang X, Zhang B. Depression of Lncrna NEAT1 Antagonizes LPSEvoked Acute Injury and Inflammatory Response in Alveolar Epithelial Cells via HMGB1-RAGE Signaling. Mediators Inflamm (2020) 2020. doi: 10.1155/ 2020/8019467

36. Gao C, Zou X, Chen H, Shang R, Wang B. Long Non-Coding RNA Nuclear Paraspeckle Assembly Transcript 1 (NEAT1) Relieves Sepsis-Induced Kidney Injury and Lipopolysaccharide (LPS)-Induced Inflammation in HK-2 Cells. Med Sci Monit: Int Med J Exp Clin Res (2020) 26:e921906-1. doi: 10.12659/MSM.921906

37. Wang W, Guo Z-H. Downregulation of Lncrna NEAT1 Ameliorates LPSInduced Inflammatory Responses by Promoting Macrophage M2 Polarization via Mir-125a-5p/TRAF6/TAK1 Axis. Inflammation (2020) 43 (4):1548-60. doi: 10.1007/s10753-020-01231-y

38. Yang J, Wu L, Liu S, Hu X, Wang Q, Fang L. Long Non-Coding RNA NEAT1 Promotes Lipopolysaccharide-Induced Injury in Human Tubule Epithelial Cells by Regulating Mir-93-5p/TXNIP Axis. Med Microbiol Immunol (2021) 210(2):121-32. doi: 10.1007/s00430-021-00705-6

39. Xiao T, Sun C, Xiao Y, Li Y. Lncrna NEAT1 Mediates Sepsis Progression by Regulating Irak2 via Sponging Mir-370-3p. Biol Open (2020) 9(6):bio049353. doi: 10.1242/bio.049353

40. Wei J, Wu C, Chen J, Shang F, Guo S, Zhang X, et al. Lncrna NEAT1 Promotes the Progression of Sepsis-Induced Myocardial Cell Injury by Sponging Mir-144-3p. Eur Rev Med Pharmacol Sci (2020) 24(2):851-61. doi: 10.26355/eurrev_202001_20069

41. Huang Q, Huang C, Luo Y, He F, Zhang R. Circulating Lncrna NEAT1 Correlates With Increased Risk, Elevated Severity and Unfavorable Prognosis in Sepsis Patients. Am J Emergency Med (2018) 36(9):1659-63. doi: 10.1016/j.ajem.2018.06.008

42. Chen C, Zhang H, Ge M, Ye J, Li R, Wang D. Lncrna NEAT1 Acts as a Key Regulator of Cell Apoptosis and Inflammatory Response by the Mir-944/ TRIM37 Axis in Acute Lung Injury. J Pharmacol Sci (2021) 145(2):202-12. doi: 10.1016/j.jphs.2020.11.009

43. Huang S, Qian K, Zhu Y, Huang Z, Luo Q, Qing C. Diagnostic Value of the Lncrna NEAT1 in Peripheral Blood Mononuclear Cells of Patients With Sepsis. Dis Markers (2017) 2017. doi: 10.1155/2017/7962836

44. Liu B, Ren H, Chen J. Lncrna NEAT1 Correlates With Th1 and Th17 and Could Serve as an Assistant Biomarker in Sepsis. Biomarkers Med (2021) 1177-86. doi: 10.2217/bmm-2020-0906

45. Xia D, Yao R, Zhou P, Wang C, Xia Y, Xu S. Lncrna NEAT1 Reversed the Hindering Effects of Mir-495-3p/STAT3 Axis and Mir-211/PI3K/AKT Axis on Sepsis-Relevant Inflammation. Mol Immunol (2020) 117:168-79. doi: 10.1016/j.molimm.2019.10.009

46. Yang Y, Yang L, Liu Z, Wang Y, Yang J. Long Noncoding RNA NEAT 1 and its Target Microrna-125a in Sepsis: Correlation With Acute Respiratory Distress Syndrome Risk, Biochemical Indexes, Disease Severity, and 28-Day Mortality. J Clin Lab Anal (2020) 34(12):e23509. doi: 10.1002/jcla.23509

47. Liu W, Wang Y, Zheng Y, Chen X. Effects of Long Non-Coding RNA NEAT1 on Sepsis-Induced Brain Injury in Mice via NF-кb. Eur Rev Med Pharmacol Sci (2019) 23(9):3933-9. doi: 10.26355/eurrev_201905_17822

48. He F, Zhang C, Huang Q. Long Noncoding RNA Nuclear Enriched Abundant Transcript 1/Mirna-124 Axis Correlates With Increased Disease Risk, Elevated Inflammation, Deteriorative Disease Condition, and Predicts
Decreased Survival of Sepsis. Med (2019) 98(32). doi: 10.1097/ MD.0000000000016470

49. Feng Y, Liu J, Wu R, Yang P, Ye Z, Song F. NEAT1 Aggravates SepsisInduced Acute Kidney Injury by Sponging Mir-22-3p. Open Med (2020) 15 (1):333-42. doi: 10.1515/med-2020-0401

50. Yang Y, Xue J, Qin L, Zhang J, Liu J, Yu J. Lncrna NEAT1 Promotes Inflammatory Response in Sepsis via the Mir-31-5p/POU2F1 Axis. Inflammation (2021) 44(4):1-11. doi: 10.1007/s10753-021-01436-9

51. Liu L, Liu F, Sun Z, Peng Z, You T, Yu Z. Lncrna NEAT1 Promotes Apoptosis and Inflammation in LPS-Induced Sepsis Models by Targeting Mir-590-3p. Exp Ther Med (2020) 20(4):3290-300. doi: 10.3892/ etm.2020.9079

52. Fang Y, Hu J, Wang Z, Zong H, Zhang L, Zhang R, et al. Lncrna H19 Functions as an Aquaporin 1 Competitive Endogenous RNA to Regulate Microrna-874 Expression in LPS Sepsis. Biomed Pharmacother (2018) 105:1183-91. doi: 10.1016/j.biopha.2018.06.007

53. Shan B, Li J-Y, Liu Y-J, Tang X-B, Zhou Z, Luo L-X. Lncrna H19 Inhibits the Progression of Sepsis-Induced Myocardial Injury via Regulation of the Mir93-5p/SORBS2 Axis. Inflammation (2021) 44(1):344-57. doi: 10.1007/ s10753-020-01340-8

54. Yu B, Cui R, Lan Y, Zhang J, Liu B. Long Non-Coding RNA H19 as a Diagnostic Marker in Peripheral Blood of Patients With Sepsis. Am J Trans Res (2021) 13(4):2923.

55. Wang H-R, Guo X-Y, Liu X-Y, Song X. Down-Regulation of Lncrna CASC9 Aggravates Sepsis-Induced Acute Lung Injury by Regulating Mir-195-5p/ PDK4 Axis. Inflammation Res (2020) 69(6):559-68. doi: 10.1007/s00011020-01316-2

56. Zhang Z, Lv M, Wang X, Zhao Z, Jiang D, Wang L. Lncrna LUADT1 Sponges Mir-195 to Prevent Cardiac Endothelial Cell Apoptosis in Sepsis. Mol Med (2020) 26(1):1-8. doi: 10.1186/s10020-020-00228-5

57. Zhang Y, Zhang Y, Xia F, Yang A, Qian J, Zhao H, et al. Effect of LncrnaMIAT on Kidney Injury in Sepsis Rats via Regulating Mir-29a Expression. Eur Rev Med Pharmacol Sci (2019) 23:10942-9. doi: 10.26355/ eurrev_201912_19797

58. Xing P-C, An P, Hu G-Y, Wang D-L, Zhou M-J. Lncrna MIAT Promotes Inflammation and Oxidative Stress in Sepsis-Induced Cardiac Injury by Targeting Mir-330-5p/TRAF6/NF- $\kappa b$ Axis. Biochem Genet (2020) 58 (5):783-800. doi: 10.1007/s10528-020-09976-9

59. Liu T, Liu J, Tian C, Wang H, Wen M, Yan M. Lncrna THRIL Is Upregulated in Sepsis and Sponges Mir-19a to Upregulate TNF- $\alpha$ in Human Bronchial Epithelial Cells. J Inflammation (2020) 17(1):1-7. doi: 10.1186/s12950-02000259-z

60. Chen H, Hu X, Li R, Liu B, Zheng X, Fang Z, et al. Lncrna THRIL Aggravates Sepsis-Induced Acute Lung Injury by Regulating Mir-424/ROCK2 Axis. Mol Immunol (2020) 126:111-9. doi: 10.1016/j.molimm.2020.07.021

61. Wang Y, Fu X, Yu B, Ai F. Long Non-Coding RNA THRIL Predicts Increased Acute Respiratory Distress Syndrome Risk and Positively Correlates With Disease Severity, Inflammation, and Mortality in Sepsis Patients. J Clin Lab Anal (2019) 33(6):e22882. doi: 10.1002/jcla.22882

62. Song X, Li L, Zhao Y, Song Y. Down-Regulation of Long Non-Coding RNA XIST Aggravates Sepsis-Induced Lung Injury by Regulating Mir-16-5p. Hum Cell (2021) 34(5):1-11. doi: 10.1007/s13577-021-00542-y

63. Wang L, Cao QM. Long Non-Coding RNA XIST Alleviates Sepsis-Induced Acute Kidney Injury Through Inhibiting Inflammation and Cell Apoptosis via Regulating Mir-155-5p/WWC1 Axis. Kaohsiung J Med Sci (2021). doi: 10.1002/kjm2.12442

64. Shen C, Li J. Lncrna XIST Silencing Protects Against Sepsis-Induced Acute Liver Injury via Inhibition of BRD4 Expression. Inflammation (2021) 44 (1):194-205. doi: 10.1007/s10753-020-01321-x

65. Xu G, Mo L, Wu C, Shen X, Dong H, Yu L, et al. The Mir-15a-5p-XISTCUL3 Regulatory Axis Is Important for Sepsis-Induced Acute Kidney Injury. Ren Fail (2019) 41(1):955-66. doi: 10.1080/0886022X.2019.1669460

66. Liang D, Jin Y, Lin M, Xia X, Chen X, Huang A. Down-Regulation of Xist and Mir-7a-5p Improves LPS-Induced Myocardial Injury. Int J Med Sci (2020) 17(16):2570. doi: 10.7150/ijms.45408

67. Li M, Zhang Z, Liu B, Chen L, Wang M. Lncrna GAS5 Upregulates Mir-214 Through Methylation to Participate in Cell Apoptosis of Sepsis. Arch Physiol Biochem (2020) 1-6. doi: 10.1080/13813455.2020.1764051 
68. Zhu Y, Sun A, Meng T, Li H. Protective Role of Long Noncoding RNA CRNDE in Myocardial Tissues From Injury Caused by Sepsis Through the Microrna-29a/SIRT1 Axis. Life Sci (2020) 255:117849. doi: 10.1016/ j.lfs. 2020.117849

69. Wang Y, Xu Z, Yue D, Zeng Z, Yuan W, Xu K. Linkage of Lncrna CRNDE Sponging Mir-181a-5p With Aggravated Inflammation Underlying Sepsis. Innate Immun (2020) 26(2):152-61. doi: 10.1177/1753425919880946

70. Sun B, Sui Y, Huang H, Zou X, Chen S, Yu Z. Effect of Lncrna CRNDE on Sepsis-Related Kidney Injury Through the TLR3/NF-Kb Pathway. Eur Rev Med Pharmacol Sci (2019) 23(23):10489-97. doi: 10.26355/ eurrev_201912_19688

71. Wu S, Qiu H, Wang Q, Cao Z, Wang J. Effects and Mechanism of Lncrna CRNDE on Sepsis-Induced Acute Kidney Injury. Anal Cell Pathol (2020) 2020. doi: $10.1155 / 2020 / 8576234$

72. Wang J, Song J, Li Y, Shao J, Xie Z, Sun K. Down-Regulation of Lncrna CRNDE Aggravates Kidney Injury via Increasing Mir-181a-5p in Sepsis. Int Immunopharmacol (2020) 79:105933. doi: 10.1016/j.intimp.2019.105933

73. Li Y, Song J, Xie Z, Liu M, Sun K. Long Noncoding RNA Colorectal Neoplasia Differentially Expressed Alleviates Sepsis-Induced Liver Injury via Regulating Mir-126-5p. IUBMB Life (2020) 72(3):440-51. doi: 10.1002/ iub. 2230

74. Jiang Z, Zhang M, Fan Z, Sun W, Tang Y. Influence of Lncrna HOTAIR on Acute Kidney Injury in Sepsis Rats Through Regulating Mir-34a/Bcl-2 Pathway. Eur Rev Med Pharmacol Sci (2019) 23(8):3512-9. doi: 10.26355/ eurrev_201904_17717

75. Yang W, Luo X, Liu Y, Xiong J, Xia H, Liu Y. Potential Role of Lncrna HULC/Mir-128-3p/RAC1 Axis in the Inflammatory Response During LPS -Induced Sepsis in HMEC-1 Cells. Mol Med Rep (2020) 22(6):5095-104. doi: $10.3892 / \mathrm{mmr} .2020 .11601$

76. Wang H, Feng Q, Wu Y, Feng L, Yuan H, Hou L, et al. Association of Circulating Long Non-Coding RNA HULC Expression With Disease Risk, Inflammatory Cytokines, Biochemical Index Levels, Severity-Assessed Scores, and Mortality of Sepsis. J Clin Lab Anal (2021) 35(3):e23656. doi: $10.1002 /$ jcla.23656

77. Chen X, Song D. LPS Promotes the Progression of Sepsis by Activation of Lncrna HULC/Mir-204-5p/TRPM7 Network in Huvecs. Biosci Rep (2020) 40(6):BSR20200740. doi: 10.1042/BSR20200740

78. Chen Y, Fu Y, Song Y-F, Li N. Increased Expression of Lncrna UCA1 and HULC Is Required for Pro-Inflammatory Response During LPS Induced Sepsis in Endothelial Cells. Front Physiol (2019) 10:608. doi: 10.3389/ fphys.2019.00608

79. Shen J, Liu L, Zhang F, Gu J, Pan G. Lncrna Tapsaki Promotes Inflammation Injury in HK-2 Cells and Urine Derived Sepsis-Induced Kidney Injury. J Pharm Pharmacol (2019) 71(5):839-48. doi: 10.1111/jphp.13049

80. Zeng Q, Wu J, Yang S. Circulating Lncrna ITSN1-2 Is Upregulated, and its High Expression Correlates With Increased Disease Severity, Elevated Inflammation, and Poor Survival in Sepsis Patients. J Clin Lab Anal (2019) 33(4):e22836. doi: 10.1002/jcla.22836

81. Wang W, Li Y, Zhi S, Li J, Miao J, Ding Z, et al. Lncrna-ROR/Microrna185-3p/YAP1 Axis Exerts Function in Biological Characteristics of Osteosarcoma Cells. Genomics (2020) 113(1 Pt 2):450-61. doi: 10.1016/j.ygeno.2020.09.009

82. Zhang P, Yi L, Qu S, Dai J, Li X, Liu B, et al. The Biomarker TCONS_00016233 Drives Septic AKI by Targeting the Mir-22-3p/AIFM1 Signaling Axis. Mol Therapy-Nucleic Acids (2020) 19:1027-42. doi: 10.1016/ j.omtn.2019.12.037

83. Qin G, Wei L, Jiang F, Li J, Zhang B, Pan D, et al. Lncrna NR024118 Is Downregulated in Sepsis and Inhibits LPS-Induced Apoptosis of Cardiomyocytes. Mol Med Rep (2021) 23(6):1-7. doi: 10.3892/ mmr.2021.12073

84. Zhang C, Li J, Li H, Wang G, Wang Q, Zhang X, et al. Lncrna MIR155HG Accelerates the Progression of Sepsis via Upregulating MEF2A by Sponging Mir-194-5p. DNA Cell Biol (2021) 40(6):811-20. doi: 10.1089/dna.2021.0038

85. Wang J, Xin S, Yang R, Jiang J, Qiao Y. Knockdown of Lncrna LUCAT1 Attenuates Sepsis-Induced Myocardial Cell Injury by Sponging Mir-642a. Mamm Genome (2021) 32(6):1-9. doi: 10.1007/s00335-021-09890-4
86. Chen M, Guan Y, Li A, Zhao Y-Z, Zhang L, Zhang L, et al. Lncrna SOX2OT Mediates Mitochondrial Dysfunction in Septic Cardiomyopathy. DNA Cell Biol (2019) 38(11):1197-206. doi: 10.1089/dna.2019.4839

87. Deng J, Tan W, Luo Q, Lin L, Zheng L, Yang J. Long Non-Coding RNA MEG3 Promotes Renal Tubular Epithelial Cell Pyroptosis by Regulating the Mir-18a-3p/GSDMD Pathway in Lipopolysaccharide-Induced Acute Kidney Injury. Front Physiol (2021) 12. doi: 10.3389/fphys.2021.663216

88. Chen K, Shi X, Jin Y, Wang F, Shen Q, Xu W. High Lncrna MEG3 Expression Is Associated With High Mortality Rates in Patients With Sepsis and Increased Lipopolysaccharide-Induced Renal Epithelial Cell and Cardiomyocyte Apoptosis. Exp Ther Med (2019) 18(5):3943-7. doi: 10.3892/etm.2019.8049

89. Wu X, Chen D, Yu L. The Value of Circulating Long Non-Coding RNA Maternally Expressed Gene 3 as a Predictor of Higher Acute Respiratory Distress Syndrome Risk and 28-Day Mortality in Sepsis Patients. J Clin Lab Anal (2020) 34(11):e23488. doi: 10.1002/jcla.23488

90. Na L, Ding H, Xing E, Gao J, Liu B, Wang H, et al. Lnc-MEG3 Acts as a Potential Biomarker for Predicting Increased Disease Risk, Systemic Inflammation, Disease Severity, and Poor Prognosis of Sepsis via Interacting With Mir-21. J Clin Lab Anal (2020) 34(4):e23123. doi: $10.1002 /$ jcla.23123

91. Du X, Tian D, Wei J, Yan C, Hu P, Wu X, et al. MEG3 Alleviated LPSInduced Intestinal Injury in Sepsis by Modulating Mir-129-5p and Surfactant Protein D. Mediators Inflamm (2020) 2020. doi: 10.1155/2020/ 8232734

92. Fang Y, Hu J, Wang Z, Zhang S, Zhang R, Sun L, et al. GAS5 Promotes Podocyte Injury in Sepsis by Inhibiting PTEN Expression. Eur Rev Med Pharmacol Sci (2018) 22(23):8423-30. doi: 10.26355/eurrev_201812_16541

93. Li L, He Y, He X-J, Bi M-R, Qi Y-H, Zhu W-W. Down-Regulation of Long Noncoding RNA LINC00472 Alleviates Sepsis-Induced Acute Hepatic Injury by Regulating Mir-373-3p/TRIM8 Axis. Exp Mol Pathol (2020) 117:104562. doi: 10.1016/j.yexmp.2020.104562

94. Wu H, Liu J, Li W, Liu G, Li Z. Lncrna-HOTAIR Promotes TNF- $\alpha$ Production in Cardiomyocytes of LPS-Induced Sepsis Mice by Activating NF-kb Pathway. Biochem Biophys Res Commun (2016) 471(1):240-6. doi: 10.1016/j.bbrc.2016.01.117

95. Shen J, Zhang J, Jiang X, Wang H, Pan G. Lncrna HOX Transcript Antisense RNA Accelerated Kidney Injury Induced by Urine-Derived Sepsis Through the Mir-22/High Mobility Group Box 1 Pathway. Life Sci (2018) 210:185-91. doi: 10.1016/j.lfs.2018.08.041

96. Alkhateeb T, Bah I, Kumbhare A, Youssef D, Yao ZQ, McCall CE, et al. Long Non-Coding RNA Hotairm1 Promotes S100A9 Support of MDSC Expansion During Sepsis. J Clin Cell Immunol (2020) 11(6).

97. Han D, Fang R, Shi R, Jin Y, Wang Q. Lncrna NKILA Knockdown Promotes Cell Viability and Represses Cell Apoptosis, Autophagy and Inflammation in Lipopolysaccharide-Induced Sepsis Model by Regulating Mir-140-5p/ CLDN2 Axis. Biochem Biophys Res Commun (2021) 559:8-14. doi: 10.1016/j.bbrc.2021.04.074

98. Wu H, Wang J, Ma Z. Long Noncoding RNA HOXA-AS2 Mediates Microrna-106b-5p to Repress Sepsis-Engendered Acute Kidney Injury. J Biochem Mol Toxicol (2020) 34(4):e22453. doi: 10.1002/jbt.22453

99. Shi C, Zhao Y, Li Q, Li J. Lncrna SNHG14 Plays a Role in Sepsis-Induced Acute Kidney Injury by Regulating Mir-93. Mediators Inflamm (2021) 2021. doi: 10.1155/2021/5318369

100. Jia Y, Li Z, Cai W, Xiao D, Han S, Han F, et al. SIRT1 Regulates Inflammation Response of Macrophages in Sepsis Mediated by Long Noncoding RNA. Biochim Biophys Acta (BBA)-Molecular Basis Dis (2018) 1864(3):784-92. doi: 10.1016/j.bbadis.2017.12.029

101. Tan J, Fan J, He J, Zhao L, Tang H. Knockdown of Lncrna DLX6-AS1 Inhibits HK-2 Cell Pyroptosis via Regulating Mir-223-3p/NLRP3 Pathway in Lipopolysaccharide-Induced Acute Kidney Injury. J Bioenerg Biomembr (2020) 52(5):367-76. doi: 10.1007/s10863-020-09845-5

102. Wang M, Wei J, Shang F, Zang K, Ji T. Long Non-Coding RNA CASC2 Ameliorates Sepsis-Induced Acute Kidney Injury by Regulating the Mir-155 and NF-Kb Pathway. Int J Mol Med (2020) 45(5):1554-62. doi: 10.3892/ ijmm.2020.4518 
103. Zhu L, Shi D, Cao J, Song L. Lncrna CASC2 Alleviates Sepsis-Induced Acute Lung Injury by Regulating the Mir-152-3p/PDK4 Axis. Immunol Invest (2021) 1-15. doi: 10.1080/08820139.2021.1928693

104. Xu Y, Shao B. Circulating Long Noncoding RNA ZNFX1 Antisense RNA Negatively Correlates With Disease Risk, Severity, Inflammatory Markers, and Predicts Poor Prognosis in Sepsis Patients. Med (2019) 98(9). doi: 10.1097/MD.0000000000014558

105. Chen D-D, Wang H-W, Cai X-J. Long Non-Coding RNA ZFAS1 Alleviates Sepsis-Induced Myocardial Injury via Target Mir-34b-5p/SIRT1. Innate Immun (2021) 27(5):377-87. doi: 10.1177/17534259211034221

106. Liu J-J, Li Y, Yang M-S, Chen R, Cen C-Q. SP1-Induced ZFAS1 Aggravates Sepsis-Induced Cardiac Dysfunction via Mir-590-3p/NLRP3-Mediated Autophagy and Pyroptosis. Arch Biochem Biophys (2020) 695:108611. doi: 10.1016/j.abb.2020.108611

107. An L, Yang T, Zhong Y, Yin Y, Li W, Gao H. Molecular Pathways in SepsisInduced Cardiomyocyte Pyroptosis: Novel Finding on Long Non-Coding RNA ZFAS1/Mir-138-5p/SESN2 Axis. Immunol Lett (2021) 238:47-56. doi: 10.1016/j.imlet.2021.07.003

108. Zhang Z, Yu T, Geng W. Long Non-Coding RNA CCHE1 Participates in Postoperative Distant Recurrence But Not Local Recurrence of Osteosarcoma Possibly by Interacting With ROCK1. BMC Musculoskeletal Disord (2020) 21(1):462. doi: 10.1186/s12891-020-3184-X

109. Xu X, Xu Y, Tao X, Liang G. Lncrna Mirt2 Upregulates Mir-1246 Through Methylation to Suppress LPS-Induced Lung Cell Apoptosis. Immun Inflamm Dis (2021) 9(3):695-701. doi: 10.1002/iid3.422

110. Liu X, Zhu N, Zhang B, Xu SB. Long Noncoding RNA TCONS_00016406 Attenuates Lipopolysaccharide-Induced Acute Kidney Injury by Regulating the Mir-687/PTEN Pathway. Front Physiol (2020) 11:622. doi: 10.3389/ fphys.2020.00622

111. Zhang H, Li L, Xu L, Zheng Y. Clinical Significance of the Serum Lncrna NORAD Expression in Patients With Neonatal Sepsis and its Association With Mir-410-3p. J Inflammation Res (2021) 14:4181. doi: 10.2147/ JIR.S315985

112. Gao Z, Huang D. Lncrna GAS5-Mediated Mir-23a-3p Promotes Inflammation and Cell Apoptosis by Targeting TLR4 in a Cell Model of Sepsis. Mol Med Rep (2021) 24(1):1-9. doi: 10.3892/mmr.2021.12149

113. Gui F, Peng H, Liu Y. Elevated Circulating lnc-ANRIL/Mir-125a Axis Level Predicts Higher Risk, More Severe Disease Condition, and Worse Prognosis of Sepsis. J Clin Lab Anal (2019) 33(6):e22917. doi: 10.1002/jcla.22917

114. Liu Y, Peng H, Gui F. Long Noncoding Plasmacytoma Variant Translocation 1 Facilitates the Surveillance of Acute Respiratory Distress Syndrome and Mortality Prediction in Sepsis. Biomarkers Med (2021) 15(6):401-12. doi: 10.2217/bmm-2020-0506

115. Zheng S, Li W, Liao W, Huang C, Zhou M, Zheng Y, et al. Silencing of Lncrna-PVT1 Ameliorates Lipopolysaccharide-Induced Inflammation in THP-1-Derived Macrophages via Inhibition of the P38 MAPK Signaling Pathway. Ann palliative Med (2021) 10(6):6410-8. doi: 10.21037/apm-211078

116. Deng L-T, Wang Q-L, Yu C, Gao M. Lncrna PVT1 Modulates NLRP3 -Mediated Pyroptosis in Septic Acute Kidney Injury by Targeting Mir-20a -5p. Mol Med Rep (2021) 23(4):1-. doi: 10.3892/mmr.2021.11910

117. Luo Y-Y, Yang Z-Q, Lin X-F, Zhao F-L, Tu H-T, Wang L-J, et al. Knockdown of Lncrna PVT1 Attenuated Macrophage M1 Polarization and Relieved Sepsis Induced Myocardial Injury via Mir-29a/HMGB1 Axis. Cytokine (2021) 143:155509. doi: 10.1016/j.cyto.2021.155509

118. Chen J, Gu X, Zhou L, Wang S, Zhu L, Huang Y, et al. Long Non-Coding RNA-HOTAIR Promotes the Progression of Sepsis by Acting as a Sponge of Mir-211 to Induce IL-6R Expression. Exp Ther Med (2019) 18(5):3959-67. doi: $10.3892 / \mathrm{etm} .2019 .8063$

119. Ni S-Y, Xu W-T, Liao G-Y, Wang Y-L, Li J. Lncrna HOTAIR Promotes LPSInduced Inflammation and Apoptosis of Cardiomyocytes via Lin28Mediated PDCD4 Stability. Inflammation (2021) 44(4):1-12. doi: 10.1007/ s10753-021-01431-0

120. Huang J, Liu Y, Xie Q, Liang G, Kong H, Liu M, et al. Expression Profiling of Long Noncoding RNA and Messenger RNA in a Cecal Ligation and Puncture-Induced Colon Injury Mouse Model. Mediators Inflamm (2020) 2020. doi: $10.1155 / 2020 / 8925973$
121. Zhang X, Huang Z, Wang Y, Wang T, Li J, Xi P. Long Non-Coding RNA RMRP Contributes to Sepsis-Induced Acute Kidney Injury. Yonsei Med J (2021) 62(3):262. doi: 10.3349/ymj.2021.62.3.262

122. Gao H, Ma H, Gao M, Chen A, Zha S, Yan J. Long Non-Coding RNA GAS5 Aggravates Myocardial Depression in Mice With Sepsis via the Microrna449b/HMGB1 Axis and the NF-kb Signaling Pathway. Biosci Rep (2021) 41 (4):BSR20201738. doi: 10.1042/BSR20201738

123. Han X, Yuan Z, Jing Y, Zhou W, Sun Y, Xing J. Knockdown of Lncrna Tapsaki Alleviates LPS-Induced Injury in HK-2 Cells Through the Mir-205/ IRF3 Pathway. Open Med (2021) 16(1):581-90. doi: 10.1515/med-2021-0204

124. Sun J, Xin K, Leng C, Ge J. Down-Regulation of SNHG16 Alleviates the Acute Lung Injury in Sepsis Rats Through Mir-128-3p/HMGB3 Axis. BMC Pulmonary Med (2021) 21(1):1-14. doi: 10.1186/s12890-021-01552-0

125. Zhao H, Chen B, Li Z, Wang B, Li L. Long Noncoding RNA DANCR Suppressed Lipopolysaccharide-Induced Septic Acute Kidney Injury by Regulating Mir-214 in HK-2 Cells. Med Sci monitor: Int Med J Exp Clin Res (2020) 26:e921822-1. doi: 10.12659/MSM.921822

126. Hu Q, Zen W, Zhang M, Wang Z, Cui W, Liu Y, et al. Long Non-Coding RNA CASC2 Overexpression Ameliorates Sepsis-Associated Acute Kidney Injury by Regulating Mir-545-3p/PPARA Axis. J Surg Res (2021) 265:22332. doi: 10.1016/j.jss.2021.03.047

127. Luo S, Huang X, Liu S, Zhang L, Cai X, Chen B. Long Non-Coding RNA Small Nucleolar RNA Host Gene 1 Alleviates Sepsis-Associated Myocardial Injury by Modulating the Mir-181a-5p/XIAP Axis In Vitro. Ann Clin Lab Sci (2021) 51(2):231-40.

128. Yang N, Wang H, Zhang L, Lv J, Niu Z, Liu J, et al. Long Non-Coding RNA SNHG14 Aggravates LPS-Induced Acute Kidney Injury Through Regulating Mir-495-3p/HIPK1. Acta Biochim Biophys Sin (2021) 53(6):719-28. doi: 10.1093/abbs/gmab034

129. Hu M, Wei J, Yang L, Xu J, He Z, Li H, et al. Linc-KIAA1737-2 Promoted LPS-Induced HK-2 Cell Apoptosis by Regulating Mir-27a-3p/TLR4/NF- $\mathrm{kb}$ Axis. J Bioenerg Biomembr (2021) 53(4):1-11. doi: 10.1007/s10863-02109897-1

130. Fu D, Zhou K, Liu J, Zheng P, Li P, Cheng W, et al. Long Non-Coding RNA Plncrna-1 Regulates Cell Proliferation, Apoptosis, and Autophagy in Septic Acute Kidney Injury by Regulating BCL2. Int J Clin Exp Pathol (2018) 11 (1):314.

131. Wang B, Sun Q, Ye W, Li L, Jin P. Long Non-Coding RNA CDKN2B-AS1 Enhances LPS-Induced Apoptotic and Inflammatory Damages in Human Lung Epithelial Cells via Regulating the Mir-140-5p/TGFBR2/Smad3 Signal Network. BMC pulmonary Med (2021) 21(1):1-12. doi: 10.1186/s12890-02101561-z

132. Wang H, Li Y, Wang Y, Li H, Dou L. Microrna-494-3p Alleviates Inflammatory Response in Sepsis by Targeting TLR6. Eur Rev Med Pharmacol Sci (2019) 23(7):2971-7. doi: 10.26355/eurrev_201904_17578

133. Li J, Zhang H, Zuo Y. Microrna-218 Alleviates Sepsis Inflammation by Negatively Regulating VOPP1 via JAK/STAT Pathway. Eur Rev Med Pharmacol Sci (2018) 22(17):5620-6. doi: 10.26355/eurrev_201809_15827

134. Abou El-Khier NT, Zaki ME, Alkasaby NM. Study of Microrna-122 as a Diagnostic Biomarker of Sepsis. Egypt J Immunol (2019) 26(2):105-16.

135. Ouyang H, Tan Y, Li Q, Xia F, Xiao X, Zheng S, et al. Microrna-208-5p Regulates Myocardial Injury of Sepsis Mice via Targeting SOCS2-Mediated NF-Kb/Hif-1 $\alpha$ Pathway. Int Immunopharmacol (2020) 81:106204. doi: 10.1016/j.intimp.2020.106204

136. Xue Z, Xi Q, Liu H, Guo X, Zhang J, Zhang Z, et al. Mir-21 Promotes NLRP3 Inflammasome Activation to Mediate Pyroptosis and Endotoxic Shock. Cell Death Dis (2019) 10(6):1-13. doi: 10.1038/s41419-019-1713-z

137. Jia $\mathrm{P}, \mathrm{Wu} \mathrm{X}$, Dai $\mathrm{Y}$, Teng J, Fang $\mathrm{Y}, \mathrm{Hu}$ J, et al. Microrna-21 Is Required for Local and Remote Ischemic Preconditioning in Multiple Organ Protection Against Sepsis. Crit Care Med (2017) 45(7):e703-e10. doi: 10.1097/ CCM.0000000000002363

138. Yao M, Cui B, Zhang W, Ma W, Zhao G, Xing L. Exosomal Mir-21 Secreted by IL-1 $\beta$-Primed-Mesenchymal Stem Cells Induces Macrophage M2 Polarization and Ameliorates Sepsis. Life Sci (2021) 264:118658. doi: $10.1016 /$ j.lfs.2020.118658

139. Sun B, Luan C, Guo L, Zhang B, Liu Y. Low Expression of Microrna-328 can Predict Sepsis and Alleviate Sepsis-Induced Cardiac Dysfunction and 
Inflammatory Response. Braz J Med Biol Res (2020) 53. doi: 10.1590/1414431×20209501

140. Liu Z, Yang D, Gao J, Xiang X, Hu X, Li S, et al. Discovery and Validation of Mir-452 as an Effective Biomarker for Acute Kidney Injury in Sepsis. Theranostics (2020) 10(26):11963. doi: 10.7150/thno.50093

141. Zhou M, Zhang L, Song M, Sun W. Microrna-218 Prevents Lung Injury in Sepsis by Inhibiting RUNX2. Eur Rev Med Pharmacol Sci (2018) 22 (23):8438-46. doi: 10.26355/eurrev_201812_16543

142. Na L, Ding H, Xing E, Zhang Y, Gao J, Liu B, et al. The Predictive Value of Microrna-21 for Sepsis Risk and its Correlation With Disease Severity, Systemic Inflammation, and 28-Day Mortality in Sepsis Patients. J Clin Lab Anal (2020) 34(3):e23103. doi: 10.1002/jcla.23103

143. Lin R, Hu H, Li L, Chen G, Luo L, Rao P. The Potential of Microrna-126 in Predicting Disease Risk, Mortality of Sepsis, and its Correlation With Inflammation and Sepsis Severity. J Clin Lab Anal (2020) 34(9):e23408. doi: $10.1002 /$ jcla. 23408

144. Wang Q, Feng Q, Zhang Y, Zhou S, Chen H. Decreased Microrna 103 and Microrna 107 Predict Increased Risks of Acute Respiratory Distress Syndrome and 28-Day Mortality in Sepsis Patients. Med (2020) 99(25). doi: 10.1097/MD.0000000000020729

145. Gao Y, Zhang N, Lv C, Li N, Li X, Li W. Lncrna SNHG1 Knockdown Alleviates Amyloid- $\beta$-Induced Neuronal Injury by Regulating ZNF217 via Sponging Mir-361-3p in Alzheimer's Disease. J Alzheimer's Dis (2020) Preprint):1-14. doi: 10.3233/JAD-191303

146. Zhu J, Lin X, Yan C, Yang S, Zhu Z. Microrna-98 Protects Sepsis Mice From Cardiac Dysfunction, Liver and Lung Injury by Negatively Regulating HMGA2 Through Inhibiting NF-kb Signaling Pathway. Cell Cycle (2019) 18(16):1948-64. doi: 10.1080/15384101.2019.1635869

147. Li S, Zhao D, Cui J, Wang L, Ma X, Li Y. Correlation of Microrna-125a/B With Acute Respiratory Distress Syndrome Risk and Prognosis in Sepsis Patients. J Clin Lab Anal (2020) 34(3):e23098. doi: 10.1002/jcla.23098

148. Liu Y, Guan H, Zhang J-L, Zheng Z, Wang H-T, Tao K, et al. Acute Downregulation of Mir-199a Attenuates Sepsis-Induced Acute Lung Injury by Targeting SIRT1. Am J Physiol-Cell Physiol (2018) 314(4):C449-C55. doi: 10.1152/ajpcell.00173.2017

149. Guo H, Tang L, Xu J, Lin C, Ling X, Lu C, et al. Microrna-495 Serves as a Diagnostic Biomarker in Patients With Sepsis and Regulates Sepsis-Induced Inflammation and Cardiac Dysfunction. Eur J Med Res (2019) 24(1):1-9. doi: 10.1186/s40001-019-0396-3

150. Shen Y, Yu J, Jing Y, Zhang J. Mir-106a Aggravates Sepsis-Induced Acute Kidney Injury by Targeting THBS2 in Mice Model1. Acta cirurgica Bras (2019) 34. doi: 10.1590/s0102-865020190060000002

151. Song Y, Dou H, Li X, Zhao X, Li Y, Hou Y. Exosomal Mir-146a Contributes to the En-Hanced Therapeutic Efficacy of IL-1 $\beta$-Primed Mesenchymal Stem Cells Against Sepsis. Stem Cells (2017) 35(5):1208-21. doi: 10.1002/ stem. 2564

152. Sun W, Li H, Gu J. Up-Regulation of Microrna-574 Attenuates Lipopolysaccharide-or Cecal Ligation and Puncture-Induced Sepsis Associated With Acute Lung Injury. Cell Biochem Funct (2020) 38(7):84758. doi: $10.1002 / \mathrm{cbf} .3496$

153. Zheng P, Feng X, Deng Q, Guo R, Li W, Hayakumo S, et al. Study on the Efficacy of Nanoantibiotics in Rats With Sepsis Based on Microrna-195 and TGF- $\beta 1 /$ Smads Signaling Pathway. J Nanosci Nanotechnol (2021) 21 (2):1357-64. doi: 10.1166/jnn.2021.18646

154. Chen L, Xie W, Wang L, Zhang X, Liu E, Kou Q. Mirna-133a Aggravates Inflammatory Responses in Sepsis by Targeting SIRT1. Int Immunopharmacol (2020) 88:106848. doi: 10.1016/j.intimp.2020.106848

155. Qin Y, Wang G, Peng Z. Microrna-191-5p Diminished Sepsis-Induced Acute Kidney Injury Through Targeting Oxidative Stress Responsive 1 in Rat Models. Biosci Rep (2019) 39(8):BSR20190548. doi: 10.1042/BSR20190548

156. Chen L, Yu L, Zhang R, Zhu L, Shen W. Correlation of Microrna-146a/B With Disease Risk, Biochemical Indices, Inflammatory Cytokines, Overall Disease Severity, and Prognosis of Sepsis. Medicine (2020) 99(22):e19754. doi: 10.1097/MD.0000000000019754

157. Zou Q, Zhao S, Wu Q, Wang H, He X, Liu C. Correlation Analysis of Microrna-126 Expression in Peripheral Blood Lymphocytes With Apoptosis and Prognosis in Patients With Sepsis. Zhonghua wei Zhong Bing ji jiu yi xue (2020) 32(8):938-42. doi: 10.3760/cma.j.cn121430-20200213-00181
158. Dang CP, Leelahavanichkul A. Over-Expression of Mir-223 Induces M2 Macrophage Through Glycolysis Alteration and Attenuates LPS-Induced Sepsis Mouse Model, the Cell-Based Therapy in Sepsis. PloS One (2020) 15 (7):e0236038. doi: 10.1371/journal.pone.0236038

159. Zhang N, Gao Y, Yu S, Sun X, Shen K. Berberine Attenuates A $\beta 42$-Induced Neuronal Damage Through Regulating Circhdac9/Mir-142-5p Axis in Human Neuronal Cells. Life Sci (2020) 117637. doi: 10.1016/j.lfs.2020.117637

160. Gao M, Yu T, Liu D, Shi Y, Yang P, Zhang J, et al. Sepsis Plasma-Derived Exosomal Mir-1-3p Induces Endothelial Cell Dysfunction by Targeting SERP1. Clin Sci (2021) 135(2):347-65. doi: 10.1042/CS20200573

161. Yao L, Liu Z, Zhu J, Li B, Chai C, Tian Y. Clinical Evaluation of Circulating Microrna-25 Level Change in Sepsis and its Potential Relationship With Oxidative Stress. Int J Clin Exp Pathol (2015) 8(7):7675.

162. Visitchanakun P, Tangtanatakul P, Trithiphen O, Soonthornchai W, Wongphoom J, Tachaboon S, et al. Plasma Mir-370-3p as a Biomarker of Sepsis-Associated Encephalopathy, the Transcriptomic Profiling Analysis of Microrna-Arrays From Mouse Brains. Shock (2020) 54(3):347-57. doi: 10.1097/SHK.0000000000001473

163. Pan T, Jia P, Chen N, Fang Y, Liang Y, Guo M, et al. Delayed Remote Ischemic Preconditioning Confersrenoprotection Against Septic Acute Kidney Injury via Exosomal Mir-21. Theranostics (2019) 9(2):405. doi: $10.7150 /$ thno. 29832

164. Zhang J, Liu Y, Liu L. Hyperoside Prevents Sepsis-Associated Cardiac Dysfunction Through Regulating Cardiomyocyte Viability and Inflammation via Inhibiting Mir-21. Biomed Pharmacother (2021) 138:111524. doi: 10.1016/j.biopha.2021.111524

165. De Melo P, Alvarez ARP, Ye X, Blackman A, Alves-Filho JC, Medeiros AI, et al. Macrophage-Derived Microrna-21 Drives Overwhelming Glycolytic and Inflammatory Response During Sepsis via Repression of the PGE2/IL-10 Axis. J Immunol (2021) 207(3):902-12. doi: 10.4049/jimmunol.2001251

166. Lin Z, Liu Z, Wang X, Qiu C, Zheng S. Mir-21-3p Plays a Crucial Role in Metabolism Alteration of Renal Tubular Epithelial Cells During Sepsis Associated Acute Kidney Injury via AKT/CDK2-FOXO1 Pathway. BioMed Res Int (2019) 2019. doi: 10.1155/2019/2821731

167. Jiang Q, Wu C, Zhang Q. Microrna-34a Participates in Lipopolysaccharide Mediated Sepsis Related Renal Function Impairment via Kruppel-Like Factor 4. Zhonghua wei zhong bing ji jiu yi xue (2018) 30(4):351-4. doi: 10.3760/cma.j.issn.2095-4352.2018.04.013

168. Leng C, Sun J, Xin K, Ge J, Liu P, Feng X. High Expression of Mir-483-5p Aggravates Sepsis-Induced Acute Lung Injury. J toxicol Sci (2020) 45(2):7786. doi: $10.2131 /$ jts. 45.77

169. Ma X, Qin J, Guo X. Mir-181-5p Protects Mice From Sepsis via Repressing HMGB1 in an Experimental Model. Eur Rev Med Pharmacol Sci (2020) 24 (18):9712-20. doi: 10.26355/eurrev_202009_23063

170. Wang J, Tao Y, Wang Z, Mao Q. Mir-20a Promotes Kidney Injury in Sepsis Rats Through Autophagy. J Biol Regulators Homeostatic Agents (2020) 34 (4):1277-83. doi: 10.23812/20-174-A

171. Wang Y, Wang H, Zhang C, Zhang C, Yang H, Gao R, et al. Plasma Hsa-Mir92a-3p in Correlation With Lipocalin-2 is Associated With Sepsis-Induced Coagulopathy. BMC Infect Dis (2020) 20(1):1-9. doi: 10.1186/s12879-0204853-y

172. He Z, Wang H, Yue L. Endothelial Progenitor Cells-Secreted Extracellular Vesicles Containing Microrna-93-5p Confer Protection Against SepsisInduced Acute Kidney Injury via the KDM6B/H3k27me3/TNF- $\alpha$ Axis. Exp Cell Res (2020) 395(2):112173. doi: 10.1016/j.yexcr.2020.112173

173. Liu D, Wang Z, Wang H, Ren F, Li Y, Zou S, et al. The Protective Role of Mir223 in Sepsis-Induced Mortality. Sci Rep (2020) 10(1):1-10. doi: 10.1038/ s41598-020-74965-2

174. Chen S, Ding R, Hu Z, Yin X, Xiao F, Zhang W, et al. Microrna-34a Inhibition Alleviates Lung Injury in Cecal Ligation and Puncture Induced Septic Mice. Front Immunol (2020) 11:1829. doi: 10.3389/fimmu.2020.01829

175. Yuan FH, Chen YL, Zhao Y, Liu ZM, Nan CC, Zheng BL, et al. Microrna-30a Inhibits the Liver Cell Proliferation and Promotes Cell Apoptosis Through the JAK/STAT Signaling Pathway by Targeting SOCS-1 in Rats With Sepsis. J Cell Physiol (2019) 234(10):17839-53. doi: 10.1002/jcp.28410

176. Zhu XG, Zhang TN, Wen R, Liu CF. Overexpression of Mir-150-5p Alleviates Apoptosis in Sepsis-Induced Myocardial Depression. BioMed Res Int (2020) 2020. doi: 10.1155/2020/3023186 
177. Liu L, Li T-M, Liu X-R, Bai Y-P, Li J, Tang N, et al. Microrna-140 Inhibits Skeletal Muscle Glycolysis and Atrophy in Endotoxin-Induced Sepsis in Mice via the WNT Signaling Pathway. Am J Physiol-Cell Physiol (2019) 317 (2):C189-C99. doi: 10.1152/ajpcell.00419.2018

178. Wang X, Wang Y, Kong M, Yang J. Mir-22-3p Suppresses Sepsis-Induced Acute Kidney Injury by Targeting PTEN. Biosci Rep (2020) 40(6): BSR20200527. doi: 10.1042/BSR20200527

179. Zhou W, Wang J, Li Z, Li J, Sang M. Microrna-205-5b Inhibits HMGB1 Expression in LPS-Induced Sepsis. Int J Mol Med (2016) 38(1):312-8. doi: 10.3892/ijmm.2016.2613

180. Liu Y, Xiao J, Sun J, Chen W, Wang S, Fu R, et al. ATG7 Promotes Autophagy in Sepsis-Induced Acute Kidney Injury and Is Inhibited by Mir -526b. Mol Med Rep (2020) 21(5):2193-201. doi: 10.3892/mmr.2020.11001

181. Wu Y, Li P, Goodwin AJ, Cook JA, Halushka PV, Zingarelli B, et al. Mir-145a Regulation of Pericyte Dysfunction in a Murine Model of Sepsis. J Infect Dis (2020) 222(6):1037-45. doi: 10.1093/infdis/jiaa184

182. Zhao D, Li S, Cui J, Wang L, Ma X, Li Y. Plasma Mir-125a and Mir-125b in Sepsis: Correlation With Disease Risk, Inflammation, Severity, and Prognosis. J Clin Lab Anal (2020) 34(2):e23036. doi: 10.1002/jcla.23036

183. Rahmel T, Schäfer ST, Frey UH, Adamzik M, Peters J. Increased Circulating Microrna-122 Is a Biomarker for Discrimination and Risk Stratification in Patients Defined by Sepsis-3 Criteria. PloS One (2018) 13(5):e0197637. doi: 10.1371/journal.pone.0197637

184. Zheng G, Pan M, Jin W, Jin G, Huang Y. Microrna-135a Is Up-Regulated and Aggravates Myocardial Depression in Sepsis via Regulating P38 MAPK/ NF- $\kappa$ b Pathway. Int Immunopharmacol (2017) 45:6-12. doi: 10.1016/ j.intimp.2017.01.029

185. Qin L, Wang M, Zhang H. Mir-133a Alleviates Renal Injury Caused by Sepsis by Targeting BNIP3L. Eur Rev Med Pharmacol Sci (2020) 24(5):2632-9. doi: 10.26355/eurrev_202003_20532

186. Colbert JF, Ford JA, Haeger SM, Yang Y, Dailey KL, Allison KC, et al. A Model-Specific Role of Microrna-223 as a Mediator of Kidney Injury During Experimental Sepsis. Am J Physiol-Renal Physiol (2017) 313(2):F553-F9. doi: 10.1152/ajprenal.00493.2016

187. Han Y, Li Y, Jiang Y. The Prognostic Value of Plasma Microrna-155 and Microrna-146a Level in Severe Sepsis and Sepsis-Induced Acute Lung Injury Patients. Clin Lab (2016) 62(12):2355-60. doi: 10.7754/Clin.Lab.2016.160511

188. Zhai Y, Ding N. Microrna-194 Participates in Endotoxemia Induced Myocardial Injury via Promoting Apoptosis. Eur Rev Med Pharmacol Sci (2018) 22(7):2077-83. doi: 10.26355/eurrev_201804_14739

189. Shangxun Z, Junjie L, Wei Z, Yutong W, Wenyuan J, Shanshou L, et al. ADAR1 Alleviates Inflammation in a Murine Sepsis Model via the ADAR1Mir-30a-SOCS3 Axis. Mediators Inflamm (2020) 2020. doi: 10.1155/2020/ 9607535

190. Sun J, Sun X, Chen J, Liao X, He Y, Wang J, et al. Microrna-27b Shuttled by Mesenchymal Stem Cell-Derived Exosomes Prevents Sepsis by Targeting JMJD3 and Downregulating NF-kb Signaling Pathway. Stem Cell Res Ther (2021) 12(1):1-15. doi: 10.1186/s13287-020-02068-w

191. Lv X, Zhang Y, Cui Y, Ren Y, Li R, Rong Q. Inhibition of Microrna-155 Relieves Sepsis-Induced Liver Injury Through Inactivating the JAK/STAT Pathway. Mol Med Rep (2015) 12(4):6013-8. doi: 10.3892/mmr.2015.4188

192. Zhou Y, Song Y, Shaikh Z, Li H, Zhang H, Caudle Y, et al. Microrna-155 Attenuates Late Sepsis-Induced Cardiac Dysfunction Through JNK and $\beta$ Arrestin 2. Oncotarget (2017) 8(29):47317. doi: 10.18632/oncotarget.17636

193. Vasques-Nóvoa F, Laundos TL, Cerqueira RJ, Quina-Rodrigues C, Soaresdos-Reis R, Baganha F, et al. Microrna-155 Amplifies Nitric Oxide/Cgmp Signaling and Impairs Vascular Angiotensin II Reactivity in Septic Shock. Crit Care Med (2018) 46(9):e945-54. doi: 10.1097/CCM.0000000000003296

194. Wang Q, Zhao C, Cai Q, Zhu H. Expression of Microrna-155 and Regulative T Cell in Sepsis Patients and Their Relationship. Zhonghua wei zhong bing ji jiu yi xue (2014) 26(3):179-83. doi: 10.3760/cma.j.issn.2095-4352.2014. 03.011

195. Wang Z-F, Yang Y-M, Fan H. Diagnostic Value of Mir-155 for Acute Lung Injury/Acute Respiratory Distress Syndrome in Patients With Sepsis. J Int Med Res (2020) 48(7):0300060520943070. doi: 10.1177/0300060520943070

196. Zhang B, Yu L, Sheng Y. Clinical Value and Role of Microrna-29c-3p in Sepsis-Induced Inflammation and Cardiac Dysfunction. Eur J Med Res (2021) 26(1):1-7. doi: 10.1186/s40001-021-00566-y
197. Sisti F, Wang S, Brandt SL, Glosson-Byers N, Mayo LD, Son YM, et al. Nuclear PTEN Enhances the Maturation of a Microrna Regulon to Limit Myd88-Dependent Susceptibility to Sepsis. Sci Signaling (2018) 11(528): eaai9085. doi: 10.1126/scisignal.aai9085

198. Gao N, Dong L. Microrna-146 Regulates the Inflammatory Cytokines Expression in Vascular Endothelial Cells During Sepsis. Die Pharmazie-An Int J Pharm Sci (2017) 72(11):700-4. doi: 10.1691/ph.2017.7600

199. Zhang YY, Liu X, Zhang X, Zhang J. Shikonin Improve Sepsis-Induced Lung Injury via Regulation of Mirna-140-5p/TLR4-a Vitro and Vivo Study. J Cell Biochem (2020) 121(3):2103-17. doi: 10.1002/jcb.28199

200. Ma H, Wang X, Ha T, Gao M, Liu L, Wang R, et al. Microrna-125b Prevents Cardiac Dysfunction in Polymicrobial Sepsis by Targeting TRAF6-Mediated Nuclear Factor kb Activation and P53-Mediated Apoptotic Signaling. J Infect Dis (2016) 214(11):1773-83. doi: 10.1093/infdis/jiw449

201. Ling Y, Li Z-Z, Zhang J-F, Zheng X-W, Lei Z-Q, Chen R-Y, et al. Microrna494 Inhibition Alleviates Acute Lung Injury Through Nrf2 Signaling Pathway via NQO1 in Sepsis-Associated Acute Respiratory Distress Syndrome. Life Sci (2018) 210:1-8. doi: 10.1016/j.lfs.2018.08.037

202. Gao M, Wang X, Zhang X, Ha T, Ma H, Liu L, et al. Attenuation of Cardiac Dysfunction in Polymicrobial Sepsis by Microrna-146a Is Mediated via Targeting of IRAK1 and TRAF6 Expression. J Immunol (2015) 195 (2):672-82. doi: 10.4049/jimmunol.1403155

203. Benz F, Tacke F, Luedde M, Trautwein C, Luedde T, Koch A, et al. Circulating Microrna-223 Serum Levels do Not Predict Sepsis or Survival in Patients With Critical Illness. Dis Markers (2015) 2015. doi: 10.1155/2015/384208

204. Li Y, Ke J, Peng C, Wu F, Song Y. Microrna-300/NAMPT Regulates Inflammatory Responses Through Activation of AMPK/Mtor Signaling Pathway in Neonatal Sepsis. Biomed Pharmacother (2018) 108:271-9. doi: 10.1016/j.biopha.2018.08.064

205. Zhang X, Wang X, Fan M, Tu F, Yang K, Ha T, et al. Endothelial HSPA12B Exerts Protection Against Sepsis-Induced Severe Cardiomyopathy via Suppression of Adhesion Molecule Expression by Mir-126. Front Immunol (2020) 11:566. doi: 10.3389/fimmu.2020.00566

206. Zheng G, Qiu G, Ge M, Meng J, Zhang G, Wang J, et al. Mir-10a in Peripheral Blood Mononuclear Cells Is a Biomarker for Sepsis and has AntiInflammatory Function. Mediators Inflamm (2020) 2020. doi: 10.1155/2020/ 4370983

207. Bai X, Zhang J, Cao M, Han S, Liu Y, Wang K, et al. Microrna-146a Protects Against LPS-Induced Organ Damage by Inhibiting Notch1 in Macrophage. Int Immunopharmacol (2018) 63:220-6. doi: 10.1016/j.intimp.2018.07.040

208. Hong J, Hu B-C, Xu L, Zheng Y, Shao Z-Q, Zhang R, et al. Microrna-19a Targets Fibroblast Growth Factor-Inducible Molecule 14 and Prevents Tubular Damage in Septic AKI. Anal Cell Pathol (2020) 2020. doi: $10.1155 / 2020 / 2894650$

209. Ge C, Liu J, Dong S. Mirna-214 Protects Sepsis-Induced Myocardial Injury. Shock (2018) 50(1):112-8. doi: 10.1097/SHK.0000000000000978

210. Meng L, Cao H, Wan C, Jiang L. Mir-539-5p Alleviates Sepsis-Induced Acute Lung Injury by Targeting ROCK1. Folia histochem cytobiologica (2019) 57 (4):168-78. doi: 10.5603/FHC.a2019.0019

211. Liu J, Shi K, Chen M, Xu L, Hong J, Hu B, et al. Elevated Mir-155 Expression Induces Immunosuppression via CD39+ Regulatory T-Cells in Sepsis Patient. Int J Infect Dis (2015) 40:135-41. doi: 10.1016/j.ijid.2015.09.016

212. Zhang J, Ding C, Shao Q, Liu F, Zeng Z, Nie C, et al. The Protective Effects of Transfected Microrna-146a on Mice With Sepsis-Induced Acute Lung Injury In Vivo. Zhonghua wei zhong bing ji jiu yi xue (2015) 27(7):591-4. doi: 10.3760/cma.j.issn.2095-4352.2015.07.010

213. Zhang W, Jia J, Liu Z, Si D, Ma L, Zhang G. Circulating Micrornas as Biomarkers for Sepsis Secondary to Pneumonia Diagnosed via Sepsis 3.0. BMC pulmonary Med (2019) 19(1):1-8. doi: 10.1186/s12890-019-0836-4

214. Jiang Y, Zhou H, Ma D, Chen ZK, Cai X. Microrna-19a and CD22 Comprise a Feedback Loop for B Cell Response in Sepsis. Med Sci monitor: Int Med J Exp Clin Res (2015) 21:1548. doi: 10.12659/MSM.894321

215. Liang G, Wu Y, Guan Y, Dong Y, Jiang L, Mao G, et al. The Correlations Between the Serum Expression of Mir-206 and the Severity and Prognosis of Sepsis. Ann Palliative Med (2020) 9(5):3222-34. doi: 10.21037/apm-20-1391

216. Funahashi Y, Kato N, Masuda T, Nishio F, Kitai H, Ishimoto T, et al. Mir-146a Targeted to Splenic Macrophages Prevents Sepsis-Induced Multiple Organ Injury. Lab Invest (2019) 99(8):1130-42. doi: 10.1038/s41374-019-0190-4 
217. Xu H, Liu X, Ni H. Clinical Significance of Mir-19b-3p in Patients With Sepsis and its Regulatory Role in the LPS-Induced Inflammatory Response. Eur J Med Res (2020) 25(1):1-7. doi: 10.1186/s40001-020-00408-3

218. Yang P, Xiong W, Chen X, Liu J, Ye Z. Overexpression of Mir-129-5p Mitigates Sepsis-Induced Acute Lung Injury by Targeting High Mobility Group Box 1. J Surg Res (2020) 256:23-30. doi: 10.1016/j.jss.2020.05.101

219. Zhang W, Lu F, Xie Y, Lin Y, Zhao T, Tao S, et al. Mir-23b Negatively Regulates Sepsis-Induced Inflammatory Responses by Targeting ADAM10 in Human THP-1 Monocytes. Mediators Inflamm (2019) 2019. doi: 10.1155/ 2019/5306541

220. Liu Q, Wang Y, Zheng Q, Dong X, Xie Z, Panayi A, et al. Microrna-150 Inhibits Myeloid-Derived Suppressor Cells Proliferation and Function Through Negative Regulation of ARG-1 in Sepsis. Life Sci (2021) 278:119626. doi: 10.1016/j.lfs.2021.119626

221. Sheng B, Zhao L, Zang X, Zhen J, Chen W. Mir-375 Ameliorates Sepsis by Downregulating Mir-21 Level via Inhibiting JAK2-STAT3 Signaling. Biomed Pharmacother (2017) 86:254-61. doi: 10.1016/j.biopha.2016.11.147

222. Zhan C-Y, Chen D, Luo J-L, Shi Y-H, Zhang Y-P. Protective Role of DownRegulated Microrna-31 on Intestinal Barrier Dysfunction Through Inhibition of NF- $\kappa \mathrm{b} / \mathrm{Hif}-1 \alpha$ Pathway by Binding to HMOX1 in Rats With Sepsis. Mol Med (2018) 24(1):1-14. doi: 10.1186/s10020-018-0053-2

223. McClure C, Brudecki L, Ferguson DA, Yao ZQ, Moorman JP, McCall CE, et al. Microrna 21 (Mir-21) and Mir-181b Couple With NFI-a to Generate Myeloid-Derived Suppressor Cells and Promote Immunosuppression in Late Sepsis. Infect Immun (2014) 82(9):3816-25. doi: 10.1128/IAI.01495-14

224. Roderburg C, Luedde M, Vargas Cardenas D, Vucur M, Scholten D, Frey N, et al. Circulating Microrna-150 Serum Levels Predict Survival in Patients With Critical Illness and Sepsis. PloS One (2013) 8(1):e54612. doi: 10.1371/ journal.pone.0054612

225. Zhou Y, Han W, Song D, Li Z, Ding H, Zhou T, et al. Effect of Mir-10a on Sepsis-Induced Liver Injury in Rats Through TGF- $\beta 1 / \mathrm{Smad}$ Signaling Pathway. Eur Rev Med Pharmacol Sci (2020) 24(2):862-9. doi: 10.26355/ eurrev_202001_20070

226. Ma F, Li Z, Cao J, Kong X, Gong G. A TGFBR2/SMAD2/DNMT1/Mir-145 Negative Regulatory Loop Is Responsible for LPS-Induced Sepsis. Biomed Pharmacother (2019) 112:108626. doi: 10.1016/j.biopha.2019.108626

227. Vasilescu C, Rossi S, Shimizu M, Tudor S, Veronese A, Ferracin M, et al. Microrna Fingerprints Identify Mir-150 as a Plasma Prognostic Marker in Patients With Sepsis. PloS One (2009) 4(10):e7405. doi: 10.1371/ journal.pone.0007405

228. Zhou YP, Xia Q. Inhibition of Mir-103a-3p Suppresses LipopolysaccharideInduced Sepsis and Liver Injury by Regulating FBXW7 Expression. Cell Biol Int (2020) 44(9):1798-810. doi: 10.1002/cbin.11372

229. Han Y, Dai Q-C, Shen H-L, Zhang X-W. Diagnostic Value of Elevated Serum Mirna-143 Levels in Sepsis. J Int Med Res (2016) 44(4):875-81. doi: 10.1177/ 0300060516645003

230. Cao X, Zhang C, Zhang X, Chen Y, Zhang H. Mir-145 Negatively Regulates TGFBR2 Signaling Responsible for Sepsis-Induced Acute Lung Injury. Biomed Pharmacother (2019) 111:852-8. doi: 10.1016/j.biopha. 2018.12.138

231. Rajput C, Tauseef M, Farazuddin M, Yazbeck P, Amin M-R, Avin BRV, et al. Microrna-150 Suppression of Angiopoetin-2 Generation and Signaling Is Crucial for Resolving Vascular Injury. Arteriosclerosis thrombosis Vasc Biol (2016) 36(2):380-8. doi: 10.1161/ATVBAHA.115.306997

232. He SY, Wang G, Pei YH, Zhu HP. Mir-34b-3p Protects Against Acute Kidney Injury in Sepsis Mice via Targeting Ubiquitin-Like Protein 4A. Kaohsiung J Med Sci (2020) 36(10):817-24. doi: 10.1002/kjm2.12255

233. Wang H, Bei Y, Shen S, Huang P, Shi J, Zhang J, et al. Mir-21-3p Controls Sepsis-Associated Cardiac Dysfunction via Regulating SORBS2. J Mol Cell Cardiol (2016) 94:43-53. doi: 10.1016/j.yjmcc.2016.03.014

234. Du X, Tian D, Wei J, Yan C, Hu P, Wu X, et al. Mir-199a-5p Exacerbated Intestinal Barrier Dysfunction Through Inhibiting Surfactant Protein D and Activating NF- $\kappa b$ Pathway in Sepsis. Mediators Inflamm (2020) 2020. doi: $10.1155 / 2020 / 8275026$

235. Su Y, Song X, Teng J, Zhou X, Dong Z, Li P, et al. Mesenchymal Stem CellsDerived Extracellular Vesicles Carrying Microrna-17 Inhibits Macrophage Apoptosis in Lipopolysaccharide-Induced Sepsis. Int Immunopharmacol (2021) 95:107408. doi: 10.1016/j.intimp.2021.107408
236. Zhu X. Mir-125b But Not Mir-125a Is Upregulated and Exhibits a Trend to Correlate With Enhanced Disease Severity, Inflammation, and Increased Mortality in Sepsis Patients. J Clin Lab Anal (2020) 34(3):e23094. doi: 10.1002/jcla.23094

237. Ling L, Zhang S-H, Zhi L-D, Li H, Wen Q-K, Li G, et al. Microrna-30e Promotes Hepatocyte Proliferation and Inhibits Apoptosis in Cecal Ligation and Puncture-Induced Sepsis Through the JAK/STAT Signaling Pathway by Binding to FOSL2. Biomed Pharmacother (2018) 104:411-9. doi: 10.1016/ j.biopha.2018.05.042

238. Liu J, Liu Y, Zhang L, Chen Y, Du H, Wen Z, et al. Down-Regulation of Circdmnt3b Is Conducive to Intestinal Mucosal Permeability Dysfunction of Rats With Sepsis via Sponging Mir-20b-5p. J Cell Mol Med (2020) 24 (12):6731-40. doi: $10.1111 / \mathrm{jcmm} .15324$

239. Wang X, Yu Y. Mir-146b Protect Against Sepsis Induced Mice Myocardial Injury Through Inhibition of Notch1. J Mol Histol (2018) 49(4):411-7. doi: 10.1007/s10735-018-9781-4

240. Yao Y, Sun F, Lei M. Mir-25 Inhibits Sepsis-Induced Cardiomyocyte Apoptosis by Targetting PTEN. Biosci Rep (2018) 38(2). doi: 10.1042/ BSR20171511

241. McClure C, McPeak MB, Youssef D, Yao ZQ, McCall CE, El Gazzar M. Stat3 and $\mathrm{C} / \mathrm{Ebp} \beta$ Synergize to Induce Mir-21 and Mir-181b Expression During Sepsis. Immunol Cell Biol (2017) 95(1):42-55. doi: 10.1038/icb.2016.63

242. Ji Z-R, Xue W-L, Zhang L. Schisandrin B Attenuates Inflammation in LPSInduced Sepsis Through Mir-17-5p Downregulating TLR4. Inflammation (2019) 42(2):731-9. doi: 10.1007/s10753-018-0931-3

243. Yu J, Chen J, Yang H, Chen S, Wang Z. Overexpression of Mir-200a-3p Promoted Inflammation in Sepsis-Induced Brain Injury Through ROS -Induced NLRP3. Int J Mol Med (2019) 44(5):1811-23. doi: 10.3892/ ijmm.2019.4326

244. Szilágyi B, Fejes Z, Póliska S, Pócsi M, Czimmerer Z, Patsalos A, et al. Reduced Mir-26b Expression in Megakaryocytes and Platelets Contributes to Elevated Level of Platelet Activation Status in Sepsis. Int J Mol Sci (2020) 21 (3):866. doi: 10.3390/ijms21030866

245. Chen X, Chen Y, Dai L, Wang N. Mir-96-5p Alleviates Inflammatory Responses by Targeting NAMPT and Regulating the NF- $\kappa b$ Pathway in Neonatal Sepsis. Biosci Rep (2020) 40(7):BSR20201267. doi: 10.1042/ BSR20201267

246. Wang Z, Ruan Z, Mao Y, Dong W, Zhang Y, Yin N, et al. Mir-27a Is Up Regulated and Promotes Inflammatory Response in Sepsis. Cell Immunol (2014) 290(2):190-5. doi: 10.1016/j.cellimm.2014.06.006

247. Zou Z, Lin Q, Yang H, Liu Z, Zheng S. Nrp-1 Mediated Plasmatic Ago2 Binding Mir-21a-3p Internalization: A Novel Mechanism for Mir-21a-3p Accumulation in Renal Tubular Epithelial Cells During Sepsis. BioMed Res Int (2020) 2020. doi: 10.1155/2020/2370253

248. Wang H, Meng K, jun Chen W, Feng D, Jia Y, Xie L. Serum Mir-574-5p: A Prognostic Predictor of Sepsis Patients. Shock (2012) 37(3):263-7. doi: 10.1097/SHK.0b013e318241baf8

249. Sun X, Icli B, Wara AK, Belkin N, He S, Kobzik L, et al. Microrna-181b Regulates NF-Kb-Mediated Vascular Inflammation. J Clin Invest (2012) 122 (6):1973-90. doi: 10.1172/JCI61495

250. Du X, Wei J, Tian D, Wu M, Yan C, Hu P, et al. Mir-182-5p Contributes to Intestinal Injury in a Murine Model of Staphylococcus Aureus PneumoniaInduced Sepsis via Targeting Surfactant Protein D. J Cell Physiol (2020) 235 (1):563-72. doi: 10.1002/jcp.28995

251. Zheng D, Yu Y, Li M, Wang G, Chen R, Fan G-C, et al. Inhibition of Microrna 195 Prevents Apoptosis and Multiple-Organ Injury in Mouse Models of Sepsis. J Infect Dis (2016) 213(10):1661-70. doi: 10.1093/infdis/ jiv760

252. Zhang Y, Xia F, Wu J, Yang A, Zhang Y, Zhao H, et al. Mir-205 Influences Renal Injury in Sepsis Rats Through HMGB1-PTEN Signaling Pathway. Eur Rev Med Pharmacol Sci (2019) 23:10950-6. doi: 10.26355/ eurrev_201912_19798

253. Wu S-Y, Zhang H, Wu W, Wu Y-Y. Value of Serum Mir-21-3p in Predicting Acute Kidney Injury in Children With Sepsis. Zhongguo Dang dai er ke za zhi= Chin J Contemp Pediatr (2020) 22(3):269-73. doi: 10.7499/j.issn.10088830.2020.03.016

254. Yi H-X, Jiang S-Y, Yu L-H, Chen K, Yang Z-X, Wu Q. Mir-181a-2-3p Alleviates the Apoptosis of Renal Tubular Epithelial Cell via Targeting GJB2 
in Sepsis-Induced Acute Kidney Injury. Mol Cell Biol (2021) 41(7):MCB. 00016-21. doi: 10.1128/MCB.00016-21

255. Fu D, Dong J, Li P, Tang C, Cheng W, Xu Z, et al. Mirna-21 has Effects to Protect Kidney Injury Induced by Sepsis. Biomed Pharmacother (2017) 94:1138-44. doi: 10.1016/j.biopha.2017.07.098

256. Pan Y, Wang J, Xue Y, Zhao J, Li D, Zhang S, et al. GSKJ4 Protects Mice Against Early Sepsis via Reducing Proinflammatory Factors and UpRegulating Mir-146a. Front Immunol (2018) 9:2272. doi: 10.3389/ fimmu.2018.02272

257. Liu Y, Cao D, Mo G, Zhang L. Effects of Microrna-294 on Inflammatory Factor of Sepsis by Targeting Triggering Receptor Expressed on Myeloid Cells-1. Zhonghua wei zhong bing ji jiu yi xue (2014) 26(9):661-5. doi: 10.3760/cma.j.issn.2095-4352.2014.09.01

258. Wang L, Wang K, Tian Z. Mir-128-3p Inhibits NRP1 Expression and Promotes Inflammatory Response to Acute Kidney Injury in Sepsis. Inflammation (2020) 43:1772-9. doi: 10.1007/s10753-020-01251-8

259. An R, Feng J, Xi C, Xu J, Sun L. Mir-146a Attenuates Sepsis-Induced Myocardial Dysfunction by Suppressing IRAK1 and TRAF6 via Targeting Erbb4 Expression. Oxid Med Cell longevity (2018) 2018. doi: 10.1155/2018/ 7163057

260. Puimège L, Van Hauwermeiren F, Steeland S, Van Ryckeghem S, Vandewalle J, Lodens S, et al. Glucocorticoid-Induced Microrna-511 Protects Against TNF by Down-Regulating TNFR 1. EMBO Mol Med (2015) 7(8):1004-17. doi: 10.15252/emmm.201405010

261. Liu Z, Tang C, He L, Yang D, Cai J, Zhu J, et al. The Negative Feedback Loop of NF-kb/Mir-376b/NFKBIZ in Septic Acute Kidney Injury. JCI Insight (2020) 5(24). doi: 10.1172/jci.insight.142272

262. Wang Z-H, Liang Y-B, Tang H, Chen Z-B, Li Z-Y, Hu X-C, et al. Dexamethasone Down-Regulates the Expression of Microrna-155 in the Livers of Septic Mice. PloS One (2013) 8(11):e80547. doi: 10.1371/ journal.pone.0080547

263. Tacke F, Roderburg C, Benz F, Cardenas DV, Luedde M, Hippe H-J, et al. Levels of Circulating Mir-133a Are Elevated in Sepsis and Predict Mortality in Critically Ill Patients. Crit Care Med (2014) 42(5):1096-104. doi: 10.1097/ CCM.0000000000000131

264. Ling L, Lu H-T, Wang H-F, Shen M-J, Zhang H-B. Microrna-203 Acts as a Potent Suppressor in Septic Shock by Alleviating Lung Injury via Inhibition of VNN1. Kidney Blood Pressure Res (2019) 44(4):565-82. doi: 10.1159/ 000500484

265. Wu X, Yang J, Yu L, Long D. Plasma Mirna-223 Correlates With Risk, Inflammatory Markers as Well as Prognosis in Sepsis Patients. Med (2018) 97(27). doi: 10.1097/MD.0000000000011352

266. Möhnle P, Schütz SV, van der Heide V, Hübner M, Luchting B, Sedlbauer J, et al. Microrna-146a Controls Th1-Cell Differentiation of Human CD4+ T Lymphocytes by Targeting Prkce. Eur J Immunol (2015) 45(1):260-72. doi: 10.1002/eji.201444667

267. Karam RA, Zidan HE, Karam NA, Abdel Rahman DM, El-Seifi OS. Diagnostic and Prognostic Significance of Serum Mirna-146-a Expression in Egyptian Children With Sepsis in a Pediatric Intensive Care Unit. J Gene Med (2019) 21(11):e3128. doi: 10.1002/jgm.3128

268. Cheng D-L, Fang H-X, Liang Y, Zhao Y, Shi C-S. Microrna-34a Promotes Inos Secretion From Pulmonary Macrophages in Septic Suckling Rats Through Activating STAT3 Pathway. Biomed Pharmacother (2018) 105:1276-82. doi: 10.1016/j.biopha.2018.06.063

269. Yang Q, Cao K, Jin G, Zhang J. Hsa-Mir-346 Plays a Role in the Development of Sepsis by Downregulating SMAD3 Expression and Is Negatively Regulated by Lncrna MALAT1. Mol Cell Probes (2019) 47:101444. doi: 10.1016/j.mcp.2019.101444

270. Sang Z, Dong S, Zhang P, Wei Y. Mir-214 Ameliorates Sepsis-Induced Acute Kidney Injury via PTEN/AKT/Mtor-Regulated Autophagy. Mol Med Rep (2021) 24(4):1-11. doi: 10.3892/mmr.2021.12322

271. Xue W-L, Bai X, Zhang L. Rhtnfr: Fc Increases Nrf2 Expression via Mir-27a Mediation to Protect Myocardium Against Sepsis Injury. Biochem Biophys Res Commun (2015) 464(3):855-61. doi: 10.1016/j.bbrc.2015.07.051

272. Yang W, Wu H, Zhang H, Liu H, Wei Y, Shi B. Prognostic Value of Picco Monitoring Combined With Plasma Microrna-150 Detection in Septic Shock Patients. Zhejiang da xue xue bao Yi xue ban=J Zhejiang Univ Med Sci (2015) 44(6):659-64.
273. Bai X, Li J, Li L, Liu M, Liu Y, Cao M, et al. Extracellular Vesicles From Adipose Tissue-Derived Stem Cells Affect Notch-Mir148a-3p Axis to Regulate Polarization of Macrophages and Alleviate Sepsis in Mice. Front Immunol (2020) 11:1391. doi: 10.3389/fimmu.2020.01391

274. Zhang T, Xiang L. Honokiol Alleviates Sepsis-Induced Acute Kidney Injury in Mice by Targeting the Mir-218-5p/Heme Oxygenase-1 Signaling Pathway. Cell Mol Biol Lett (2019) 24(1):1-15. doi: 10.1186/s11658-019-0142-4

275. Wang H-J, Deng J, Wang J-Y, Zhang P-J, Xin Z, Xiao K, et al. Serum Mir-122 Levels Are Related to Coagulation Disorders in Sepsis Patients. Clin Chem Lab Med (CCLM) (2014) 52(6):927-33. doi: 10.1515/cclm-2013-0899

276. Xin Y, Tang L, Chen J, Chen D, Wen W, Han F. Inhibition of Mir-101-3p Protects Against Sepsis-Induced Myocardial Injury by Inhibiting MAPK and NF- $\mathrm{kb}$ Pathway Activation via the Upregulation of DUSP1. Int J Mol Med (2021) 47(3):1-. doi: 10.3892/ijmm.2021.4853

277. Pan W, Wei N, Xu W, Wang G, Gong F, Li N. Microrna-124 Alleviates the Lung Injury in Mice With Septic Shock Through Inhibiting the Activation of the MAPK Signaling Pathway by Downregulating MAPK14. Int Immunopharmacol (2019) 76:105835. doi: 10.1016/j.intimp.2019.105835

278. Luo N, Gao H, Wang Y, Li H, Li Y. Mir-942-5p Alleviates Septic Acute Kidney Injury by Targeting FOXO3. Eur Rev Med Pharmacol Sci (2020) 24 (11):6237-44. doi: 10.26355/eurrev_202006_21521

279. Liu S, Liu C, Wang Z, Huang J, Zeng Q. Microrna-23a-5p Acts as a Potential Biomarker for Sepsis-Induced Acute Respiratory Distress Syndrome in Early Stage. Cell Mol Biol (2016) 62(2):31-7.

280. Ma J, Xu L-Y, Sun Q-H, Wan X-Y. Inhibition of Mir-1298-5p Attenuates Sepsis Lung Injury by Targeting SOCS6. Mol Cell Biochem (2021) 476(10):112. doi: 10.1007/s11010-021-04170-w

281. Zheng G, Qu H, Li F, Ma W, Yang H. Propofol Attenuates Sepsis-Induced Acute Kidney Injury by Regulating Mir-290-5p/CCL-2 Signaling Pathway. Braz J Med Biol Res (2018) 51. doi: 10.1590/1414-431x20187655

282. Paik S, Choe JH, Choi G-E, Kim J-E, Kim J-M, Song GY, et al. Rg6, a Rare Ginsenoside, Inhibits Systemic Inflammation Through the Induction of Interleukin-10 and Microrna-146a. Sci Rep (2019) 9(1):1-15. doi: 10.1038/ s41598-019-40690-8

283. Wang X, Gu H, Qin D, Yang L, Huang W, Essandoh K, et al. Exosomal Mir223 Contributes to Mesenchymal Stem Cell-Elicited Cardioprotection in Polymicrobial Sepsis. Sci Rep (2015) 5(1):1-16. doi: 10.1038/srep13721

284. Gu W, Wen D, Lu H, Zhang A, Wang H, Du J, et al. Mir-608 Exerts AntiInflammatory Effects by Targeting ELANE in Monocytes. J Clin Immunol (2020) 40(1):147-57. doi: 10.1007/s10875-019-00702-8

285. Sun Y, Li Q, Gui H, Xu D-P, Yang Y-L, Su D-F, et al. Microrna-124 Mediates the Cholinergic Anti-Inflammatory Action Through Inhibiting the Production of Pro-Inflammatory Cytokines. Cell Res (2013) 23(11):127083. doi: $10.1038 / \mathrm{cr} .2013 .116$

286. Zhang J, Wang C, Tang X, Wei Y. Urinary Mir-26b as a Potential Biomarker for Patients With Sepsis-Associated Acute Kidney Injury: A Chinese Population-Based Study. Eur Rev Med Pharmacol Sci (2018) 22(14):460410. doi: 10.26355/eurrev_201807_15518

287. Ni J, He J, Kang L, Zhong Z, Wang L, Yin S. Effects of Dexmedetomidine Pretreatment on Rats With Sepsis-Induced Acute Kidney Injury and Mir146a Expression. Cell Mol Biol (2020) 66(2):93-8. doi: 10.14715/cmb/ 2020.66.2.15

288. Huo R, Dai M, Fan Y, Zhou J-Z, Li L, Zu J. Predictive Value of Mirna-29a and Mirna-10a-5p for 28-Day Mortality in Patients With Sepsis-Induced Acute Kidney Injury. Nan fang yi ke da xue xue bao=J South Med Univ (2017) 37(5):646-51. doi: 10.3969/j.issn.1673-4254.2017.05.13

289. Cao Y-Y, Wang Z, Wang Z-H, Jiang X-G, Lu W-H. Inhibition of Mir-155 Alleviates Sepsis-Induced Inflammation and Intestinal Barrier Dysfunction by Inactivating NF-kb Signaling. Int Immunopharmacol (2021) 90:107218. doi: $10.1016 /$ j.intimp.2020.107218

290. Ma F, Liu F, Ding L, You M, Yue H, Zhou Y, et al. Anti-Inflammatory Effects of Curcumin Are Associated With Down Regulating Microrna-155 in LPSTreated Macrophages and Mice. Pharm Biol (2017) 55(1):1263-73. doi: 10.1080/13880209.2017.1297838

291. Wu Z-J, Chen Y-F, Wang H-D, Gao F-H. Expression of Plasma Mirna-497 in Children With Sepsis-Induced Myocardial Injury and its Clinical Significance. Zhongguo dang dai er ke za zhi= Chin J Contemp Pediatr (2018) 20(1):32-6. doi: 10.7499/j.issn.1008-8830.2018.01.007 
292. Lou W, Yan J, Wang W. Downregulation of Mir-497-5p Improves SepsisInduced Acute Lung Injury by Targeting IL2RB. BioMed Res Int (2021) 2021. doi: $10.1155 / 2021 / 6624702$

293. Wang Y, Li T, Wu B, Liu H, Luo J, Feng D, et al. STAT1 Regulates MD-2 Expression in Monocytes of Sepsis via Mir-30a. Inflammation (2014) 37 (6):1903-11. doi: 10.1007/s10753-014-9922-1

294. Ma Y, Liu Y, Hou H, Yao Y, Meng H. Mir-150 Predicts Survival in Patients With Sepsis and Inhibits LPS-Induced Inflammatory Factors and Apoptosis by Targeting NF- $\kappa \mathrm{b} 1$ in Human Umbilical Vein Endothelial Cells. Biochem Biophys Res Commun (2018) 500(3):82837. doi: 10.1016/j.bbrc.2018.04.168

295. Brudecki L, Ferguson DA, McCall CE, El Gazzar M. Microrna-146a and RBM4 Form a Negative Feed-Forward Loop That Disrupts Cytokine Mrna Translation Following TLR4 Responses in Human THP-1 Monocytes. Immunol Cell Biol (2013) 91(8):532-40. doi: 10.1038/icb.2013.37

296. Banerjee S, Meng J, Das S, Krishnan A, Haworth J, Charboneau R, et al. Morphine Induced Exacerbation of Sepsis Is Mediated by Tempering Endotoxin Tolerance Through Modulation of Mir-146a. Sci Rep (2013) 3 (1):1-12. doi: 10.1038/srep01977

297. Yang Q, Zhang D, Li Y, Li Y, Li Y. Paclitaxel Alleviated Liver Injury of Septic Mice by Alleviating Inflammatory Response via Microrna-27a/TAB3/NF- $\mathrm{kb}$ Signaling Pathway. Biomed Pharmacother (2018) 97:1424-33. doi: 10.1016/ j.biopha.2017.11.003

298. Wang J-F, Yu M-L, Yu G, Bian J-J, Deng X-M, Wan X-J, et al. Serum Mir146a and Mir-223 as Potential New Biomarkers for Sepsis. Biochem Biophys Res Commun (2010) 394(1):184-8. doi: 10.1016/j.bbrc.2010.02.145

299. Mei L, He M, Zhang C, Miao J, Wen Q, Liu X, et al. Paeonol Attenuates Inflammation by Targeting HMGB1 Through Upregulating Mir-339-5p. Sci Rep (2019) 9(1):1-15. doi: 10.1038/s41598-019-55980-4

300. Wang X, Hao L, Bu H-F, Scott AW, Tian K, Liu F, et al. Spherical Nucleic Acid Targeting Microrna-99b Enhances Intestinal MFG-E8 Gene Expression and Restores Enterocyte Migration in Lipopolysaccharide-Induced Septic Mice. Sci Rep (2016) 6(1):1-13. doi: 10.1038/srep31687

301. Yao Y, Xu K, Sun Y, Tian T, Shen W, Sun F, et al. Mir-215-5p Inhibits the Inflammation Injury in Septic H9c2 by Regulating ILF3 and LRRFIP1. Int Immunopharmacol (2020) 78:106000. doi: 10.1016/j.intimp.2019.106000

302. Wang H, Zhang P, Chen W, Feng D, Jia Y, Xie L-X. Evidence for Serum Mir15a and Mir-16 Levels as Biomarkers That Distinguish Sepsis From Systemic Inflammatory Response Syndrome in Human Subjects. Clin Chem Lab Med (2012) 50(8):1423-8. doi: 10.1515/cclm-2011-0826

303. Geng X, Jia Y, Zhang Y, Shi L, Li Q, Zang A, et al. Circular RNA: Biogenesis, Degradation, Functions and Potential Roles in Mediating Resistance to Anticarcinogens. Epigenomics (2020) 12(3):267-83. doi: 10.2217/epi-20190295

304. Jiang WY, Ren J, Zhang XH, Lu ZL, Feng HJ, Yao XL, et al. Circc3p1 Attenuated Pro-Inflammatory Cytokine Production and Cell Apoptosis in Acute Lung Injury Induced by Sepsis Through Modulating Mir-21. J Cell Mol Med (2020) 24(19):11221-9. doi: 10.1111/jcmm.15685

305. Tian C, Liu J, Di X, Cong S, Zhao M, Wang K. Exosomal Hsa_Circrna_104484 and Hsa_Circrna_104670 may Serve as Potential Novel Biomarkers and Therapeutic Targets for Sepsis. Sci Rep (2021) 11 (1):1-18. doi: 10.1038/s41598-021-93246-0

306. Shi Y, Sun CF, Ge WH, Du YP, Hu NB. Circular RNA VMA21 Ameliorates Sepsis-Associated Acute Kidney Injury by Regulating Mir-9-3p/SMG1/ Inflammation Axis and Oxidative Stress. J Cell Mol Med (2020) 24 (19):11397-408. doi: 10.1111/jcmm.15741

307. He Y, Sun Y, Peng J. Circ_0114428 Regulates Sepsis-Induced Kidney Injury by Targeting the Mir-495-3p/CRBN Axis. Inflammation (2021) 44(4):1-14. doi: 10.1007/s10753-021-01432-z

308. Wei B, Yu L. Circular RNA PRKCI and Microrna-545 Relate to Sepsis Risk, Disease Severity and 28-Day Mortality. Scand J Clin Lab Invest (2020) 80 (8):659-66. doi: 10.1080/00365513.2020.1827291

309. Liu S, Zhang D, Liu Y, Zhou D, Yang H, Zhang K, et al. Circular RNA Circ_0001105 Protects the Intestinal Barrier of Septic Rats by Inhibiting Inflammation and Oxidative Damage and YAP1 Expression. Gene (2020) 755:144897. doi: 10.1016/j.gene.2020.144897

310. Ma X, Zhu G, Jiao T, Shao F. Effects of Circular RNA Ttc3/Mir-148a/Rcan2 Axis on Inflammation and Oxidative Stress in Rats With Acute Kidney
Injury Induced by Sepsis. Life Sci (2021) 272:119233. doi: 10.1016/ j.lfs. 2021.119233

311. Shi X, Ma W, Li Y, Wang H, Pan S, Pan Y, et al. Circprkci Relieves Lipopolysaccharide-Induced HK2 Cell Injury by Upregulating the Expression of Mir-545 Target Gene ZEB2. BioFactors (2020) 46(3):475-86. doi: $10.1002 /$ biof. 1620

312. Xiong H, Wang H, Yu Q. Circular RNA Circ_0003420 Mediates Inflammation in Sepsis-Induced Liver Damage by Downregulating Neuronal PAS Domain Protein 4. Immunopharmacol Immunotoxicology (2021) 43(3):271-82. doi: 10.1080/08923973.2021.1887212

313. Shen W, Zhao X, Li S. Exosomes Derived From Adscs Attenuate Sepsis-Induced Lung Injury by Delivery of Circ-Fryl and Regulation of the Mir-490-3p/SIRT3 Pathway. Inflammation (2021) 1-12. doi: 10.1007/s10753-021-01548-2

314. Zhang X, Dong S. Circ_0091702 Relieves Lipopolysaccharide (LPS)-Induced Cell Injury by Regulating the Mir-182/PDE7A Axis in Sepsis. Biosci Biotechnol Biochem (2021) 85(9):1962-70. doi: 10.1093/bbb/zbab100

315. Li X, Li R, Gong Q, Shi D, Song L, Song Y. Circular RNA Circvma21 Ameliorates Lipopolysaccharide (LPS)-Induced Acute Kidney Injury by Targeting the Mir-199a-5p/NRP1 Axis in Sepsis. Biochem Biophys Res Commun (2021) 548:174-81. doi: 10.1016/j.bbrc.2021.02.028

316. Xu H-P, Ma X-Y, Yang C. Circular RNA TLK1 Promotes Sepsis-Associated Acute Kidney Injury by Regulating Inflammation and Oxidative Stress Through Mir-106a-5p/HMGB1 Axis. Front Mol Biosci (2021) 8. doi: $10.3389 /$ fmolb.2021.660269

317. Hong X, Li S, Wang J, Zhao Z, Feng Z. Circular RNA Circfads2 Is Overexpressed in Sepsis and Suppresses LPS-Induced Lung Cell Apoptosis by Inhibiting the Maturation of Mir-15a-5p. BMC Immunol (2021) 22(1):17. doi: 10.1186/s12865-021-00419-7

318. Tan M, Bei R. Circ_0091702 Serves as a Sponge of Mir-545-3p to Attenuate Sepsis-Related Acute Kidney Injury by Upregulating THBS2. J Mol Histol (2021) 52(4):1-12. doi: 10.1007/s10735-021-09991-z

319. Wei W, Yao Y, Bi H, Xu W, Gao Y. Circular RNA Circ_0068, 888 Protects Against Lipopolysaccharide-Induced HK-2 Cell Injury via Sponging Microrna-21-5p. Biochem Biophys Res Commun (2021) 540:1-7. doi: 10.1016/j.bbrc.2020.12.018

320. Li M, Hu J, Peng Y, Li J, Ren R. Circptk2-Mir-181c-5p-HMGB1: A New Regulatory Pathway for Microglia Activation and Hippocampal Neuronal Apoptosis Induced by Sepsis. Mol Med (2021) 27(1):1-15. doi: 10.1186/ s10020-021-00305-3

321. Li H, Zhang X, Wang P, Zhou X, Liang H, Li C. Knockdown of Circ-FANCA Alleviates LPS-Induced HK2 Cell Injury via Targeting Mir-93-5p/OXSR1 Axis in Septic Acute Kidney Injury. Diabetol Metab Syndrome (2021) 13 (1):1-14. doi: 10.1186/s13098-021-00625-8

322. Lin Q, Liang Q, Qin C, Li Y. Circankrd36 Knockdown Suppressed Cell Viability and Migration of LPS-Stimulated RAW264. 7 Cells by Sponging Mir-330. Inflammation (2021) 44(5):1-10. doi: 10.1007/s10753-021-01480-5

323. Xiong Y, Wang Y, Tian H, Li Y, Xu Q, He Z. CircPRKCI alleviates lipopolysaccharide (LPS)-induced HK-2 cell injury by regulating miR106b-5p/GAB1 axis. J Cardiovasc Pharmacol (2021) 78(4):523-33. doi: 10.1097/FJC.0000000000001031

Conflict of Interest: The authors declare that the research was conducted in the absence of any commercial or financial relationships that could be construed as a potential conflict of interest.

Publisher's Note: All claims expressed in this article are solely those of the authors and do not necessarily represent those of their affiliated organizations, or those of the publisher, the editors and the reviewers. Any product that may be evaluated in this article, or claim that may be made by its manufacturer, is not guaranteed or endorsed by the publisher.

Copyright $\odot 2021$ Ghafouri-Fard, Khoshbakht, Hussen, Taheri and Arefian. This is an open-access article distributed under the terms of the Creative Commons Attribution License (CC BY). The use, distribution or reproduction in other forums is permitted, provided the original author(s) and the copyright owner(s) are credited and that the original publication in this journal is cited, in accordance with accepted academic practice. No use, distribution or reproduction is permitted which does not comply with these terms. 